\title{
Allergie, Pathomechanismen, Krankheitsbilder
}

\author{
C. Kroegel, B. Bartuschka, M. Henzgen
}

3.1 Einleitung - 116

3.1.1 Klassifikation und Definition allergischer Erkrankungen - 116

3.1.2 Epidemiologie - 120

3.1.3 Ökonomische Aspekte allergischer Erkrankungen - 122

3.1.4 Genetische Prädisposition und andere Risikofaktoren - 122

3.1.5 Natürlicher Verlauf und Prognose - 123

3.1.6 Spezifische und unspezifische Auslöser allergischer Erkrankungen - 124

3.1.7 Formen der allergischen Immunreaktion - 126

3.1.8 Zellen der allergischen Entzündung - 127

3.1.9 Mediatoren der allergischen Entzündung - 130

3.1.10 Extrazelluläre Matrixproteine - 135

3.2 Diagnostik - 135

3.2.1 Allgemeine Allergiediagnostik - 136

3.2.2 Spezielle Allergiediagnostik - 139

3.2.3 Diagnostisches Vorgehen - 145

3.2.4 Differenzialdiagnosen - 145

3.3 Monitoring allergischer Erkrankungen - 149

3.4 Therapie - 151

3.4.1 Allgemeine therapeutische Maßnahmen - 151

3.4.2 Spezifische Immuntherapie (Hyposensibilisierung) - 152

3.4.3 Pharmakologische Behandlung - 153

3.4.4 Zukünftige antiallergische Medikamente - 159

Literatur -160 


\subsection{Einleitung}

Etwa ein Fünftel der Bevölkerung industrialisierter Länder leidet an mindestens einer Erkrankung aus dem allergischen Formenkreis. Hierzu gehören neben Manifestationen der Haut und des Gastrointestinaltrakts insbesondere die allergischen Erkrankungen der oberen und unteren Atemwege. Aufgrund der hohen und weiter steigenden Prävalenz von Allergien und den sich hieraus ableitenden volkswirtschaftlichen Belastungen ist die Allergologie in den letzten Jahren mehr und mehr in den Mittelpunkt des allgemeinen Interesses gerückt. Zudem haben neue wissenschaftliche Erkenntnisse zu einer Erweiterung des pathogenetischen Verständnisses insbesondere allergischer Atemwegserkrankungen geführt, die zunehmend auch die therapeutischen Möglichkeiten erweitern.

Im nachfolgenden Kapitel wird versucht, diese aktuellen Aspekte der Allergologie im Spannungsfeld zwischen Epidemiologie, Ökonomie, Pathogenese und Therapie integriert darzustellen. Neben Dermatologen und Hals-Nasen-Ohren-Ärzten sind die Pneumologen die Fachärzte, die am häufigsten die Zusatzbezeichnung Allergologie in einer 18-monatigen Ausbildungszeit erwerben, was die Einteilung dieses Kapitels rechtfertigt.

\subsubsection{Klassifikation und Definition allergischer Erkrankungen}

\section{Klassifikation}

Unter Allergien fasst man eine Gruppe bestimmter Erkrankungen der Haut, des Gastrointestinaltrakts und vor allem der Lunge zusammen, die auf eine Immunreaktion gegenüber definierten Antigenen, Allergenen oder Haptenen aus der unmittelbaren Umgebung zurückgeht. Das klinische Bild ist je nach der auslösenden Substanz, dem beteiligten Immunmechanismus und dem betroffenen Organ unterschiedlich.

Die Einteilung der Erkrankungen erfolgt am sinnvollsten auf dem Boden der zugrunde liegenden immunologischen Mechanismen, die sich an der 1963 von Coombs u. Gell vorgeschlagenen Klassifikation orientiert (•Tab. 3.1).

Neben den 4 ursprünglichen Immunmechanismen werden granulomatöse Formen als Typ-V-Reaktionen abgegrenzt, wenngleich sie aufgrund der zellvermittelten Reaktion grundsätzlich zu den Typ-IV-Reaktionen gerechnet werden könnten. Da bei dem granulomatösen Typ jedoch nicht Lymphozyten, sondern Makrophagen das entzündliche Geschehen dominieren, ist eine gesonderte Gruppierung dieser Formen gerechtfertigt. Zudem entstehen im Gegensatz zu den Typ-IV-Reaktionen die granulomatösen Reaktionen vom Typ V durch partikuläre, unlösliche Allergene. Es bleibt allerdings abzuwarten, ob sich diese Nomenklatur durchsetzt. Schließlich sei die kutane basophile Hypersensitivität (Jones-Mote-Reaktion) erwähnt, deren klinische und pathophysiologische Bedeutung jedoch unklar ist.

Die in - Tab. 3.1 dargestellte Einteilung in 5 allergische Reaktionen zeigt, dass sich die pathogenetischen Mechanismen einzelner Erkrankungen überlappen können. In - Abb. 3.1 sind deshalb die auf mehrere Mechanismen zurückgehenden Erkrankungen den auf einem isolierten Mechanismus beruhenden Krankheiten gegenübergestellt. Eine detaillierte Besprechung aller in Tab. 3.1 aufgeführten allergischen Erkrankungen würde den zur

- Tab. 3.1. Klassifikation allergischer Erkrankung auf dem Boden des zugrunde liegenden Immunreaktion

\begin{tabular}{|c|c|c|}
\hline Formen & Immunmechanismus & Allergische Erkrankungen \\
\hline Typ-I-Allergien & $\begin{array}{l}\text { Klassische IgE-vermittelte Allergien (Th2-Zellen, } \\
\text { Mastzellen, Eosinophile) }\end{array}$ & $\begin{array}{l}\text { - Allergisches Asthma bronchiale } \\
\text { - Rhinitis allergica } \\
\text { - Conjunctivitis allergica } \\
\text { - Atopische Dermatitis } \\
\text { - Allergische Gastroenteropathie } \\
\text { - Anaphylaxie } \\
\text { - Allergische Urtikaria } \\
\text { - Allergische bronchopulmonale Aspergillose }\end{array}$ \\
\hline Typ-II-Allergien & $\begin{array}{l}\text { Zytotoxische Antikörper/Komplement } \\
\text { (IgG und IgM-Antikörper) }\end{array}$ & $\begin{array}{l}\text { - Allergische hämolytische Anämien } \\
\text { - Allergische Agranulozytose } \\
\text { - Allergische Thrombozytopenie }\end{array}$ \\
\hline Typ-III-Allergien & $\begin{array}{l}\text { Immunkomplexvermittelt (IgG, IgM, Komplement } \\
\text { und Neutrophile) }\end{array}$ & $\begin{array}{l}\text { - Serumkrankheit } \\
\text { - Akute Hypersensitivitätspneumonitis (EAA) }\end{array}$ \\
\hline Typ-IV-Allergien & Zellvermittelt (T-Lymphozyten, Makrophagen) & $\begin{array}{l}\text { - Allergisches Kontaktekzem } \\
\text { chronische Hypersensitivitätspneumonitis (EAA) } \\
\text { - Allergische Gastroenteropathie }\end{array}$ \\
\hline Typ-V-Allergien & Granulomatöse Reaktionen (Makrophagen) & Berylliose, Talkose \\
\hline
\end{tabular}


Verfügung stehenden Rahmen dieses Kapitels sprengen. Aus diesem Grund wird der Schwerpunkt des Kapitels bewusst auf allergische Krankheiten der Atemwege und Lunge gelegt.

\section{Definitionen}

Ein grundlegendes Problem im Rahmen der Allergologie ist die z.T. diffuse und oft variierende Definition allergologischer Begriffe. Um dieser begrifflichen Verwirrung vorzubeugen, sollen hier zunächst in alphabetischer Reihenfolge die wichtigsten zur Allergologie gehörenden, aktuell gültigen Begriffe definiert und abgegrenzt werden.

\section{Allergie}

Unter Allergie versteht man allgemein eine über die Norm hinausgehende Immunreaktion nach Exposition mit exogenen körperfremden Antigenen bzw. Allergenen. Der Begriff wurde bereits 1906 vom Wiener Pädiater Clemens von Pirquet (1874-1929) geprägt. Als synonyme Ausdrücke werden Überempfindlichkeit, Hypersensibilität oder Hypersensitivität gebraucht.

\section{Allergisch bronchopulmonale Aspergillose}

Bei der allergischen bronchopulmonalen Aspergillose (ABPA) handelt es sich um eine seltenere pulmonale Erkrankung, die auf eine Typ-I-Reaktion, z. T. auch auf eine
Typ-III-Reaktion (Arthus-Reaktion) gegenüber Aspergillus fumigatus und anderen Pilzen bzw. Mikroorganismen zurückgeht. Klinisch manifestiert sich die ABPA durch zunehmende asthmatische Beschwerden, Hämoptysen, Thoraxschmerzen sowie Myalgien. Eine Dyskrinie mit Bildung eines zähen Schleims führt charakteristischerweise zu sog. »mucoid impactions« mit Entwicklung zentral lokalisierter Bronchiektasen. Eine frühzeitige Diagnosestellung ist von Bedeutung, da die ABPA unbehandelt zu einem fortschreitenden fibrotischen Umbau der Lunge führt. Die Diagnose der ABPA basiert auf den folgenden von Patterson vorgeschlagenen Kriterien:

- anamnestisch bekanntes, rekurrierendes Asthma,

- transiente oder persistierende Lungeninfiltrate,

- zentrale Bronchiektasen,

- periphere, bronchoalveoläre und Sputumeosinophilie,

- lokale Sofortreaktion nach kutaner Antigenprovokation,

- lokale, verzögerte Reaktion nach kutaner Antigenprovokation,

- präzipitierende IgG-Antikörper gegen Aspergillusspezies,

- Erhöhung des Gesamt-IgE (>1000 U/ml) und

- Nachweis von aspergillusspezifischem IgE.

Die Bestimmung des spezifischen Aspergillus-IgE ist ein nützlicher differenzialdiagnostischer Parameter für die Abgrenzung des allergischen Asthma bronchiale. Etwa

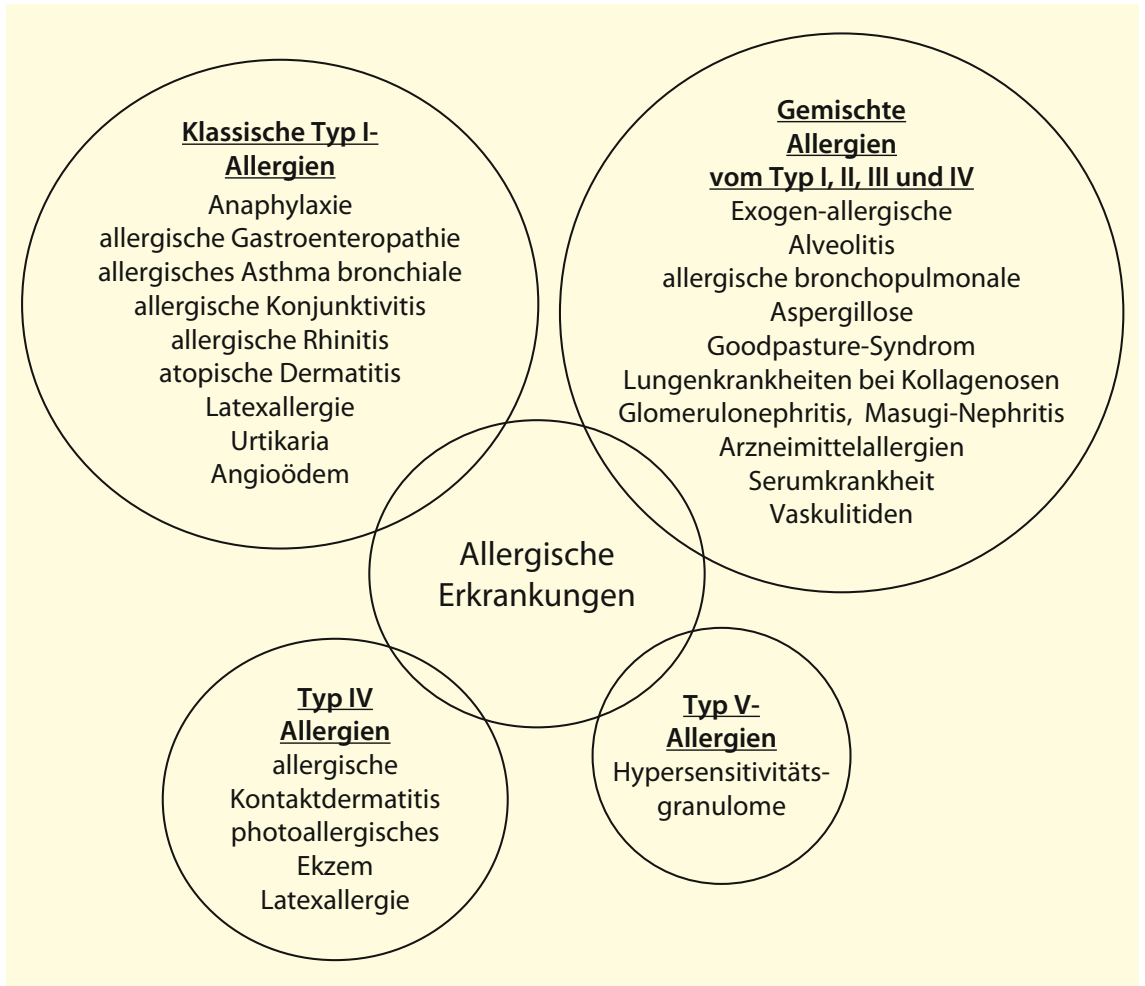

- Abb. 3.1. Einteilung allergischer Erkrankungen nach dem zugrunde liegenden immunologischen Mechanismus 
$10 \%$ der Patienten mit zystischer Fibrose entwickeln im Verlauf ihrer Erkrankung eine ABPA.

\section{Allergische Diathese}

Nicht alle Personen mit erhöhten Gesamt-IgE- und spezifischen IgE-Spiegeln sowie einer positiven Hautreaktion klagen über klinische Beschwerden. Diese subklinische allergische Reaktionsbereitschaft bezeichnet man als allergische Diathese.

\section{Allergische Gastroenteropathie}

Unter einer allergischen Gastroenteropathie oder Nahrungsmittelallergie im engeren Sinne versteht man eine immunologische Reaktion des Körpers gegenüber einer kleinen Menge an aufgenommener Nahrung. Von dieser eigentlichen Nahrungsmittelallergie abzugrenzen sind

- nichtallergische Nahrungsmittelintoleranz (z. B. pharmakologisch, toxisch, metabolisch) und

- Nahrungsmittelabneigung (psychogen).

Nahrungsmittelallergien gehen meist auf die klassische Typ-I-Reaktion mit Bildung von spezifischem IgE zurück. Gelegentlich treten aber auch Typ-IV-Reaktionen auf.

Patienten mit einer echten Nahrungsmittelallergie geben ein oder mehrere definierte Nahrungsmittel an, die meist innerhalb von wenigen Minuten Symptome auslösen. Hierzu gehören charakteristischerweise Pruritus und Schwellung der Zunge bzw. der Mundschleimhaut und des Oropharynx (orales Allergiesyndrom), die nach einer gewissen Latenz von Übelkeit, Erbrechen, Abdominalschmerzen und Diarrhoe gefolgt werden. Zusätzlich können sich die Beschwerden auf andere Organe (Rhinitis, Asthma, Urtikaria, Angioödem, Anaphylaxie) ausdehnen.

$\mathrm{Zu}$ den häufigsten ursächlich verantwortlichen Nahrungsmitteln gehören bei Kindern Milch, Eier und Erdnüsse. Bei Erwachsenen stehen dagegen Gemüse (Sellerie, Karotten), Nüsse und Früchte, Fisch und Schalentiere im Vordergrund. Die Diagnose beruht neben der sorgfältig erhobenen Anamnese auf der Hauttestung mit Nahrungsmittelallergenen (auch direkt mit frischen Nahrungsmitteln, sog. Prick-Prick-Methode), dem Nachweis von nahrungsmittelspezifischem IgE sowie einem Allergenauslassversuch und der oralen Provokation.

\section{Anaphylaxie}

Der Begriff Anaphylaxie geht auf die Franzosen Charles Richet (1850-1935) und Paul Portier (1866-1962) zurück. Heute versteht man unter dem Begriff eine fulminante systemische allergische Sofortreaktion, die sich gleichzeitig an mehreren Organen (Lunge, Atemwege, Zirkulation, Magen-Darm-Trakt, Haut) manifestiert. Sie tritt gewöhnlich nur wenige Minuten nach Allergenexposition auf und ist durch Pruritus, Urtikaria, Atemwegsobstruktion, Lungenödem, Dyspnoe, Hypotonie und Schock gekenn- zeichnet. Zu den häufigsten Auslösern anaphylaktischer Reaktionen gehören:

- Nahrungsmittel (Meeresfrüchte, Sellerie, Gewürze, Eier, Milch, Nüsse),

- Bienen- und Wespengifte (s. dort),

- Medikamente (Penizillin-Antibiotika, Aspirin) und

- Latex.

Der Pathomechanismus geht am häufigsten auf IgEvermittelte Typ-I-Reaktionen zurück. Zu den möglichen anderen Mechanismen gehören Immunkomplex- bzw. Komplement-vermittelte Typ-II-Reaktionen (Transfusionsreaktion) sowie die Störung des Arachidonsäuremetabolismus (Aspirin-Intoleranz).

Von der immunologisch vermittelten Anaphylaxie sind die nichtimmunologischen anaphylaktoiden Reaktionen abzugrenzen. Hierzu gehören beispielsweise die direkten mastzellvermittelten (Röntgenkontrastmittel, Pentamidin, Opiate), physikalischen (belastungs- bzw. kälteinduzierte Anaphylaxie) und idiopathischen Formen.

\section{Asthma bronchiale}

Der Begriff Asthma hat seinen Ursprung im Altertum und ist aus dem griechischen Wort "asthmatai« (Homer, »Ilias«) abgeleitet, was so viel heißt wie »keuchen« oder »geräuschvoll atmen«. Die Definition des Asthma wurde seither vor dem Hintergrund der jeweils gültigen pathophysiologischen Konzeption mehrfach modifiziert. Heute lässt sich die Erkrankung unter Einschluss verschiedener Aspekte als eine entzündliche Bronchialerkrankung unterschiedlicher Ätiologie definieren, die folgendermaßen gekennzeichnet ist:

- klinisch durch eine rekurrierende bis persistierende Bronchialverengung mit Giemen und Dyspnoe unterschiedlichen Grades,

- lungenfunktionell durch eine zumeist vollständige, seltener auch teilreversible Atemwegsobstruktion,

- pathophysiologisch durch eine bronchiale Hyperreagibilität (BHR),

- histopathologisch durch eine eosinophile Bronchitis

- immunhistologisch durch eine Anreicherung aktivierter $\mathrm{CD}^{+}{ }^{+}$-T-Zellen sowie aktivierter eosinophiler Granulozyten und

- immunologisch durch die Freisetzung von Zytokinen bzw. anderen Mediatoren.

Die klinische Manifestation der Erkrankung reicht von leicht symptomatischen über häufig rekurrierende Formen bis hin zum schweren perennialen, instabilen Asthma (Brittle-Asthma) und dem Status asthmaticus.

Grundsätzlich unterteilt man das Asthma bronchiale je nach vorhandener oder nicht vorhandener allergischer Diathese in:

- extrinsisches oder allergisches Asthma,

- intrinsisches oder nichtallergisches Asthma. 
Andere Bezeichnungen wie anstrengungs-, analgetikaassoziiertes oder nächtliches (nokturnalen) Asthma stellen keine eigenständigen Formen eines Asthma bronchiale dar. Diese Ausdrücke beziehen sich vielmehr auf häufige und eindeutig definierbare Auslöser bzw. die tageszeitliche Zuordnung asthmatischer Beschwerden, durch die sich ein vorbestehendes intrinsisches oder extrinsisches Asthmas bevorzugt manifestiert.

\section{Atopie}

Der Begriff der Atopie wurde 1932 von Arthur Fernandez Coca (1875-1959) und Robert A. Cooke (1890-1960) geprägt, um eine Subgruppe allergischer Patienten $\mathrm{zu}$ bezeichnen, die auf der Grundlage einer genetischen Prädisposition gegenüber bestimmten Allergenen spezifische IgE-Antikörper (ursprünglich als sog. Reagine bezeichnet) im Blut aufweisen. Die Atopie bezeichnet also eine gesteigerte Bereitschaft eines Individuums, nach Allergenkontakt mit einer Immunreaktion vom Typ I zu reagieren (sog. Atopiker). $\mathrm{Zu}$ den korrespondierenden klinischen Reaktionen gehören vor allem das Asthma bronchiale, die Rhinitis allergica, das atopische Ekzem oder die Anaphylaxie.

\section{Atopische Dermatitis}

Bei der atopischen Dermatitis handelt es sich um eine multifaktoriell bedingte, multimodale, in der Regel chronisch-rezidivierende, pruriginöse, ekzematöse, entzündliche Hauterkrankung, die dem atopischen Formenkreis zuzuordnen ist. Sie lässt sich in 3 altersabhängige Manifestationsformen gliedern. Das infantile Stadium bis $\mathrm{zu}$ einem Alter von 2 Jahren geht mit einem stark juckenden und verkrustenden Erythem als sog. Milchschorf (Crusta lactea) im Bereich der Parietalregion, der Stirn, der Wangen (»weeping patches«) und der Streckseiten der Extremitäten einher. Das kindliche Stadium im Alter von 2-12 Jahren zeigt ein papulöses »Beugeekzem « in den Ellenbeugen und Kniekehlen, aber auch an der volaren Seite der Handgelenke, den Fußgelenken und am Nacken. Verdickte kutane Plaques zeigen Lichenifikationen sowie Exkoriationen. Im Erwachsenenstadium nach der Pubertät bilden sich die Beschwerden häufig zurück oder treten schubweise auf. Dann finden sich Lichenifikationen an den Ellenbeugen, der Stirn sowie periorbital. Handgelenke, Hände, Fußgelenke, Füße, Finger und Zehen können gelegentlich ebenfalls beteiligt sein.

\section{Conjunctivitis allergica}

Unter der Conjunctivitis allergica wird eine atopische, entzündliche Reaktion der Konjunktiva auf dem Boden einer IgE-vermittelten Reaktion gegenüber Allergenen verstanden. Sie geht klinisch mit einer Rötung und vermehrten Tränensekretion einher und ist häufig mit der Rhinitis allergica vergesellschaftet.

\section{Exogen-allergische Alveolitis}

Die exogen-allergische Alveolitis (EAA) oder Hypersensitivitätspneumonitis bezeichnet eine seltene interstitielle Lungenerkrankung, die sich bei prädisponierten Individuen auf dem Boden einer Typ-III- und Typ-IV-Reaktion gegenüber inhalativen Antigenen entwickelt und im fortgeschrittenen Stadium zu einer pulmonalen Fibrose führt. Die klassische Form der Erkrankung geht ätiologisch auf aktinomyzetenhaltigen Kompost (verschimmeltes Heu) bei der Farmerlunge zurück, obwohl zahlreiche andere Antigene (Vogel- und Tierantigene) ebenfalls als Ursache in Frage kommen können. Beschwerden in Form von allgemeinem Krankheitsgefühl, Fieber, Husten, Hämoptysen und Dyspnoe treten bei der akuten Form einige Stunden nach der Exposition auf. Die chronische Form der EAA verläuft meist subklinisch und fällt erst im fortgeschrittenen Stadium der manifesten Lungenfibrose auf.

Die Diagnose der EEA lässt sich nach den aktuellen Kriterien der Arbeitsgemeinschaft Exogen-allergische Alveolitis wie folgt ermitteln:

- Antigenexposition,

- expositions- und/oder zeitabhängige Symptome,

- spezifische IgG-Antikörper im Serum (»Präzipitine«),

- Sklerophonie,

- Röntgenzeichen der EAA, ggf. im HR-CT,

- $\mathrm{pO}_{2}$ in Ruhe und/oder bei Belastung erniedrigt oder $\mathrm{D}_{\mathrm{L}} \mathrm{CO}$ eingeschränkt.

Sind alle 6 Kriterien erfüllt, liegt eine EAA vor. Fehlt eines der genannten Kriterien, so kann es durch eins der folgenden ersetzt werden:

- Lymphozytose in der bronchoalveolären Lavage (BAL),

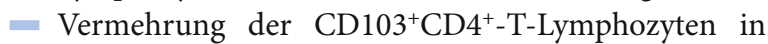
der BAL auf $>50 \%$,

- mit der EAA zu vereinbarender histopathologischer Befund,

- positiver Karenztest,

- positive inhalative Expositions- oder Provokationstestung.

Sind insgesamt 6 Kriterien erfüllt, liegt eine EAA vor.

Bei Verdacht auf eine immunologische Reaktion gegenüber Aspergillus kann die Diagnose zusätzlich über den serologischen Nachweis von rekombinanten Aspergillusgenen (r Asperg. f 2,4,6) gestellt werden.

\section{Insektengiftallergie}

Bei der Insektengiftallergie handelt es sich um eine Typ-IReaktion vorwiegend nach Bienen- oder Wespenstichen. Dabei können milde bis schwere allergische Allgemeinsymptome bzw. überschießende Lokalreaktionen am Einstichort auftreten, die von der üblichen lokalen Schwellung auf dem Boden unspezifisch wirkender toxischer Giftbestandteile zu unterscheiden sind. 
Die diagnostische Abklärung erfolgt durch Bestimmung des spezifischen IgE gegenüber Insektengiftbestandteilen (Phospholipase, Melittin etc.) und durch einen Hauttest in Verbindung mit der Anamnese. Da Reaktionen nach Insektenstich gelegentlich tödlich enden, besteht nach Auftreten allergischer Allgemeinsymptome jeglicher Art die Indikation zur Hyposensibilisierung. Außerdem müssen Insektengiftallergiker obligat mit Notfallmedikamenten (z. B. Kortisonpräparat, Antihistaminikum, Adrenalinselbstinjektor) ausgestattet werden.

\section{Pseudoallergie}

Sämtliche Symptome, wie z. B. Asthma, Rhinitis, Urtikaria, die auf eine allergische Sofortreaktion hinweisen, können auch durch nichtimmunologische Mechanismen bisher nicht sicher geklärter Pathogenese ausgelöst werden. Als klassische Beispiele sind hier die Histaminfreisetzung aus Mastzellen oder basophilen Granulozyten durch Opiate, nichtsteroidale Antiphlogistika oder jodhaltige Röntgenkontrastmittel, Lokalanästhetika, Plasmaexpander und Konservierungsmittel zu nennen. In diesen Fällen spricht man von einer Pseudoallergie.

\section{Rhinitis allergica}

Die Rhinitis allergica, im Volksmund auch Heuschnupfen genannt, findet erstmals im 6. Jahrhundert in der Dissertationsarbeit von Rhazes über Die Ursache der Coryza des Frühlings Erwähnung. Spätere Arbeiten von Bostock, Wyman, Blackley und Wolff-Eisner etablierten die Rhinitis als klinische Manifestation der Atopie. Heute lässt sich die Rhinitis als Entzündung der nasalen Mukosa definieren, die einhergeht:

- klinisch mit Hypersekretion, Niesreiz sowie nasaler Kongestion,

- immunologisch auf dem Boden IgE-vermittelter Mechanismen gegenüber Allergenen mit lokaler Sekretion von Zytokinen, eosinophilem kationischem Protein (ECP) und anderen Mediatoren,

- histologisch mit einer Infiltration vor allem durch eosinophile Granulozyten und

- immunhistologisch mit einer Anreicherung aktivierter T-Lymphozyten und degranulierter eosinophiler Granulozyten.

Je nach Umfang und Ausmaß der Allergensensibilisierung reicht die klinische Manifestation von leichten saisonalen bis zu schweren perennialen Formen und tritt in der Regel gemeinsam mit der Conjunctivitis allergica auf. Sie ist eng mit dem Asthma korreliert.

\section{Urtikaria und Angioödem}

Unter Urtikaria oder Nesselsucht versteht man eine allergische Überempfindlichkeit der Haut und Schleimhäute, die auf dem Boden einer Immunreaktion vom Typ I hervorgerufen wird. Urtikarielle Hauterscheinungen imponieren klinisch als umschriebene, erhobene, erythematöse und juckende Quaddeln oder unter Einbeziehung der Subkutis als Angioödem und werden durch eine immunologische Typ-I-Reaktion vermittelt. Darüber hinaus können andere Ursachen wie physikalische Mechanismen (Wärme, Kälte, Druck), Infekte und Autoimmunmechanismen eine Manifestation der Erkrankung auslösen.

Von der allergischen Urtikaria ist die nichtallergische Urtikaria abzugrenzen. Hierzu gehört die "physikalische» Urtikaria (Urticaria factitia, Kälte- bzw. Wärmeurtikaria, Lichturtikaria und Druckurtikaria), die »cholinerge« Urtikaria (durch psychische Alteration und Stress, Schwitzen, körperliche Anstrengung) sowie eine Urtkaria im Rahmen von Vaskulitiden.

\subsubsection{Epidemiologie}

\section{Prävalenz allergischer Erkrankungen}

Zur Prävalenz allergischer Erkrankungen in Deutschland liegen in der Zwischenzeit verschiedene Studien an Kindern und Erwachsenen vor. In Bayern und NordrheinWestfalen weisen etwa ein Drittel aller Schulanfänger eine allergische Sensibilisierung gegenüber Aero- oder seltener Nahrungsmittelallergenen auf. Davon leiden rund 12\% an Rhinokonjunktivitis, $12 \%$ an atopischem Ekzem, $7 \%$ an Nahrungsmittelallergien und 5\% an Asthma bronchiale. Bei einer epidemiologischen Querschnittsuntersuchung an 9.403 9- bis 11-jährigen Schulkindern im Raum München wiesen 33\% der Kinder eine allergische Erkrankung (Rhinitis allergica, allergisches Asthma, atopische Dermatitis) auf. Zu vergleichbaren Ergebnissen kam eine Studie an Schulkindern aus Südbaden.

Im Rahmen einer multizentrischen Studie an 11.838 Erwachsenen im reproduktionsfähigen Alter wurde die Lebenszeitprävalenz allergischer Erkrankungen mittels Fragebogen ermittelt. Dabei zeigte sich, dass 21\% der Väter und 22\% der Mütter an mindestens einer allergischen Manifestation leiden. Im einzelnen litten 3,6 bzw. 4,1\% der Befragten an Asthma bronchiale, 16,0 bzw. 15,5\% an Rhinitis allergica und 1,7 bzw. 3,5\% an atopischer Dermatitis.

Aus globaler Perspektive zeigt die Prävalenz allergischer Erkrankungen regional erhebliche Unterschiede. Wie die erste der 3 geplanten ISAAC-Studien (International Study on Asthma and Allergy in Children) an 463.801 Kindern im Alter von 13-14 Jahren aus 5 Erdteilen darlegt, klagen vor allem Kinder aus England, Irland, Neuseeland, Australien und Kanada in der 12-monatigen Erfassungsperiode über allergische Symptome (jeweils ca. 30\% mit Asthmasymptomen, 18\% mit Symptomen einer Rhinokonjunktivitis und 10-15\% mit Symptomen einer atopischen Dermatitis). Bemerkenswert ist, dass auch in einzelnen afrikanischen und lateinamerikanischen Län- 
dern (Nigeria, Peru, Paraguay, Kenia, Uruguay) eine hohe Prävalenz allergischer Erkrankungen beobachtet wird.

In Deutschland beträgt die Anzahl der im Rahmen der ISAAC-Studie ermittelten Kinder mit asthmatischen und rhinokonjunktivitischen Beschwerden jeweils 14\% und die der Kinder mit atopischer Dermatitis 7\%. In Indonesien ebenso wie in Indien, China, Griechenland und mehreren osteuropäischen Staaten war dagegen die Prävalenz der 3 allergischen Manifestationen mit weniger als $5 \%$ vergleichsweise gering.

Die Ursachen für die erhebliche länderabhängige Variation der Prävalenz allergischer Erkrankungen sind bisher nicht bekannt. Hierzu wird möglicherweise die 2 . Stufe des ISAAC-Projekts weiteren Aufschluss geben, in der die Beziehung zwischen der Erkrankung und dem sozialen Status, dem Impfstatus, dem Klima und den Ernährungsgewohnheiten untersucht werden soll.

\section{Ursachen der steigenden Prävalenz}

Die Prävalenz allergischer Erkrankungen nimmt weltweit zu. Verschiedene Faktoren werden mit dieser Entwicklung in Verbindung gebracht, ohne dass deren ursächliche und relative Bedeutung bisher eindeutig definiert werden konnte. So werden neben der steigenden Umweltbelastung, Urbanisierung und den klimatischen Veränderungen auch die sich ändernden sozialen und diätetischen Lebensgewohnheiten sowie die Möglichkeiten des modernen Wohnungsbaus diskutiert.

Beispielsweise könnte die steigende Prävalenz mit der zunehmenden Schadstoffbelastung der Umwelt in Zusammenhang stehen. Aber auch die Einführung von gepolstertem Mobiliar bei verbesserten Isolierungstechniken für Fenster und Türen dürften die Konzentration von Aeroallergenen und Hausstaubmilben erhöhen. In diesem Sinne könnten ferner klimatische Veränderungen, die neben dem Pollenflug auch das Wachstum von Insekten, Milben oder Schimmelpilzen begünstigen, einen Einfluss besitzen. Andere Ursachen für die allergische Sensibilisierung könnten in der synergistischen Wirkung von Umweltverschmutzung und Nikotinabusus liegen. Auch die zunehmende Urbanisation scheint mit der ansteigenden Prävalenz allergischer Erkrankungen assoziiert zu sein. Andere Faktoren diätetischer und sozioökonomischer Natur werden ebenfalls diskutiert.

Hinweise auf die relative Bedeutung der oben genannten Faktoren ergeben sich aus vergleichenden Untersuchungen zur Prävalenz allergischer Erkrankungen zwischen West- (München) und Ostdeutschland (Leipzig). Die erste Studie wurde in den Jahren 1991/92 mittels Fragebogen an Kindern im Alter von 9-11 Jahren durchgeführt. Während die Häufigkeit der Bronchitis im Osten mit 30,9\% etwa doppelt so hoch war, erwies sich im Westen die Prävalenz von Heuschnupfen (2,4\% vs.
7,7\%), Asthma bronchiale (6,6 vs. 7,7\%) und atopischer Dermatitis (13,0 vs. $13,9 \%)$ als höher. Gleichzeitig war der Schwefeldioxid- und Schwebstaubgehalt im Osten deutlich größer, während die Luftverschmutzung durch Stickoxide (Autoabgase) in München höher lag.

Eine Folgestudie aus den Jahren 1995/96 ergab, dass die Prävalenz der Rhinitis in Leipzig mit 5\% in der Zwischenzeit auf das Doppelte angestiegen war. Darüber hinaus stieg in diesem Zeitraum die Häufigkeit positiver Hauttestreaktionen gegenüber Hausstaubmilben, Gras-, Hasel- und Birkenpollen um 30\% auf 80\% an. Während die Sensibilisierungsrate der Kinder im Westen im Vergleich zur Voruntersuchung unverändert mit 36\% blieb, war im Osten insgesamt die Prävalenz aller allergischer Beschwerden von 19 auf 27\% angestiegen. Parallel hierzu war der Gehalt an Schwefeldioxid in den 4 Jahren auf rund ein Fünftel zurückgegangen, der von Stickoxiden dagegen um fast die Hälfte gestiegen. Andere potenzielle Risikofaktoren wie passive Nikotinexposition, Wohnungsfeuchtigkeit und Haustierhaltung nahmen in Leipzig zu. Interessanterweise ergab die Studie eine positive Korrelation zwischen dem Konsum von Margarine und Heuschnupfen, während der Verbrauch von Butter mit einer niedrigeren Prävalenz der Rhinitis assoziiert war. Diese Daten deuten darauf hin, dass sowohl bestimmte Umweltschadstoffe als auch Lebensgewohnheiten als Ursache für die steigende Prävalenz allergischer Erkrankungen in Betracht kommen.

\section{Mortalität}

Allergische Erkrankungen führen nicht selten zu einer beträchtlichen Mortalität. Hierzu gehören vor allem die plötzlichen Todesfälle im Rahmen des allergischen Asthma bronchiale, der Anaphylaxie (Insektengift, Antibiotika etc.) und der vorzeitige Tod im fortgeschrittenen Stadium der EAA. Laut Todesscheindiagnose (ICD-Nummer $493=$ Asthma) sterben pro Jahr etwa 1.000 Personen an den Folgen eines Asthmas, was einer Mortalität von einem Todesfall pro 100.000 Bundesbürgern entspricht. Damit liegt die Asthmamortalität in Deutschland unter der anderer Länder (4-6 Todesfälle pro 100.000 Einwohner). Allerdings müssen diese Zahlen mit einer gewissen Vorsicht interpretiert werden, da aufgrund der gelegentlich schwierigen differenzialdiagnostischen Abgrenzung anderer obstruktiver Erkrankungen asthmabedingte Todesfälle in den ICD-Positionen 490-496 versteckt sein dürften. Umgekehrt ist aber auch anzunehmen, dass chronische obstruktive Bronchitiden (COPD) fälschlicherweise unter dem ICD-Schlüssel 493 notiert werden.

Die Inzidenz asthmabedingter Todesfälle scheint weltweit anzusteigen. Die hierfür verantwortlichen Faktoren sind bisher nicht bekannt, dürften aber mit der generellen Zunahme der allergischen Erkrankungen im Zusammenhang stehen. Trotzdem lassen sich einige Risikofaktoren 
identifizieren, die mit einem Todesfall assoziiert sind (s. Übersicht).

Risikofaktoren einer tödlich verlaufenden Asthmaexazerbation

- Persönliches Umfeld:

- psychische und psychosoziale Probleme,

- niedriger sozioökonomischer Status,

- Drogenabusus,

- niedrige Compliance;

- medizinische Versorgung:

- Unterschätzung der Erkrankung vonseiten des Arztes und des Patienten,

- inadäqate medizinische Versorgung;

- Krankheitsaktivität:

- vorausgegangene lebensbedrohliche, schwere Asthmaattacken,

- vorausgegangene Intubation aufgrund eines Status asthmaticus,

- intensivmedizinische Behandlung aufgrund des bestehenden Asthma bronchiale,

- Krankenhauseinweisung wegen Asthma in den vorausgegangenen 12 Monaten,

- 3 oder mehr Notfallbehandlungen in den vorausgegangenen 12 Monaten,

- Hospitalisation oder Notfallbehandlung im vorausgegangenen Monat,

- Verbrauch von mehr als 2 Kanistern kurz wirksamer $\beta 2$-Mimetika innerhalb eines Monats,

- gegenwärtige Einnahme von oralen Kortikosteroiden,

- kurz vorausgegangene Beendigung einer oralen Kortikosteroidtherapie,

- Komorbidität (kardiovaskuläre Erkrankungen, Infektionen);

- allergische Diathese:

- Sensibilisierung gegenüber Alternaria.

(Mod. nach National Institutes of Health 1998)
Schätzungen gehen davon aus, dass in Westdeutschland jährlich etwa 3,6 Mio. Arbeitsunfähigkeitstage durch Asthma entstehen. Die direkten und indirekten Kosten für die Volkswirtschaft belaufen sich auf einen Betrag von 5-20 Mrd. DM pro Jahr. Dabei besteht ein Zusammenhang zwischen den anfallenden Kosten und dem Schweregrad der Erkrankung. So verursachen die 25\% der Patienten mit mittelschweren und schweren Asthmaformen etwa $50 \%$ der Gesamtkosten.

Die erste Untersuchung errechnete auf der Grundlage der Daten aus dem Jahr 1992 jährliche Aufwendungen für leichtes Asthma in Höhe von 360 DM, für mittelschweres Asthma von 2.045 DM und für schweres Asthma in Höhe von 14.770 DM. Eine weitere Studie ermittelte jährliche Behandlungskosten für leichtes Asthma in Höhe von 3.339 DM, für mittelschweres Asthma von 5.260 DM und für schweres Asthma von 12.016 DM. Die überproportional mit der Schwere der Erkrankung ansteigenden Kosten gehen hiernach vor allem auf die häufigere stationäre Behandlung und indirekte Kosten zurück. Die jährlichen Ausgaben liegen bei Frauen gegenüber Männern um etwa 800 DM höher. Das Aufkommen für asthmatische Kinder liegt jährlich bei 2.595 DM für leichte, bei 3.225 DM für mittelschwere und bei 4.811 DM für schwere Formen. Die steigenden Kosten gehen hier vor allem auf Medikamentenkosten zurück. Dabei sind die intangiblen Kosten nicht erfasst.

Der Zusammenhang zwischen Schweregrad und Kosten betont die Bedeutung präventiver Maßnahmen für die Begrenzung der jährlichen Aufwendungen für das Asthma bronchiale. Hierfür muss eine Verbesserung der medikamentösen Behandlungsmöglichkeiten, aber auch die Verbesserung der Compliance beispielsweise durch eine Ausweitung von Patientenschulungen angestrebt werden. Eine nicht unerhebliche Rolle für die jährlich anfallenden Kosten bildet dabei nämlich auch die Compliance der Patienten. Schätzungen gehen davon aus, dass Aufwendungen in Höhe von etwa 2,5 Mrd. DM durch Medikamente verlorengehen, die nicht regelrecht eingenommen werden und verfallen.

\subsubsection{Genetische Prädisposition und andere Risikofaktoren}

Atopische Erkrankungen treten familiär gehäuft auf. Sowohl Zwillings- als auch Familienstudien konnten überzeugend darlegen, dass die allergische Diathese partiell unter genetischer Kontrolle steht. Nachkommen von Eltern mit allergischer Diathese ohne Asthma besitzen kein erhöhtes Risiko, an Asthma zu erkranken. Dagegen ist im Falle eines klinisch manifesten Asthma bronchiale bei allergischen Individuen die Wahrscheinlichkeit, dass deren Kinder an Asthma erkranken, um das 2- bis 
3-fache gegenüber dem Risiko der Allgemeinbevölkerung erhöht.

Ein gesteigertes Risiko, an Asthma zu erkranken, liegt ebenfalls dann vor, wenn bei den Eltern eine allergische Diathese und eine bronchiale Hyperreagibilität auch ohne manifeste Symptome besteht. Das Risiko der Kinder asthmatischer Eltern ohne allergische Diathese ist dagegen nicht größer als das der allgemeinen Bevölkerung.

Hohe Serum-IgE-Konzentrationen scheinen nach einem autosomal rezessiven Modus mit zusätzlicher polygenetischer Komponente übertragen zu werden. Andere Studien identifizierten einen autosomal dominanten Erbgang, bei dem die verantwortlichen Gene auf Chromosom 11q13, 5q13-q33 und 6p21.3 lokalisiert sind. Das Gen wird jedoch nur dann exprimiert, wenn es mütterlicherseits vererbt wird. Auch für die bronchiale Hyperreagibilität scheint ein genetischer Hintergrund zu bestehen, der mit Allelen der Regionen 5q31-p33 bzw. 11p13 assoziiert ist. Auf Chromosom 5 finden sich auch die Gene für verschiedene relevante Zytokine (IL-3, IL-5, GM-CSF) und die $\beta$-Untereinheit des hochaffinen IgE-Rezeptors. Mutationen in diesem Bereich könnten durch eine Aktivierung der immunologischen Reaktion für die genetische Komponente des Asthma bronchiale verantwortlich sein. Diese Daten belegen die Vermutung einer genetischen Prädisposition allergischer Erkrankungen und sprechen insgesamt für einen polygenetischen Erbgang.

\subsubsection{Natürlicher Verlauf und Prognose}

Die Daten zum zeitlichen Verlauf und zur Prognose allergischer Erkrankungen sind aufgrund des langen zeitlichen Aspekts begrenzt. Einige größere der bisher veröffentlichten Untersuchungen sollen hier kurz dargestellt werden.

Panhuysen und Mitarbeiter beobachteten 181 Asthmatiker über einen Zeitraum von 25 Jahren. Nach diesem Intervall war bei 38 Patienten oder $21 \%$ keine bronchiale Hyperreagibilität mehr nachweisbar. Ferner zeigten 45 der Untersuchten (25\%) eine $\mathrm{FEV}_{1}$ (»forced exspiratory volume «) von über $90 \%$ und 72 (40\%) klagten nicht mehr über pulmonale Beschwerden. Davon wurden insgesamt 20 Personen (11\%) nicht mehr als Asthmatiker eingestuft. Die Rückbildung des Asthma bronchiale oder der bronchialen Hyperreagibilität war mit einem jüngeren Alter und einer weniger stark ausgeprägten Obstruktion während der ersten Untersuchung, einem kürzeren Intervall zwischen Diagnosestellung und Einleitung der Therapie sowie einem niedrigeren IgE assoziiert. Diese Daten deuten darauf hin, dass ein mildes Asthma bronchiale und eine frühzeitige therapeutische Intervention Indizes für eine günstige Langzeitprognose darstellen.

Eine andere Untersuchung von Rackermann zum natürlichen Verlauf der allergischen Rhinitis zeigte, dass von den ursprünglich 86 Kindern nach einem Zeitraum von 24 Jahren noch immer 84 an Symptomen litten. Allerdings waren 42 der Rhinitiker (50\%) nicht mehr auf Medikamente angewiesen. Drei (3,5\%) litten nach dieser Zeit an schwerem Heuschnupfen, bei $13(15,1 \%)$ hatte sich im Verlauf zusätzlich ein saisonales Asthma und bei $7(8,1 \%)$ ein perenniales Asthma entwickelt. Nach dieser Studie kam es also etwa bei einem Viertel innerhalb des Beobachtungszeitraums von 24 Jahren zu einer Ausdehnung der Erkrankung auf andere Organe. Obwohl diese Daten eine Entwicklung von der Rhinitis allergica zum Asthma (»Etagenwechsel«) nahelegen, fehlen noch immer Untersuchungen, die diesen Verlauf ausreichend erklären.

Die Möglichkeit eines in der Kindheit aufgetretenen Asthma bronchiale, das sich während der Entwicklung bis zur Pubertät wieder zurückbildet, wird von epidemiologischen Studien allerdings relativiert. Hiernach bildet sich zwar das kindliche Asthma tatsächlich in 30-50\% der Fälle zurück, manifestiert sich aber nicht selten erneut während der Adoleszenz. Bis zu zwei Drittel der betroffenen Kinder klagen dagegen während der Pubertät und im Erwachsenenleben unverändert über asthmatische Symptome. Selbst wenn die asthmatische Obstruktion klinisch nicht mehr zum Ausdruck kommt, bestehen häufig bei den Betroffenen nach wie vor z. B. ein chronisch rezidivierender Husten, eine bronchiale Hyperreagibilität oder eine obstruktive Ventilationsstörung fort.

Fasst man die derzeit zur Verfügung stehenden Erfahrungen zum natürlichen Verlauf allergischer Erkrankungen zusammen, lassen sich grundsätzlich 3 Verlaufsformen erkennen:

- spontane Remission mit Besserung im Sinne einer partiellen oder vollständigen Rückbildung der klinischen Beschwerden,

- fortbestehende Beschwerden mit unveränderter Intensität und unverändertem Manifestationsmuster der Symptome und

- Verschlechterung der Symptomatik bzw. Ausweitung der klinischen Manifestation auf andere Organe.

Die den individuellen natürlichen Verlauf und die Prognose allergischer Erkrankungen bestimmenden Faktoren sind weitgehend unbekannt. Kinder mit früh aufgetretenem schwerem Asthma, mit atopischem Ekzem oder mit einer positiven Familienanamnese tendierten zur lebenslangen Persistenz der Erkrankung. Milderes kindliches Asthma ohne Ekzem besitzt dagegen eine bessere Prognose mit häufigeren Spontanremissionen. Auch ein früh aufgetretenes Asthma, ein niedrigeres IgE und eine unverzügliche Behandlung ist mit einer günstigeren Prognose assoziiert. In Einzelfällen beobachtet man bei Asthmatikern unter Remission eine erneute klinische Manifestation oder eine Verschlechterung nach protrahierten respiratorischen Infekten. 
Aber auch ein zwischenzeitlich betriebener Nikotinabusus muss als Risikofaktor angesehen werden und kann nach einer mehrjährigen Latenz zu einer erneuten klinischen Manifestation führen. In diesen Fällen handelt es sich dann um eine sog. Mischform, die pathogenetisch sowohl auf Elemente eines allergischem Asthma als auch einer chronisch obstruktiven Bronchitis (COPD) zurückgeht. Diese obstruktiven Mischerkrankungen erweisen sich nicht selten als besonders therapieresistent.

\subsubsection{Spezifische und unspezifische Auslöser allergischer Erkrankungen}

Unter Auslösern oder Triggern versteht man Faktoren, die beim Allergiker akute Exazerbationen ihrer Erkrankung hervorrufen. Grundsätzlich lassen sich spezifische und unspezifische Trigger voneinander unterscheiden. Bei den spezifischen Triggern handelt es sich um die für die Erkrankung ätiologisch verantwortlichen Allergene (Typ-I-Reaktion), Antigene (Typ-II- und Typ-IV-Reaktion) oder Haptene (vor allem Typ-IV-Reaktion). Demgegenüber versteht man unter unspezifischen Triggern nichtimmunologische, irritative Substanzen, die auf dem Boden einer bestehenden Erkrankung Symptome hervorrufen (• Abb. 3.2).

\section{Antigene, Allergene und Haptene}

\section{Antigene}

Antigene (immunogene Proteine, Proteoglykane oder Haptene) sind körperfremde Substanzen unserer unmittelbaren Umgebung, die die Bildung von Antikörpern auslösen. Bei prädisponierten Personen führt diese Im- munreaktion indirekt zu einer klinisch manifesten Erkrankung. Je nach chemischer Struktur und individueller Prädisposition induzieren antigene Moleküle entweder eine allergische Typ-I- (IgE-vermittelte), eine Typ-II- bzw. Typ-III- (IgG-vermittelte) oder Typ-IV-(zellvermittelte) Immunreaktion nach Coombs u. Gells.

\section{Allergene}

Eine Untergruppe der Antigene sind die Allergene, die unter anderem eine allergische Reaktion vom Typ I mit Synthese von IgE auslösen. Fremdproteine, die mit IgGAntikörpern in der doppelten Geldiffusion präzipitieren, bezeichnet man dagegen als Antigene und die korrespondierenden Antikörper als Präzipitine. Sie spielen z. B. bei der Pathogenese der exogen-allergischen Alveolitis eine Rolle.

\section{Haptene}

Haptene schließlich sind kleine, selbst nicht immunogene Moleküle, die ihre Immunogenität erst nach Bindung an ein Trägerprotein erhalten. Ein klassisches Beispiel hierfür bildet die Typ-IV-Reaktion durch Nickel oder Chromat.

\section{Eigenschaften allergener Substanzen}

Nicht alle Umweltantigene wirken auch als Allergen, sondern nur ein Spektrum bestimmter Proteine, von denen einige häufiger vorkommen als andere. Obwohl die Ursache für die unterschiedliche Potenz verschiedener Antigene, allergische Reaktionen auszulösen, noch nicht bekannt ist, finden sich jedoch einige allgemeine Eigenschaften, die eine solche Reaktion begünstigen (•Tab. 3.2).

Die meisten Allergene sind relativ kleine, leicht lösliche Proteinmoleküle, die in trockener Form mittels Trägersubstanzen wie Pollenkörnern oder Milbenfäzes
- Abb. 3.2. Mögliche spezifische (dunkler Kasten) und unspezifische Auslöser oder Trigger (heller Kasten) für allergische Erkrankungen

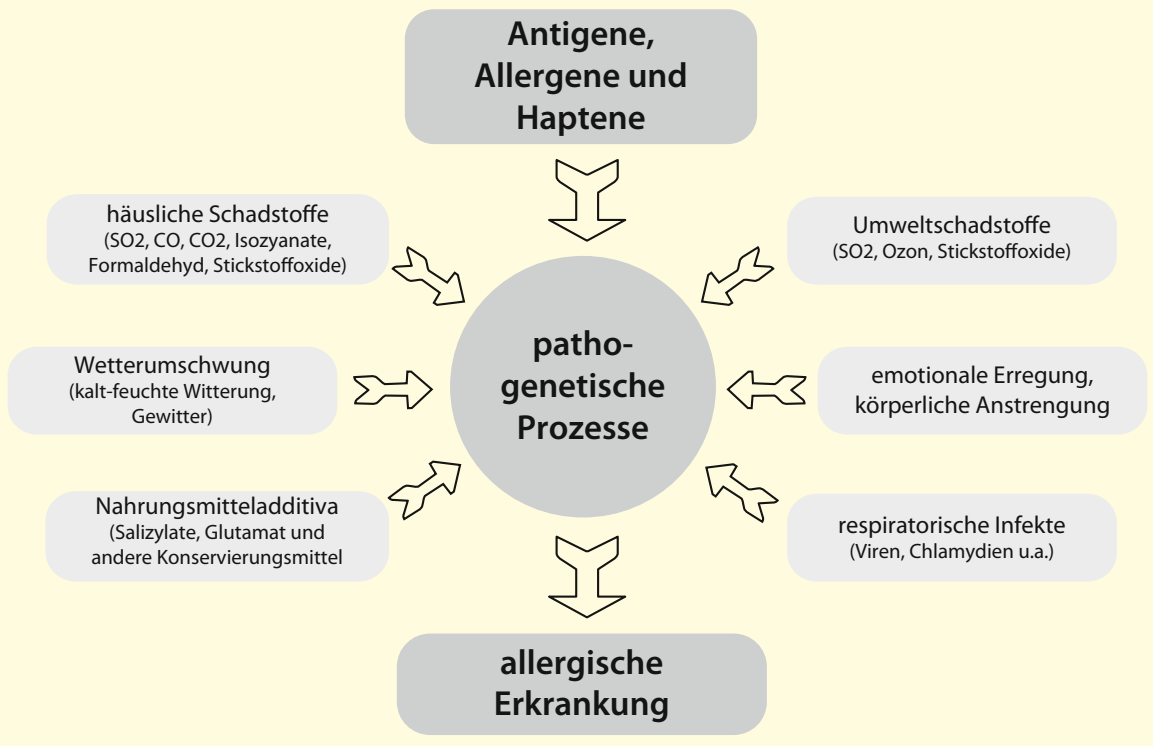


inhaliert werden. Das Allergen löst sich in der feuchtigkeitsgesättigten Umgebung der Atemwege und diffundiert aus der Partikelhülle in die Mukosa. Die Allergene gelangen so in die Umgebung von immunkompetenten Zellen, wie etwa dendritischen Zellen und Lymphozyten (Sensibilisierung). Für die Initiierung einer Immunreaktion sind nur sehr geringe Mengen des Allergens erforderlich. Spezifisches IgE ist dabei das Endprodukt einer immunologischen Reaktion vom Typ I, die eine Allergenerkennung und -verarbeitung, die Proliferation eines spezifischen T-Zellklons sowie die Differenzierung einer IgE-produzierenden B-Plasmazelle einschließt. Das freigesetzte IgE gelangt über das Blut ins Gewebe und besetzt die gewebeständigen Mastzellen.

\section{Herkunft der Allergene}

Ihrer Herkunft nach können Allergene aus der pflanzlichen, tierischen und unbelebten Natur unterschieden werden. Die größte Bedeutung haben Allergene aus der Pflanzenwelt, hier insbesondere Pollen anemophiler Pflanzen (Windbestäuber).

In der Bundesrepublik Deutschland und der Schweiz spielen in erster Linie Baum- (z. B. Birke), Gräser-, Getreide- und Kräuterpollen (z. B. Beifuß) eine Rolle. Hierzu kommen aus den Mittelmeerländern (v. a. Italien, Spanien, Griechenland) die Pollen des Glaskrauts (Parietaria officinalis), der Olive sowie des Traubenkrauts (Ambrosia artemisiifolia) hinzu. Letzteres spielt als Ragweed zusammen mit der Küchenschabe auch in den Vereinigten Staaten eine größere Rolle als Allergen.

\section{Kreuzallergie}

Nicht selten findet sich bei einer Sensibilisierung gegenüber einem Allergen eine Kreuzallergie gegenüber anderen, nicht verwandten Allergenen. Ein klassisches Beispiel hierfür bildet die pollenassoziierte Nahrungsmittelallergie. So besteht bei Birken-, Hasel- und Erlenpollenallergien häufig gleichzeitig auch eine Reagibilität gegenüber rohem
Stein- oder Kernobst (v. a. Äpfeln), aber auch gegenüber Kartoffeln und Karotten. Diese äußert sich bei Verzehr durch oropharyngeale Beschwerden mit Pruritus oder Rachenödem bzw. nach Inhalation als Rhinitis oder Asthma. Bei manuellem Umgang mit diesen Allergenen kann sich eine Urtikaria der Finger und Hände entwickeln.

Verantwortlich hierfür sind thermolabile, beiden Allergenen gemeinsame, allergiedeterminierende Proteine oder Epitope, die durch Kochen denaturiert werden. Im Rahmen von beifußpollenassoziierten Nahrungsmittelallergien sind die verantwortlichen kreuzreagierenden Epitope (Gewürze, Sellerie) thermostabil und verursachen auch nach Erhitzen allergische Reaktionen.

\section{Unspezifische Trigger}

Unter unspezifischen Triggern versteht man bestimmte Umweltirritanzien, meteorologische Bedingungen, physikalische Reize, Infektionen oder extreme emotionale Belastungen. Unspezifische Trigger sind somit nicht primär für die Entwicklung der allergischen Erkrankung verantwortlich, sondern führen vielmehr zu einer symptomatischen Reaktion auf dem Boden einer vorbestehenden manifesten Allergie.

Diese Unterscheidung wird am Beispiel der bronchialen Hyperreagibilität beim allergischen Asthma bronchiale am besten deutlich. So entwickelt sich die bronchiale Hyperreagibilität auf dem Boden der durch das Allergen ausgelösten Atemwegsentzündung. Der Kontakt mit unspezifischen Triggern verursacht nun beim Betroffenen auch in Abwesenheit eines relevanten Allergens eine Bronchokonstriktion. Andere Beispiele für eine Gewebehyperreagibilität sind die nasale Hyperreagibilität oder der Dermographismus. Die unspezifischen Trigger erweitern also in Verbindung mit der Hyperreagibilität des betroffenen Organs das Spektrum der Symptome auslösender Faktoren und tragen auf diese Weise zu Exazerbationen und zur Schwere des Krankheitsverlaufs bei.

- Tab. 3.2. Allgemeine Eigenschaften allergener Substanzen

\begin{tabular}{l|l|l}
\hline Parameter & Eigenschaften & Bedeutung \\
\hline Chemische Natur & Protein & Nur Proteine induzieren eine T-Zellreaktion \\
\hline Struktur & Niedriges Molekulargewicht & Ermöglicht Diffusion aus Kapsel und durch Gewebe \\
\hline $\begin{array}{l}\text { Physikochemische Eigen- } \\
\text { schaften }\end{array}$ & Hohe Löslichkeit & $\begin{array}{l}\text { Rasche Bereitstellung aus der trockenen Allergenkapsel } \\
\text { und Aufnahme im Körper }\end{array}$ \\
\cline { 2 - 3 } & Stabilität & Persistiert auch unter trockenen Bedingungen \\
\hline Konzentration & Niedrig & $\begin{array}{l}\text { Begünstigt Aktivierung IL-4-produzierender } \\
\text { CD4+-Lymphozyten }\end{array}$ \\
\hline Immunogene Eigenschaften & $\begin{array}{l}\text { MHC-bindende Peptide bzw. } \\
\text { Sequenzen }\end{array}$ & \begin{tabular}{l} 
Für T-Zellaktivierung und -proliferation erforderlich \\
\hline
\end{tabular} \\
\hline
\end{tabular}


$\mathrm{Zu}$ den häufigsten unspezifischen Auslösern gehören:

- Umweltschadstoffe,

- körperliche Anstrengung,

- Wetteränderungen und bestimmte Wetterlagen,

- emotionale Affektionen,

- nichtsteroidale Antiphlogistika und

- respiratorische Infekte vor allem durch Viren, möglicherweise aber auch durch intrazelluläre Pathogene wie Chlamydia pneumoniae oder Mycoplasma pneumoniae.

Als weniger häufige unspezifische Trigger gelten eine Rhinitis, Sinusitis, Polyposis, ein gastroösophagealer Reflux, Menstruation und Schwangerschaft. Aus therapeutischer Sicht ist es stets sinnvoll, die individuell relevanten Trigger und den individuellen Schweregrad zu identifizieren. Die wichtigsten unspezifischen Trigger sind in - Abb. 3.2 zusammengefasst und den spezifischen sowie für das Asthma ursächlich verantwortlichen allergenen Auslösern gegenübergestellt.

\subsubsection{Formen der allergischen Immunreaktion}

Die allergische Entzündung lässt sich als komplexe zelluläre und humorale Gewebeveränderung verstehen, die der Sicherung und Wiederherstellung der individuellen Inte- grität oder Homöostase dient. Dem Organismus stehen hierfür sowohl unspezifische als auch spezifische immunologische Effektormechanismen zur Verfügung, deren Ziel es ist, das Antigen/Pathogen zu eliminieren. Bei den meisten Infektionskrankheiten wird dieses Ziel entweder im Sinne einer Restitutio ad integrum oder einer Defektheilung und Etablierung eines Status quo zwischen Organismus und Antigen/Pathogen erreicht.

Neben infektiösen Partikeln reagiert der Organismus auch auf bestimmte nichtinfektiöse Proteine, zu denen unter anderem Autoantigene, Allergene oder Haptene zählen. Ein Beispiel für eine solche immunologische Reaktion gegen nichtinfektiöse Antigene bilden die entzündlichen Prozesse der Atemwege beim Asthma bronchiale und der Rhinitis allergica nach Polleninhalation oder der Haut nach Kontakt mit Nickel bzw. anderen Kontaktallergenen.

Wie bereits in $>$ Abschn. 3.1.1 angedeutet wurde, lassen sich allergische Immunreaktionen auf der Grundlage des mobilisierten Immunmechanismus und der Präsentation des Antigens/Allergens in verschiedene Klassen oder Typen unterteilen (• Abb. 3.3). Die Frage, welcher Typ der Immunreaktion mobilisiert wird, hängt vermutlich von der Prädisposition des Individuums und den physikochemischen Eigenschaften des Antigens/Allergens ab. Es sei an dieser Stelle darauf hingewiesen, dass die Einteilung zwar auf den zugrunde liegenden Immunmechanismen

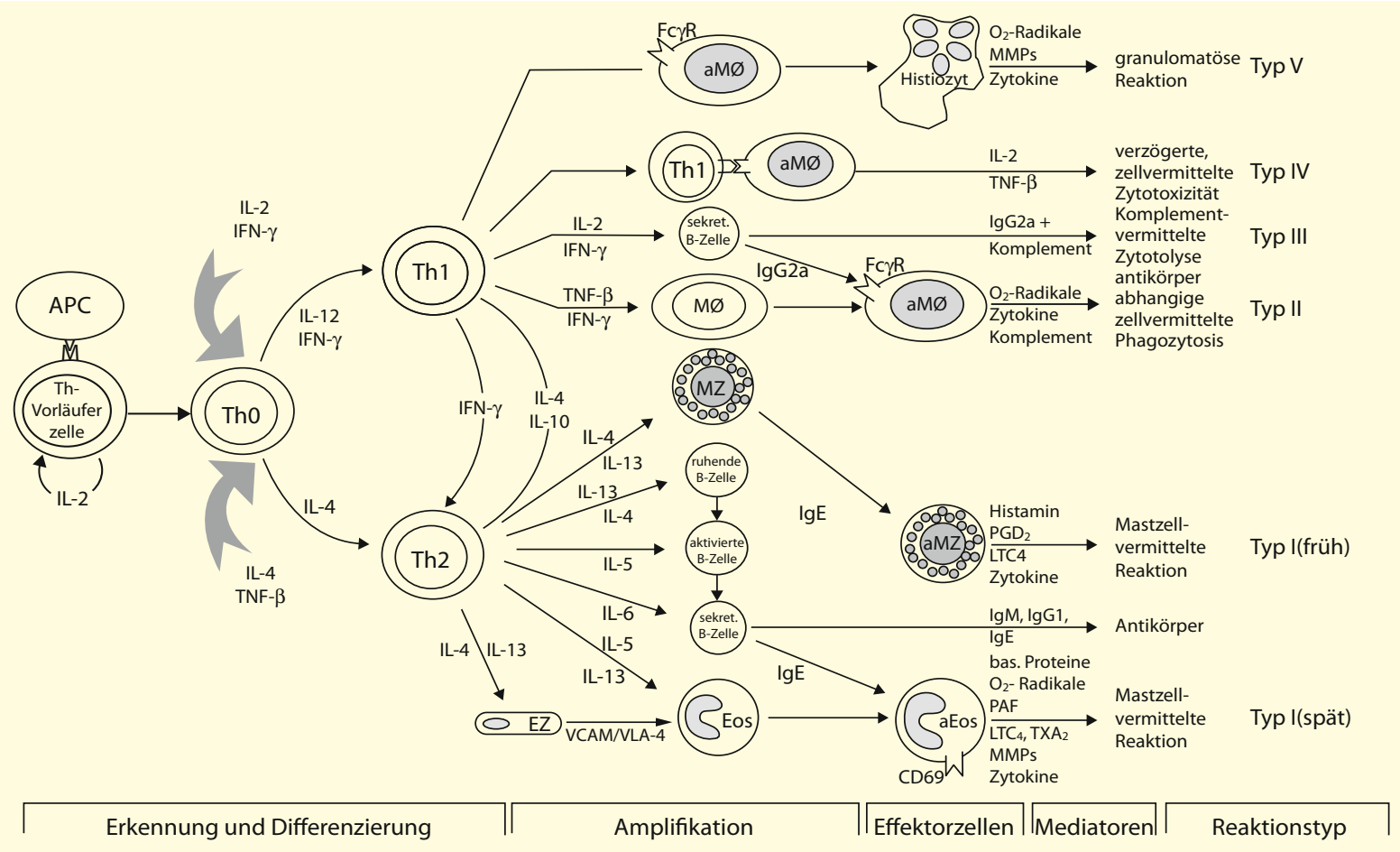

- Abb. 3.3. Immunmechanismen der verschiedenen allergischen Reaktionsformen. $a M \varnothing$ aktivierter Makrophage, $A P C$ antigenpräsentierende Zelle, Eos Eosinophile, EZ Endothelzellen, IL Interleukin, MØ Makrophage, MZ Mastzelle, Th T-Helferzelle 
beruht und aus didaktischen Gründen sinnvoll ist. Da jedoch die Prozesse nicht immer isoliert ablaufen und sich z.T. überschneiden, stellt diese Klassifikation nur eine Annäherung an die In-vivo-Verhältnisse dar.

Bei Typ I-III handelt es sich um antikörpervermittelte Reaktionen, die sich durch den Allergentyp unterscheiden.

Typ-I-Reaktion. Die Immunreaktion vom Typ I mit der Bildung von spezifischen IgE, Mastzellsensibilisierung, Aktivierung von Th2-Lymphozyten und Infiltration durch eosinophile Granulozyten ist die häufigste Form der allergischen Immunreaktion. Sie gilt als die klassische allergische Immunreaktion bei Rhinitis allergica, allergischem Asthma bronchiale und atopischer Dermatitis, bildet aber auch eine Komponente der immunologischen Reaktion bei der allergischen bronchopulmonalen Aspergillose.

Im Gegensatz zur Typ-I-Reaktion werden Typ-II- und Typ-III-Reaktionen durch antigenspezifisches IgG vermittelt. Hierbei kommt es entweder zur Aktivierung der komplementabhängigen oder von phagozytenabhängigen Effektormechanismen, die jeweils unterschiedliche pathologische Veränderungen und Symptome induzieren.

Typ-II-Reaktion. Typ-II-Reaktionen sind gegen Zelloberflächen oder matrixassoziierte Antigene gerichtet. Sie spielen im Rahmen allergischer bzw. anaphylaktischer Reaktionen bei medikamenteninduzierten Krankheiten eine Rolle.

Typ-III-Reaktion. Dagegen erfolgt die Typ-III- Reaktion gegen lösliche Antigene, die über die Bildung von Immunkomplexen die Entzündung hervorruft, wie man sie im Rahmen der exogen-allergischen Alveolitis oder autoimmunologischer Erkrankungen findet.

Typ-IV-Reaktion. Typ-IV-Reaktionen werden durch TLymphozyten vermittelt, die sich wiederum in 2 Klassen unterteilen lassen. Die erste Form erfolgt über die Bildung von regulatorischen Th1-Zellen die vor allem über die Aktivierung von Makrophagen eine Gewebeentzündung induzieren. Die zweite Unterform geht mit Differenzierung von zytotoxischen T-Zellen einher, die aufgrund ihrer Funktion direkt eine Gewebeschädigung hervorrufen. Diese spielen z. B. bei der Kontaktdermatitis eine Rolle.

\subsubsection{Zellen der allergischen Entzündung}

Die oben skizzierten Formen der allergischen Entzündung lassen sich als komplexe immunologische Vorgänge verstehen, an denen eine ganze Palette verschie- denster Zellen beteiligt ist. Hierzu gehören Granulozyten, Thrombozyten, Lymphozyten, dendritische Zellen, Fibroblasten und selbst Epithelzellen. Darüber hinaus wird bestimmten Subpopulationen von Makrophagen eine Funktion im Rahmen der Allergenpräsentation zugeschrieben. Die relative Bedeutung der einzelnen Zelltypen wird von der Klasse der induzierten Immunreaktion bestimmt.

Die verschiedenen an der Entzündung beteiligten Zellen lassen sich, mit einigen Ausnahmen und Überschneidungen entsprechend ihrer jeweils im Vordergrund stehenden Rolle untergliedern in:

- initiierende und amplifizierende Zellen,

- Effektorzellen,

- Effektorzielzellen oder Strukturzellen.

\section{Initiierende Zellen}

Die zu dieser Gruppe gehörenden Zellen setzen die Immunreaktion entweder durch indirekte Exposition mit inhalierten Allergenen (Typ I und III) oder direkten Kontakt (Typ IV) in Gang. Nach heutiger Vorstellung gehören hierzu die dendritischen Zellen sowie Makrophagen/ Monozyten, die als allergenpräsentierende Zellen (APC) begrifflich zusammengefasst werden.

\section{Dendritische Zellen (allergenpräsentierende Zellen)}

Ausgangspunkt einer immunologischen Reaktion, wie auch der im Rahmen allergischer Erkrankungen, ist die Interaktion des Antigens/Allergens mit APC und einem genetisch definierten, spezifischen T-Zellklon. Folgende Eigenschaften der APC sind für ihre Funktion bei allergischen Erkrankungen relevant:

- APC (Langerhans-Zellen) bzw. APC-ähnliche Zellen (mononukleäre Zellen) finden sich konstitutionell in allen Geweben und sind nach Antigenexposition im Atemwegsepithel von Asthmatikern vermehrt nachzuweisen.

- Bestimmte Blutmonozyten mit antigenpräsentierenden Eigenschaften infiltrieren in die Atemwege und Lunge z. B. $\mathrm{Fc}_{\varepsilon} \mathrm{RI}$-exprimierende Zellen deren Aktivität durch Bindung von IgE um ein Vielfaches gesteigert wird.

- APC verarbeiten das Allergen und präsentieren der allergenrestringierten $\mathrm{CD} 4^{+}$-Zelle immunogene Sequenzen im Kontext von Klasse-II-MHC-Antigenen und einem oder mehreren kostimulatorischen Signalen.

\section{Lymphozyten}

Lymphozyten stellen eine funktionell sehr heterogene Gruppe von Zellen dar, die auf verschiedenen Ebenen in die Pathogenese der allergischen Entzündung eingreift. Während B-Lymphozyten nach Differenzierung 
in Plasmazellen das IgE bilden, sind CD4 $4^{+}$- (Helfer- bzw. Inducerzellen) und $\mathrm{CD}^{+}{ }^{+}$-T-Lymphozyten (zytotoxische bzw. Suppressorzellen) sowohl an der Allergenerkennung als auch an der Regulation des Entzündungsablaufs beteiligt:

- In den Atemwegen von Asthmatikern oder Rhinitikern oder der Haut von Patienten mit atopischer Dermatitis finden sich charakteristischerweise aktivierte, IL-2-Rezeptor-tragende (IL-2R+2)T-Lymphozyten.

- Innerhalb der $\mathrm{CD}^{+}$-Lymphozyten dominiert der Th2-Subtyp mit Sekretion von IL-4, IL-5, IL-6 und IL-13.

- Th2-Lymphozyten dürften über die Freisetzung von IL-4, IL-5 und IL-13 die Synthese von IgE durch BLymphozyten regulieren.

- Th2-Zellen aktivieren mittels IL-4 und IL-13 Mastzellen und mittels IL-5 und IL-13 eosinophile Granulozyten.

- Th2-Lymphozyten induzieren über die Freisetzung von IL-4 und IL-13 z. B. die Expression des Adhäsionsmoleküls VCAM-1 auf Endothelzellen und tragen zur Regulation der IgE-Synthese sowie mittels IL-5 zur selektiven Rekrutierung von Eosinophilen aus der Zirkulation bei.

- Th1-Lymphozyten mit Sekretion von IL-2 und INF- $\gamma$ spielen dagegen im Rahmen der Kontaktallergie eine pathogenetische Rolle über die Regulation der IgGSynthese und der zellulären Immunreaktion vom verzögerten Typ (Typ IV nach Coombs u. Gell).

An Entzündungsreaktionen sind neben Effektorlymphozyten auch T-Zellpopulationen mit spezifischen suppressiven bzw. regulatorischen Eigenschaften beteiligt. Hierzu gehört eine erst vor wenigen Jahren beschriebene, im Thymus heranreifende, natürliche Population von antigenspezifischen T-regulatorischen $\mathrm{CD} 4^{+}$-T-Lymphozyten (»T-regulatory cells«; Tregs), von denen die meisten das $\mathrm{CD} 25^{+}$-Antigen und andere Antigene wie das T-Lymphozyten-assoziierte Antigen-4 (CTLA-4), den glukokortikoidinduzierten Tumor Necrosis Factor Receptor (GITR) und in hohem Umfang L-Selektin (CD62- $\mathrm{L}^{\mathrm{HI}}$ ) konstitutiv auf ihrer Oberfläche exprimieren.

Sie vermitteln ihre suppressive Wirkung bei direktem Zell-Zell-Kontakt durch membranassoziierte Moleküle. Aufgrund ihrer Funktion werden $\mathrm{CD} 4{ }^{+} \mathrm{CD} 25^{+}$-T-Zellen als "natürliche" Suppressorzellen (Trn) oder "adaptive« Tregs (Tra), und letztere nochmals in $\operatorname{Tr} 1$ und $\operatorname{Tr} 2(\mathrm{Th} 3)$ Zellen unterteilt. Sowohl Trn als auch Tra exprimieren den Transkriptionsfaktor (FoxP3) (»forkhead transcription factor «; Scurfin/FoxP3), der für die Entwicklung und Funktion der Tregs verantwortlich ist. Neben ihrer Rolle bei Autoimmunopahtien sind Tregs ebenfalls an der Pathogenese allergischer Erkrankungen beteiligt.

\section{Effektorzellen}

Unter Effektorzellen versteht man enddifferenzierte Zelltypen, die am distalen Ende der Immunreaktion den proentzündlichen Effekt der Immunreaktion am Zielorgan über verschiedene pharmakologische oder zytotoxische Mechanismen vermitteln. $\mathrm{Zu}$ den Effektorzellen zählen Mastzellen, basophile und eosinophile Granulozyten (Typ I), Makrophagen und zytotoxische T-Lymphozyten (Typ IV).

\section{Mastzellen und basophile Granulozyten}

Mastzellen lassen sich in allen Körpergeweben gleichmäßig verteilt und bevorzugt im perivaskulären Bereich nachweisen. Es handelt sich um große, mononukleäre Zellen, deren Zytoplasma durch runde, metachromatische Granula ausgefüllt ist. Als ortständige Zellen kommen sie bereits kurz nach Exposition mit dem die Atemwegsmukosa penetrierenden Allergen in Kontakt. Die Mastzelle spielt bei der Entwicklung der allergischen Frühreaktion eine wesentliche Rolle.

- Mastzellen enthalten an Proteoglykane gebundenes Heparin und eine Reihe verschiedener Enzyme, wie z.B. Hydrolasen und Metalloproteinasen, in ihren Granula.

- Nach Aktivierung synthetisieren Mastzellen verschiedene Lipidmediatoren, zu denen vor allem das Prostaglandin $\mathrm{D}_{2}$, das Thromboxan $\mathrm{A}_{2}$, Leukotrien $\mathrm{B}_{4}$ und $\mathrm{C}_{4}$ sowie der plättchenaktivierende Faktor (PAF) gehören.

- Mastzellen sind aber auch in der Lage eine Anzahl von Zytokinen, einschließlich IL-4 und IL-13, zu bilden.

Im Gegensatz zu den gewebeständigen Mastzellen treten Basophile aus dem Blut in das betroffene Epithelgewebe über. Sie sind den Mastzellen jedoch strukturell und funktionell sehr ähnlich und setzen neben Histamin eine Reihe von Lipidmediatoren frei. Ihre Funktion im Rahmen des Asthma bronchiale ist bisher noch nicht definiert. Sie infiltrieren zwar das Bronchialgewebe gemeinsam mit den Eosinophilen während der verzögerten allergischen Reaktion, sind aber nur in deutlich geringerer Zahl nachweisbar.

\section{Eosinophile Granulozyten}

In Ruhe imponiert der reife eosinophile Granulozyt als eine runde bis ovoide, $12-15 \mu \mathrm{m}$ im Durchmesser messende Zelle, die sich bereits lichtmikroskopisch durch ihren zweigelappten Nukleus sowie durch große bikonvexe, azidophile Granula leicht von dem polymorphkernigen neutrophilen Granulozyten abgrenzen lässt. Diese sog. sekundären oder spezifischen Granula bestehen aus einem zentral gelegenen, elektronendichten Bereich (»core») und einer weniger elektronendichten Matrix. Diese Gra- 
nula enthalten den größten Teil der für Eosinophile charakteristischen basischen Proteine.

- Der eosinophile Granulozyt ist eine potente zytotoxische Effektorzelle, die verschiedene Klassen von Mediatoren (basische Proteine, Enzyme, Lipidmediatoren, $\mathrm{O}_{2}$-Radikale und Zytokine) bildet.

- Der eosinophile Granulozyt unterscheidet sich von anderen Leukozyten durch den hohen Gehalt an basischen Proteinen. Hierzu gehören das "major basic protein" (MBP), das »eosinophil cationic protein" (ECP) und das »eosinophil-derived neurotoxin" (EDN), das auch als Eosinophilprotein X (EPX) bezeichnet wird.

- In hohen Konzentrationen sind die basischen Proteine zytotoxisch und zerstören bzw. schädigen nicht nur Parasiten, sondern auch Bronchialepithelzellen, Nervenzellen, Herzmuskelzellen und Tumorzellen.

- In niedrigen Konzentrationen aktivieren die Proteine aber auch Mastzellen, Basophile, Neutrophile und Thrombozyten.

- Die eosinophile Peroxidase (EPO) führt allein oder in Gegenwart von Halogenidionen zu einer Schädigung verschiedener Zielzellen und -geweben, die der zytotoxischen Wirkung der anderen basischen Proteine vergleichbar ist.

- Eosinophile produzieren neben der enzymatischen Peroxidierung durch die EPO auch eine Reihe reaktiver $\mathrm{O}_{2}$-Spezies (Superoxidanionen, Wasserstoffperoxid, Hydroxylradikale, Singulett-Sauerstoff), die ebenfalls zur Effektorfunktion der Zelle betragen.

- Eosinophile produzieren verschiedene Lipidmediatoren, zu denen vor allem das Leukotrien $\mathrm{C}_{4}$, Prostaglandin $\mathrm{D}_{2}$, das Thromboxan $\mathrm{A}_{2}$ sowie der plättchenaktivierende Faktor (PAF) gehören.

- Ebenso wie Mastzellen sezernieren Eosinophile in gewissem Umfang Zytokine, einschließlich IL-4 und IL-13.

Mithilfe der oxidativen und nichtoxidativen Effektormechanismen vermittelt der eosinophile Granulozyt eine Schädigung körpereigenen Gewebes, was je nach Lokalisation, Gewebe bzw. Organ zu unterschiedlichen Symptomen führt.

\section{Neutrophile Granulozyten}

Neutrophile Granulozyten sind polymorphkernige Granulozyten (PMN), deren oxidative und nichtoxidative Effektormechanismen in erster Linie die Abwehr bakterieller Infektionen vermitteln. Sie sind darüber hinaus als distale Effektorzellen an bestimmten akuten und chronischen Entzündungen beteiligt (chronische Bronchitis, Emphysem, Lungenfibrose, ARDS etc.). Ihre Rolle im Rahmen allergischer Erkrankungen wie dem Asthma bronchiale oder der atopischen Dermatitis ist jedoch noch immer umstritten, sodass hier nicht näher auf den neutrophilen Granulozyten eingegangen werden soll.

\section{Makrophagen}

Makrophagen entwickeln sich aus zirkulierenden Blutmonozyten nach Einwanderung ins Gewebe. Tatsächlich finden sich verschiedene Hinweise darauf, dass den Makrophagen im Rahmen allergischer Krankheiten eine Rolle zukommt. Ihre Bedeutung für die Entstehung und den Verlauf der allergischen Entzündung ist jedoch noch nicht ausreichend untersucht.

- Makrophagen werden z. B. im Rahmen der asthmatischen Entzündung vermehrt und aktiviert.

- Makrophagen aus atopischen Personen exprimieren verstärkt den niederaffinen IgE-Rezeptor (FceRII, CD23) und Komplementrezeptoren.

- Makrophagen sezernieren verschiedene für die allergische Entzündung relevante Mediatoren (Leukotriene, Prostanoide, Thromboxan, PAF, Zytokine).

\section{Thrombozyten}

Thrombozyten sind polymorph geformte, kernlose Zellen, die aus Megakaryozyten im Knochenmark hervorgehen. Obwohl ihre Funktion vor allem im Rahmen der (patho-)physiologischen Gerinnungsprozesse zu suchen ist, wird den Thrombozyten seit einiger Zeit auch eine Rolle im Rahmen allergisch-entzündlicher Vorgänge zugeschrieben:

- Thrombozyten spielen eine Rolle bei der Entwicklung der allergischen Spätreaktion und der Gewebeinfiltration durch eosinophile Granulozyten.

- Thrombozyten werden durch Zytokine, Anti-IgE und PAF aktiviert.

- Sie produzieren verschiedene lösliche Faktoren (»platelet-derived histamine releasing factor «, Plättchenfaktor 4, RANTES [»regulated on activation normal T-cell expressed and secreted «] oder PAF), die aufgrund ihrer chemotaktischen Eigenschaften an der Orchestrierung des entzündlichen Infiltrats beteiligt sein dürften.

\section{Effektorzielzellen (Strukturzellen)}

Als Effektorzielzellen werden die Strukturzellen der Atemwege bezeichnet, in deren unmittelbarer Nachbarschaft Entzündungszellen infiltrieren und in deren Umgebung sich die eigentliche Entzündung ausbreitet. Erst in den letzten Jahren wurde deutlich, dass diese Zellen dabei nicht als passive »Bystander « zu betrachten sind. Vielmehr nehmen sie unter physiologischen Bedingungen Aufgaben bei der Aufrechterhaltung der Homöostase wahr und können unter pathophysiologischen Bedingungen offenbar sowohl pro- als auch antiinflammatorisch auf die entzündlichen Vorgänge Einfluss nehmen. 
Respiratorische (bronchiale) Epithelzellen

Bronchiale Epithelzellen bilden eine primäre Barriere, die tiefer gelegenes Gewebe und den Organismus vor inhalativen Irritantien und Noxen schützt. Darüber hinaus sind sie immunreaktive Zellen, die eine Reihe proinflammatorischer Mediatoren bilden:

- Endothelzellen sezernieren unterschiedliche Mediatoren, einschließlich Stickstoffmonoxid (NO), neutrale Endopeptidasen sowie Lipidmediatoren, die ihrerseits den Bronchotonus und die Funktion struktureller und infiltrierender Zellen regulieren.

- Sie bilden darüber hinaus die Zytokine IL-6, IL-8, IL-10, GM-CSF und MCP-1a.

- Die Funktion des respiratorischen Epithelgewebes wird während der asthmatischen Entzündung (fokale Zerstörung und Desquamation) beeinträchtigt und führt zum Ausfall seiner regulatorischen Funktion.

\section{Myofibroblasten}

Myofibroblasten stellen einen Zelltyp dar, der vor allem im Granulationsgewebe der Wundheilung gefunden wird. Sie besitzen Eigenschaften, die sowohl an Fibroblasten als auch an Muskelzellen erinnern. Die hohe synthetische Kapazität der Myofibroblasten findet in den zahlreichen zytoplasmatischen Polyribosomen ihren Ausdruck. Die kontraktilen Eigenschaften werden durch ein dichtes Maschenwerk aus dünnen Filamenten vermittelt, das dem Zytoskelett glatter Muskelzellen ähnelt. Diese Zellen exprimieren ferner die muskelzellspezifischen intermediären Filamente, Desmin sowie den mit glatten Muskelzellen assoziierten Isotyp des Aktins, $\boldsymbol{\alpha}$-Aktin.

- Myofibroblasten finden sich im Rahmen der asthmatischen Atemwegsentzündung vermehrt.

- Sie werden durch eine Reihe von Mediatoren aktiviert, zu denen Histamin, Tryptase, IL-1, IL-4, PDGF, TGF- $\beta$ und Endothelin gehören.

- Myofibroblasten produzieren extrazelluläre Matrixproteine, wie z.B. Kollagen oder Fibronectin, und sind auf diese Weise am Umbau oder Remodelling der Atemwege beteiligt.

\section{Glatte Muskelzellen}

Glatte Muskelzellen vermitteln einen wesentlichen Teil der Obstruktion im Rahmen des Asthma bronchiale. Eine Hypertrophie bzw. Hyperplasie der Atemwegsmuskulatur gilt als eine charakteristische Veränderung im Rahmen des Asthma bronchiale, deren Ursache jedoch noch nicht bekannt ist (z. B. durch Mediatoren mit muskelproliferierender Wirkung wie Histamin oder Endothelin). Die pathophysiologische Bedeutung der Zunahme an bronchialer Muskelmasse beim Asthma bronchiale ist aber ebenfalls noch immer umstritten. Auch Muskelzellen setzen verschiedene Mediatoren frei und sind offenbar stärker in die Entzündung mit einbezogen als lange Zeit angenommen.

\subsubsection{Mediatoren der allergischen Entzündung}

Die oben aufgeführten Entzündungszellen bilden verschiedene Klassen von Mediatoren, die mit der Pathogenese der asthmatischen Entzündungsreaktion in Verbindung gebracht werden (• Abb.3.4). Einem Teil der Mediatoren kommt in erster Linie eine Rolle bei der Regulation der Entzündungszellen untereinander zu (primär regulatorische Mediatoren). Ein anderer Teil vermittelt die Aktivierung von Effektorzellen im Bronchialgewebe. Andere wiederum beeinflussen die Kontraktilität und Reagibilität der Bronchialmuskulatur. Diese aus aktivierten Entzündungszellen freigesetzten Mediatoren werden als primäre Effektormoleküle bezeichnet. Ihre Wirkung an der Effektorzielzelle (meist Strukturzelle) führt zur Sekretion weiterer Mediatoren, die sekundäre Effektormoleküle genannt werden. Eine Einteilung muss aber auch hier artifiziell bleiben, da in den meisten Fällen Mediatoren einer Gruppe sowohl regulatorische als auch Effektorfunktionen ausüben.

\section{Primär regulatorische Mediatoren}

$\mathrm{Zu}$ den Mediatoren mit überwiegend regulatorischen Funktionen gehört die große Gruppe der Zytokine einschließlich der Chemokinine.

\section{Zytokine}

Zytokine bilden eine große Gruppe von zentral und peripher wirkenden Proteinmediatoren. Sie werden von nahezu allen regulierenden und Entzündungszellen, aber auch von Strukturzellen gebildet.

- Zytokine sind an der Bildung, Reifung und Differenzierung von Zellen im Knochenmark beteiligt.

- Im Entzündungsgeschehen dienen sie vor allem der Regulation der allergischen Entzündung über ihren Einfluss auf Lymphozyten, z. B. bei der Antigenpräsentation oder der IgE-Synthese.

- Zytokine modifizieren darüber hinaus die Aktivität peripherer Entzündungszellen (Eosinophile, Mastzellen, etc.).

- Allergische Erkrankungen sind durch die Bildung bzw. Expression eines charakteristischen Musters von Zytokinen (IL-4, IL-5, IL-6, IL-13, TNF- $\alpha$ und GMCSF) charakterisiert.

\section{Primäre Effektormediatoren}

\section{Chemokine}

Chemokine bilden eine Gruppe von derzeit 28 strukturell verwandten Proteinen mit chemotaktischen Eigenschaften für Leukozyten. Chemokine spielen eine wesentliche Rolle bei der Attraktion zirkulierender Zellen im Rahmen der asthmatischen Entzündung. Sie lassen sich aufgrund 


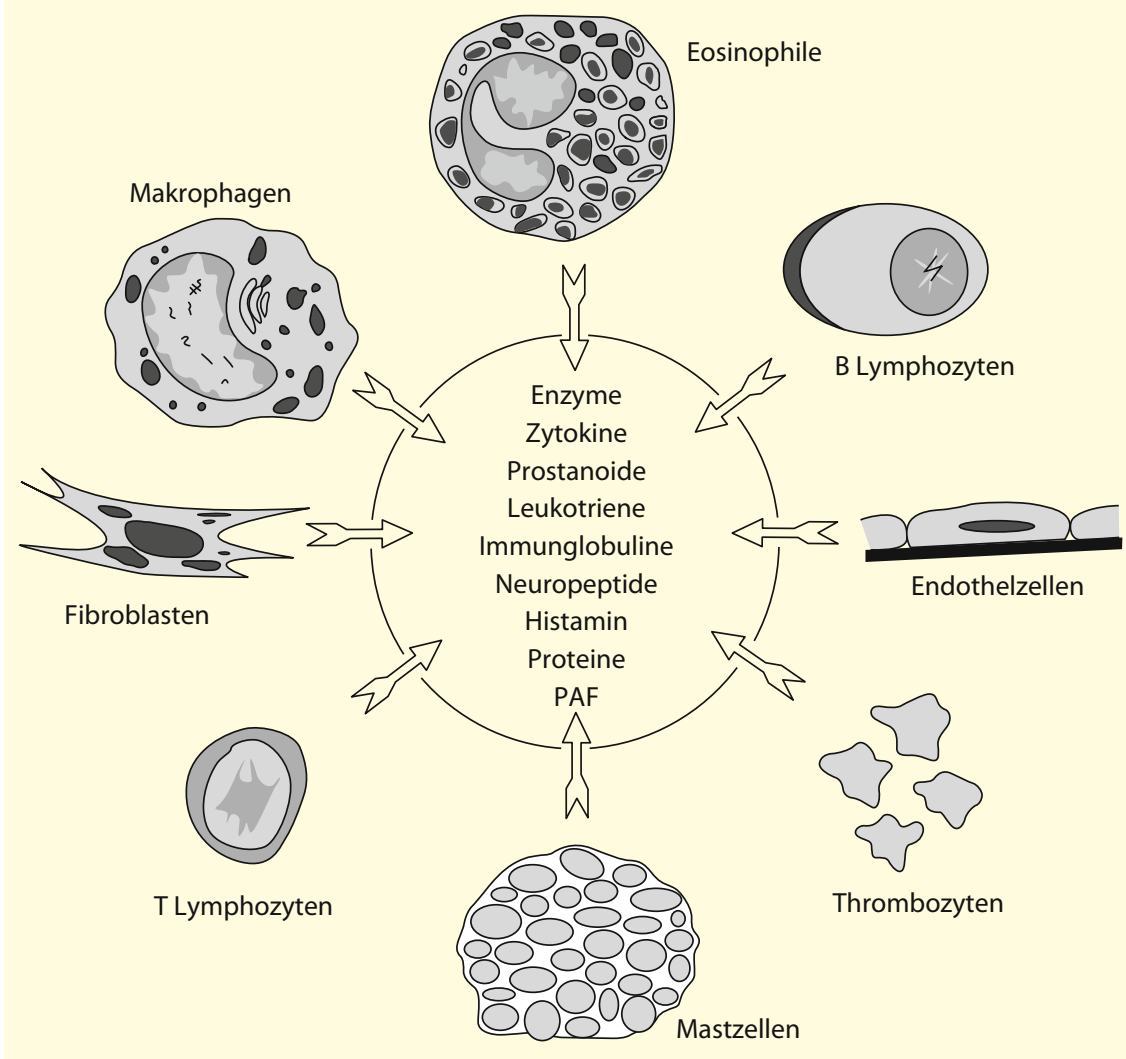

- Abb. 3.4. Mediatoren, die im Rahmen der allergischen Entzündung von den beteiligten Entzündungszellen freigesetzt werden struktureller Eigenschaften in die $\alpha$ - (oder CXC-)Subfamilie und die $\beta$ - (oder CC-)Subfamilie unterteilen. Vor allem der Gruppe der $\beta$-Chemokine wird aufgrund ihrer Wirkung auf Lymphozyten, Mastzellen und Eosinophile eine Rolle bei der allergischen Entzündung in Zusammenhang zugeschrieben.

- Zu den relevanten Chemokinen der $\beta$-Subfamilie zählen »macrophage inflammatory protein $1 \alpha$ « (MIP-1 $1 \alpha)$, "monocyte chemotactic protein « (MCP-1 bis MCP-4), RANTES, Lymphotactin und Eotaxin.

- Chemokine werden von den meisten Zelltypen, einschließlich T-Lymphozyten, Thrombozyten, Fibroblasten, Endothelzellen und Epithelzellen, produziert.

- Unter In-vitro-Bedingungen besitzen Chemokine eine dem PAF oder C5a vergleichbare biologische chemotaktische Wirkung auf Eosinophile und, mit Ausnahmen, auch auf Neutrophile.

- RANTES induziert ferner die Freisetzung von ECP und $\mathrm{O}_{2}$-Radikalen aus Eosinophilen.

- RANTES wirkt nicht auf Neutrophile und könnte daher zur Selektion des charakteristischen Infiltrats durch Eosinophile bei allergischen Erkrankungen vom Typ I beteiligt sein.

- Das erst kürzlich beschriebene Eotaxin gilt als ein hoch selektiver und für Eosinophile spezifischer chemotaktischer Faktor.

\section{Immunglobulin E}

Das Immunglobulin E (IgE) findet sich bei aktiven allergischen Erkrankungen regelmäßig im Blut erhöht und stellt als Gesamt-IgE oder allergenspezifisches IgE einen wichtigen Parameter für die Diagnostik und Therapie dieser Krankheitsgruppe dar (s. unten). Es wird aus bestimmten Plasmazellen nach Isotypenumschaltung freigesetzt. Der größte Teil ist allerdings an Mastzellen im Gewebe gebunden, die hierdurch unmittelbar das eindringende Allergen spezifisch erkennen können.

Die physiologische Rolle des IgE umfasst den Schutz von Schleimhautoberflächen des Körpers durch die unmittelbare Einleitung einer lokalen Abwehrreaktion gegen bestimmte infektiöse Partikel, wie z. B. Parasiten. Seine pathophysiologische Rolle erstreckt sich dagegen auf die Auslösung der allergischen Sofortreaktion bei entsprechend prädisponierten Individuen und möglicherweise auch auf die Einleitung der verzögerten allergischen Reaktion.

IgE bindet primär an hochaffine IgE-Rezeptoren (FceRI) auf Mastzellen, basophilen Granulozyten und epidermalen Langerhans-Zellen. Daneben kann das IgE mit einem zweiten, niederaffinen IgE-Rezeptor (FceRII) interagieren, der mit dem Leukozytendifferenzierungsantigen CD23 identisch ist. FceRII findet sich auf reifen, ruhenden B-Lymphozyten, Gewebe- bzw. Alveolarmak- 
rophagen, Monozyten und epidermalen Langerhans-Zellen. Der Rezeptor wird ebenso auf allergenstimulierten T-Lymphozyten exprimiert und spielt unter anderem bei der Regulation der IgE-Bildung eine Rolle. Das Vorkommen niederaffiner Rezeptoren für IgE auf Eosinophilen ist umstritten.

\section{Immunglobulin G}

Das IgG ist das verbreitetste Immunglobulin und dient der Abwehr des Körpers gegen Pathogene. Seine Bedeutung für die Allergologie bezieht sich auf seine pathogenetische Rolle im Rahmen von Typ-II- und Typ-III-Reaktionen, wie z. B. der exogen-allergischen Alveolitis. Hier bildet der Nachweis von antigenspezifischem IgG (Präzipitin) einen wichtigen diagnostischen Parameter zur Identifizierung der Ursache.

\section{Immunglobulin A}

Monomeres $\operatorname{Ig} \mathrm{A}$ und vor allem das dimere $(\operatorname{Ig} \mathrm{A})_{2}$ ist das vorherrschende Immunglobulin der seromukösen Sekrete auf den Schleimhäuten und dient der lokalen Immunabwehr. (IgA) ${ }_{2}$ gilt als ein potenter Aktivator der eosinophilen Granulozyten und führt nach Bindung an die Zelle zur Freisetzung der granulär gespeicherten basischen Proteine. Im Rahmen der asthmatischen Entzündung könnte es durch die direkte Aktivierung eosinophiler Granulozyten auf der Schleimhautoberfläche von unmittelbarer pathogenetischer Bedeutung sein.

\section{Histamin}

Histamin ist ein biogenes Amin, das aus der Aminosäure Histidin hervorgeht und in den metachromatischen Granula von Mastzellen und Basophilen, an saure Proteoglykane gebunden, gespeichert ist. Seine Wirkung wird durch Bindung entweder an sog. $\mathrm{H}_{1}$ - oder $\mathrm{H}_{2}$, möglicherweise sogar $\mathrm{H}_{3}$-Rezeptoren, vermittelt. Die Aktivierung von $\mathrm{H}_{1^{-}}$ Rezeptoren induziert die klassischen Zeichen der Entzündung, zu denen eine gesteigerte Gefäßpermeabilität mit Ausbildung eines Gewebeödems (Tumor), eine Gefäßdilatation mit Erythem (Rubor), Überwärmung (Calor), Pruritus (Dolor) sowie die Kontraktion glatter Muskulatur (Functio laesa) gehören. Beim Asthma bronchiale dürfte Histamin vor allem an der Vermittlung der asthmatischen Früh- oder Sofortreaktion beteiligt sein.

\section{Leukotriene}

Einige der potentesten primären Effektormediatoren im Rahmen allergischer Erkrankungen entstehen beim Abbau ungesättigter Arachidonsäure durch die 5-Lipoxygenase zu Leukotrienen und durch die Cyclooxygenase zu Prostaglandinen. Die biologische Aktivität der Leukotriene ist bereits seit 50 Jahren bekannt. Sie führen $\mathrm{zu}$ einer sich langsam entwickelnden und anhaltenden Kontraktion glatter Muskelzellen und wurden deshalb ursprünglich als »slow-reacting substance of anaphylaxis« oder SRS-A bezeichnet.

- Die biologische Aktivität der SRS-A geht auf ein Gemisch der 3 Zysteinylleukotriene $\mathrm{LTC}_{4}, \mathrm{LTD}_{4}$ und $\mathrm{LTE}_{4}$ zurück.

- $\mathrm{LTC}_{4}$ und $\mathrm{LTD}_{4}$ induzieren über eine länger anhaltende starke Kontraktion der glatten Muskulatur auch die Mukussekretion sowie ein Gewebeödem.

- Die inhalative Applikation von $\mathrm{LTD}_{4}$ und $\mathrm{LTE}_{4}$ in vivo führt zu einer Infiltration der Atemwege durch eosinophile Granulozyten.

- $\mathrm{LTB}_{4}$ ist ein chemotaktischer Faktor für humane neutrophile Granulozyten.

- Leukotrienrezeptorantagonisten und Leukotriensynthesehemmer besitzen einen protektiven Effekt auf die Bronchokonstriktion während der asthmatischen Früh- und Spätreaktion. Sie führen zudem zu einer Reduktion der Eosinophilenzahl im Blut und in den Atemwegen, $\mathrm{zu}$ einer Abnahme der asthmatischen Beschwerden und zu einer Verbesserung der Lebensqualität.

\section{Prostanoide}

Unter der Bezeichnung Prostanoide werden die verschiedenen Prostaglandine (PG), das Prostazyklin $\left(\mathrm{PGI}_{2}\right)$ und die Thromboxane (Tx) zusammengefasst. Sie entstehen aus der Arachidonsäure unter dem Einfluss der Cyclooxygenase, einem Enzym, das sich durch die nichtsteroidalen Antirheumatika Aspirin oder Indomethacin hemmen lässt. Prostanoide wie $\mathrm{PGD}_{2}, 9 \alpha, 11 \beta-\mathrm{PGF}_{2}, \mathrm{PGI}_{2}$, 6-keto$\mathrm{PGF}_{1 \alpha}$ und $\mathrm{TxA}_{2}$ finden sich neben Histamin bereits 10 min nach Antigenprovokation im Bronchoalveolarraum. Aber auch während der Spätreaktion werden bestimmte Prostanoide, wenn auch in geringeren Mengen, gebildet. Die Synthese dieser Lipidmediatoren in dieser frühen Phase geht vor allem auf gewebeständige Mastzellen, in der Spätphase auf Eosinophile, Thrombozyten und möglicherweise auf Makrophagen zurück.

Prostanoide zeigen eine Vielfalt pro- und antientzündlicher pharmakologischer Wirkungen. $\mathrm{PGF}_{2 \alpha}, \mathrm{PGD}_{2}$ und das Thromboxan $\mathrm{A}_{2}$ induzieren eine Bronchokonstriktion und verstärken die cholinerge synaptische Signalübertragung. $\mathrm{PGI}_{2}$ und $\mathrm{PGE}_{2}$ gelten als potente Vasodilatatoren, die in Gegenwart von $\mathrm{LTB}_{4}$ die Gefäßpermeabilität erhöhen und ein Bronchialödem verursachen. $\mathrm{PGI}_{2}, \mathrm{PGD}_{2}$, $\mathrm{PGF}_{2 \alpha}$ sowie TxA $\mathrm{A}_{2}$ verstärken die Produktion und Freisetzung von Mukus aus Drüsenzellen des Bronchialsystems.

\section{Plättchenaktivierender Faktor}

Der plättchenaktivierende Faktor (PAF) wurde ursprünglich durch seine Wirkung auf Thrombozyten entdeckt, hat aber potente biologische Effekte auf verschiedenste Gewebe und Entzündungszellen. Er wird aus Membranphospholipiden unter dem katalytischen Einfluss einer 
Phospholipase $\mathrm{A}_{2}$ und einer Azetyltransferase in Eosinophilen, Neutrophilen, Makrophagen, Thrombozyten und Mastzellen gebildet.

- PAF oder sein stabiles Abbauprodukt lyso-PAF wurden in z. T. hohen Konzentrationen im Bronchoalveolarraum von Asthmatikern nachgewiesen.

- Er besitzt eine potente chemotaktische und aktivierende Wirkung auf Eosinophile und andere Effektorzellen.

- Ferner führt PAF zu Permeabilitätserhöhung und Ödembildung in den Atemwegen und anderen Geweben und ist indirekt an der Entwicklung der bronchialen Hyperreagibilität beteiligt.

- Die Ergebnisse mit der ersten Generation spezifischer PAF-Rezeptor-Antagonisten blieben allerdings ohne klinischen Effekt.

\section{Proteine}

An allergischen Entzündungen sind eine Reihe von Proteinmediatoren beteiligt. Hier sind zunächst die Proteine der Komplementkaskade zu nennen. Die Aktivierung des Komplementsystems ist ein integraler Bestandteil verschiedener physiologischer und pathophysiologischer Vorgänge. Seine Aktivierung über den klassischen oder alternativen Weg führt letztlich zur Bildung von 3 Proteinen ( $\mathrm{C} 3 \mathrm{a}, \mathrm{C} 4 \mathrm{a}, \mathrm{C} 5 \mathrm{a})$, denen eine proentzündliche Wirkung zugeschrieben wird. Von diesen Anaphylatoxinen besitzt das C5a die stärkste biologische Aktivität auf Entzündungszellen. Nach Kontakt mit eosinophilen Granulozyten führt das Protein unter anderem zur Chemotaxis, Degranulation und Freisetzung von Lipidmediatoren. Andere pathophysiologische Effekte umfassen die Kontraktion glatter Muskelzellen und die Erhöhung der vaskulären Permeabilität.

Eine andere Gruppe von Proteinen bilden die von Eosinophilen abstammenden basischen Proteine MBP, ECP und EPO (s. oben). Neben der Zerstörung des respiratorischen Epithels können sie jedoch auch andere Entzündungszellen wie Neutrophile, Mastzellen und Thrombozyten stimulieren. Zudem wird ihnen eine Rolle bei der Ausbildung der bronchialen Hyperreagibilität zugeschrieben. Die Bestimmung basischer Proteine von Eosinophilen im Sputum, Serum oder der bronchoalveolären Lavageflüssigkeit (BAL) kann zur Diagnostik und Beurteilung der Krankheitsaktivität allergischer Erkrankungen herangezogen werden ( Kap. 3.2).

\section{Kinine}

Bei den Kininen handelt es sich um biologisch aktive Oligopeptide, die aus dem hochmolekularen Kininogen unter dem Einfluss von Kininogenasen wie dem Kallikrein freigesetzt werden. Hierzu gehören beim Menschen das Kallidin, das Methionyl-Lysyl-Bradykinin und das Bradykinin. Die Wirkung der Kinine umfasst eine Erhö- hung der vaskulären Permeabilität, eine Vasodilatation sowie die Induktion von Husten. Über das den HagemanFaktor (Faktor XII) aktivierende Kininogen stehen sie auch mit der Gerinnungskaskade und der Fibrinolyse in Beziehung.

Faktor XII ist seinerseits in der Lage, Kallikrein zu aktivieren, das neben seinem Einfluss auf die Kininsekretion auch das fibrinolytische Plasmin freisetzt. Der C1-Esterase-Inhibitor (C1-INA) hemmt neben seinem Einfluss auf die Startsequenz der klassischen Komplementkaskade auch die kallikreinvermittelte Bildung von Bradykinin. Die ungebremste Bradykininfreisetzung beim genetisch fixierten Mangel (Typ I) oder der Dysfunktion des C1INA-Moleküls gilt als wichtiger Pathomechanismus beim hereditären Angioödem.

Sowohl Bradykinin als auch Kallidin werden z.T. durch das Angiotensinkonversionsenzyms (»angiotensin converting enzyme«; ACE) in inaktive Peptide umgewandelt. Die Hemmung des Enzyms durch ACE-Hemmer wird deshalb für das Angioödem unter Therapie mit Captopril oder Enapril verantwortlich gemacht. Die gesteigerte Konzentration des Bradykinins dürfte ferner für den ACE-Hemmer-assoziierten Husten verantwortlich sein.

Metalloproteinasen und endogene Gewebeinhibitoren Matrixmetalloproteinasen (MMP) bezeichnen eine Gruppe zinkhaltiger Enzyme, die Proteine und Proteoglykane der extrazellulären Matrix (ECM) des Bindegewebes abbauen. Sie spielen eine wesentliche Rolle bei der normalen Gewebehomöostase. Ein Gleichgewicht zwischen der Aktivität der MMP und ihren endogenen Gewebeinhibitoren (TIMP) sorgt vermutlich für eine kontinuierliche Erneuerung und Reparatur des ECM-Maschenwerks mit Wiederherstellung der ursprünglichen physiologischen Bedingungen nach passageren Störungen.

Im Rahmen chronisch entzündlicher Prozesse kann es jedoch über eine Imbalance zwischen MMP und TIMP $\mathrm{zu}$ einer Verschiebung des Gleichgewichts zwischen Abbau und Ablagerung der ECM-Proteine kommen. Da Asthma mit einer Zunahme der ECM in den subepithelialen Schichten der Atemwege einhergeht, liegt es nahe zu vermuten, dass das MMP-TIMP-System auch bei der asthmatischen Entzündung eine Rolle spielt.

Während eine Beteiligung dieses Systems im Rahmen der Tumorinvasion, Metastasierung und Angiogenese vermutet wird, finden sich nun auch Hinweise dafür, dass es beim Asthma bronchiale eine aktive Rolle spielt. So zeigte sich bei Untersuchungen zur Ultrastruktur der Atemwege ein Abbau von Elastin bei einigen Asthmatikern. Darüber hinaus ließen sich während symptomatischer Perioden der Asthmaerkrankung im Urin Proteoglykanderivate als Ausdruck des gesteigerten ECMMetabolismus nachweisen. 
Untersuchungen an Patienten mit natürlichem Asthma und am Modell der segmentalen Allergenprovokation zeigen ferner, dass MMP im Rahmen der verzögerten allergischen Reaktion in den Atemwegen freigesetzt werden. Danach kommt es im Rahmen der asthmatischen Spätreaktion vor allem zur Sekretion der MMP-9 und MMP-2. Parallel hierzu finden sich in der BAL-Flüssigkeit auch vermehrte Konzentrationen der TIMP-1. Aufgrund der potenziellen Bedeutung des Atemwegsremodelling für den Langzeitverlauf des Asthma bronchiale wird das MMP-TIMP-System in den kommenden Jahren stärker in den Mittelpunkt des Interesses rücken.

\section{Sauerstoffspezies}

$\mathrm{O}_{2}$-Spezies sind kurzlebige, aber hoch toxische Radikale des oxidativen Zellmetabolismus, die während der Zellaktivierung von Entzündungszellen in die Umgebung freigesetzt werden. Hierzu zählen:

- Superoxidanionen $\left(\mathrm{O}_{2}^{-}\right)$,

- Hydroxylradikale $\left(\mathrm{OH}^{*}\right)$,

- Singulett-Sauerstoff (O) oder

- Wasserstoffperoxid $\left(\mathrm{H}_{2} \mathrm{O}_{2}\right)$.

Die oxidative Wirkung dieser $\mathrm{O}_{2}$-Metabolite zerstört organische Moleküle, Mikroorganismen und Säugetierzellen und -gewebe. Die Bildung der $\mathrm{O}_{2}$-Metaboliten beim Asthma spielt vor allem bei der Schädigung des Bronchialepithels durch eosinophile Granulozyten eine wichtige Rolle.

\section{Sekundäre Effektormediatoren}

\section{Neuropeptide}

Arbeiten aus den letzten Jahren haben eine Reihe von Peptiden aus Nervenendigungen charakterisiert, die die Funktion des Bronchialsystems modifizieren können. Diese Neuropeptide beeinflussen den Muskeltonus von Bronchien und Lungengefäßen und erhöhen die bronchiale Mukussekretion. Das vasoaktive intestinale Peptid (VIP) oder das "peptide histidin methionin« (PHM) zeigen beispielsweise starke bronchodilatatorische Eigenschaften. Während der asthmatischen Entzündungsreaktion werden beide Peptide rascher abgebaut und tragen hierdurch zu einer erhöhten bronchialen Reagibilität bei.

Andere Neuropeptide aus sensorischen Nervenendigungen, wie die SubstanceP (SP), das Neurokinin A (NKA) oder das "calcitonin gene-related peptide» (CGRP), besitzen proinflammatorische Eigenschaften und sind so direkt an den entzündlichen Vorgängen beteiligt.

Die pharmakologische Wirksamkeit der derzeit zur Verfügung stehenden Neuropeptidrezeptorantagonisten ist bisher allerdings nur wenig überzeugend. Weiterführende Untersuchungen zur Bedeutung der Neuropeptide beim Asthma bronchiale sind daher erforderlich.

\section{Endotheline}

Unter dem Begriff Endotheline werden 3 Isoformen eines aus 21 Aminosäuren aufgebauten ubiquitären Peptids zusammengefasst. Sie werden von Epithelzellen, Endothelzellen, Makrophagen, Thrombozyten und pulmonalen neuroendokrinen Zellen unter dem Einfluss verschiedener Mediatoren gebildet, zu denen IL- $1 \alpha$, IL-1 $\beta$, TNF- $\alpha$, TGF- $\beta$, Thrombin sowie IgE-anti-IgE-Komplexe und Lipopolysaccharide gehören.

- Endotheline spielen eine Rolle bei der Regulation des Gefäßtonus.

- Endothelin-1 und Endothelin-2, möglicherweise auch Endothelin-3, kontrahieren isolierte Atemwegsmuskulatur.

- Endotheline induzieren ferner ein lokales Mukosaödem und tragen zur Entwicklung der bronchialen Hyperreagibilität sowie glandulären Hypersekretion bei.

\section{Stickstoffmonoxid}

Stickstoffmonoxid (NO) ist ein leicht diffundierendes Gas, das sowohl als intrazelluläres als auch interzelluläres Signal wirkt. NO wird über eine induzierbare, $\mathrm{Ca}^{2+}$ unabhängige NO-Synthase (iNOS) oder über eine $\mathrm{Ca}^{2+}$ Calmodulin-abhängige Isoform (cNOS) aus L-Arginin gebildet. Als NO-Produzenten gelten Makrophagen, Neutrophile, glatte Muskelzellen und Fibroblasten, Endothelzellen, Epithelzellen, Neurone und Thrombozyten.

Als Stimuli der iNOS wurden Zytokine, einschließlich TNF- $\alpha$, TNF- $\beta$, IL- 1 und IFN- $\gamma$ sowie Endotoxin identifiziert. Im Gegensatz dazu wird eine Aktivierung der cNOS durch Bradykinin, Histamin, PAF und Leukotrien induziert. Aufgrund dieser Konstellation könnte NO eine regulatorische Rolle bei der Relaxation der Atemwegsmuskulatur, der Neurotransmission, der Regulation epithelialer Funktionen und bei der Modulation von Entzündungszellen spielen.

Die NO-Konzentration in der Exspirationsluft von Asthmatikern ist höher als in der von gesunden, nichtasthmatischen Personen. Das widerspricht auf den ersten Blick seiner Wirkung als Bronchodilatator, könnte aber Ausdruck einer kompensatorischen NO-Synthese als Resultat bronchokonstriktorischer oder entzündlicher Stimuli sein. Eine abschließende Zuordnung der Rolle des NO im Rahmen der Pathogenese des Asthma bronchiale lässt sich gegenwärtig noch nicht vornehmen. Seine Konzentration im Exhalat lässt sich als Entzündungsparameter für das Monitoring des Asthma bronchiale einsetzen ( $\triangleright$ Kap. 3.3).

\section{Neutrale Endopeptidase}

Die neutrale Endopeptidase (NEP) ist ein membrangebundenes, zinkhaltiges Ektoenzym, das eine Reihe von Substratmolekülen, wie Bradykinin, Substance P, Neurokinin A, "vasoaktive intestinal peptide «, Bombesin unter anderem, am N-terminalen Ende der hydrophoben Aminosäuren 
spaltet. Durch diesen Effekt verlieren die Neurotransmitter ihre biologische Aktivität, sodass NEP die lokale extrazelluläre Peptidhormonkonzentration reguliert.

Die Expression der NEP wird ihrerseits durch Zigarettenrauch, der das Enzymprodukt hemmt, oder entzündliche Veränderungen, die mit einer Hemmung der NEP-Transkription und Internalisierung des Exoenzyms einhergehen, reguliert. Umgekehrt lässt sich die lokale NEP-Aktivität durch Glukokortikoide oder die Einwanderung NEP-tragender Zellen erhöhen. Obwohl weitere Untersuchungen erforderlich sind, weisen die vorliegenden Ergebnisse der NEP eine regulatorische Rolle in der Pathogenese des Asthma zu.

\section{Matrixproteinfragmente}

Wie weiter unten noch dargelegt wird, bildet die extrazelluläre Matrix ein faseriges, dreidimensionales Netzwerk, das für die Gewebestruktur und -homöostase von grundlegender Bedeutung ist. Im Rahmen allergischer Erkrankungen wird dieses Faserwerk durch die gesteigerte Aktivität der Metalloproteinasen und anderer Enzyme teilweise ab- bzw. umgebaut. Dabei werden Matrixproteinfragmente freigesetzt, die ihrerseits chemotaktische Eigenschaften besitzen und auf diese Weise die Migration infiltrierender Zellen beeinflussen.

\subsubsection{Extrazelluläre Matrixproteine}

Die extrazelluläre Matrix besteht aus verschiedenen Proteinen, die aufgrund ihrer physikochemischen und strukturellen Eigenschaften je nach Zusammensetzung dem Bindegewebe seine charakteristischen Eigenschaften verleihen. $\mathrm{Zu}$ dieser Gruppe von Proteinen gehören die interstitiellen Kollagene, wie Glykoproteine, Proteoglykane und Elastin. Innerhalb der Glykoproteine wird nochmals zwischen Fibronektin, Tenaskin und Laminin unterschieden. Die Basalmembran der Atemwege enthält Typ-IV-Kollagen, Laminin und Fibronektin, während die sich basal anschließende retikuläre Schicht aus Fibronektin und den interstitiellen Kollagenen vom Typ I, III und $\mathrm{V}$ besteht. Welche möglichen pathophysiologischen Konsequenzen sich grundsätzlich aus dem Umbau und der vermehrten Deposition der Matrixproteine in den Atemwegen ergeben können und welche Mechanismen hierbei beteiligt sind, beginnt sich erst jetzt allmählich abzuzeichnen (s. unten).

Extrazelluläre Matrixproteine lassen sich zwischen den sie umgebenden glatten Muskelzellen, dem Gefäßplexus, dem Atemwegsknorpel, der Atemwegsmukosa und den subepithelialen Gewebeschichten einschließlich der Basalmembran finden. Die Matrixproteine durchflechten als ein extrazelluläres Maschenwerk das Bindegewebe und dienen somit unter physiologischen Bedingungen dem Erhalt von Struktur, Form und Funktion der Lunge bzw. der Atemwege. Neben ihrer mechanischen Aufgabe spielen extrazelluläre Matrixproteine auch bei der Regulation des Mikromilieus eine wichtige Rolle. Zellen interagieren z. B. über Integrinrezeptoren mit Matrixproteinen oder binden Zytokine, wie z. B. PDGF, TGF- $\beta$, oder GMCSF. Sie nehmen so indirekt Einfluss auf Differenzierung, Wachstum und Aktivierungsgrad umgebender Zellen.

\subsection{Diagnostik}

Die Diagnostik bei Verdacht auf Vorliegen allergischer Krankheiten dient einerseits dazu, die Verdachtsdiagnose $\mathrm{zu}$ sichern und andererseits, die ursächlich verantwortlichen Allergene zu identifizieren. Die Identifikation des individuellen Sensibilisierungsmusters ist in mehrfacher Hinsicht für das therapeutische Vorgehen von Bedeutung: - für die gezielte präventive Allergenkarenz, z. B. in Form einer Meidung bestimmter Nahrungsmittel oder anderer Allergene durch eine entsprechende Diät bzw. die Wahl eines geeigneten Berufs,

- für die Wahl von Maßnahmen zur Allergenvermeidung (Klima-, Wohnortswechsel, Wohnungseinrichtung, spezielle Bettbezüge, Aufstellen von Lufttrocknern bei Milbenallergie etc.),

- für die Entscheidung für oder gegen eine Desensibilisierungsbehandlung (s. dort).

Die Diagnostik bei begründetem Verdacht auf Vorliegen einer allergischen Erkrankung gliedert sich in eine allgemeine und eine spezielle Allergiediagnostik (• Abb. 3.5).

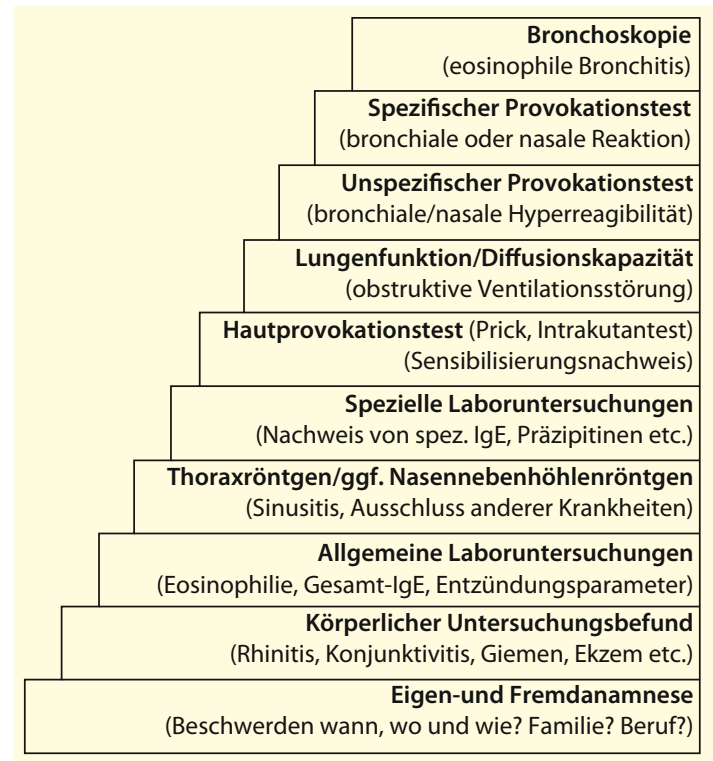

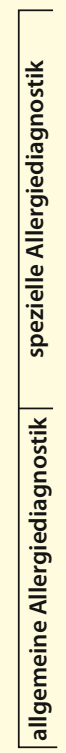

- Abb. 3.5. Stufenplan der Allergie- und Asthmadiagnostik 


\subsubsection{Allgemeine Allergiediagnostik}

\section{Anamnese}

Im Rahmen der allgemeinen Diagnostik spielt die Anamnese eine herausragende Rolle und kann bereits zu wesentlichen Hinweisen auf das Vorliegen einer allergischen Erkrankung führen. So bietet die eingehende Analyse der Umgebung in Hinblick auf potenzielle Allergenträger (Haustiere) oder den Umgang mit Irritanzien oft erste Hinweise auf das Vorliegen einer allergischen Erkrankung. In gleichem Maße ist die Familienanamnese hilfreich, da aufgrund der genetischen Prädisposition allergischer Erkrankungen häufig Erkrankungen im näheren Familienkreis (Eltern, Großeltern, Geschwister) bestehen.

Zur Anamnese gehört auch die Erfassung des Tabakrauchens mit Abschätzung der gesamten Nikotinbelastung in Form von Packyears. Dabei entspricht 1 Packyear dem Genuss von 1 Packung mit 20 Zigaretten pro Tag über einen Zeitraum von 1 Jahr. Ein langjähriger Nikotinabusus führt zur chronischen Bronchitis bzw. zur chronisch obstruktiven Bronchitis, z. T. mit Entwicklung eines Emphysems, die zu den wichtigsten Differenzialdiagnosen des allergischen Asthma bronchiale gehören ( Kap. 3.2.4).

Bei manifester Allergie vom Typ I (z. B. Hausstaubmilben-, Pollen- oder Latexallergie) steht eigenanamnestisch die Assoziation von Symptomen mit einer bestimmten Umgebung (Arbeitsplatz, innerhalb oder außerhalb der Wohnung) oder mit einer Jahreszeit (Frühjahr, Sommer) im Vordergrund. Während Pollenallergiker ihre Beschwerden saisonal vor allem beim Aufenthalt im Freien entwickeln, beobachten Patienten mit einer Allergie gegenüber Hausstaubmilben Symptome vor allem während des Bettenmachens, der Staubsaugerreinigung und beim Schlafen (v. a. in feuchter Umgebung). In 25-50\% der Fälle entwickeln sich die Symptome jedoch nicht unmittelbar, sondern erst innerhalb von $10 \mathrm{~h}$ nach der Exposition (verzögerte Typ-I-Reaktion!), was gelegentlich die anamnestische Zuordnung der Beschwerden zu einer allergischen Ursache erschweren kann.

Einige Standardfragen können bei der Anamneseerhebung hilfreich sein (s. Übersicht).

Wichtige Fragen zur Identifizierung einer möglichen allergischen Erkrankung

- Klagt der Patient über rekurrierende Hautveränderungen, Rhinorrhoe, Tränen der Augen und/oder Giemen?

- Klagt der Patient über störenden nächtlichen Husten?

- Klagt der Patient über Husten oder Giemen nach körperlicher Anstrengung?
- Klagt der Patient über Exantheme, Rhinorrhoe, Husten, Giemen oder Brustenge nach Exposition mit inhalierbaren Allergenen oder unspezifischen Triggern?

- Klagt der Patient über eine Neigung zu Infektion der tieferen Atemwege oder über Atemwegsinfektionen, die länger als 10 Tage anhalten?

Die Bejahung einer oder mehrerer dieser Fragen sollte eine zugrunde liegende Allergie denken lassen. Aber auch ein Pruritus im Bereich des Halses oder der Ohren ist neben einer Nahrungsmittelallergie eine häufige Manifestation bei Pollenallergie der oberen Atemwege. Tritt Giemen mit oder ohne Husten bzw. Dyspnoe hinzu, muss an ein Asthma bronchiale gedacht werden. Die Angabe von thorakalem Engegefühl, Husten und Dyspnoe bei Exposition gegenüber unspezifischen Atemwegsirritanzien, wie z. B. Nikotinrauch, Haarspray etc., oder beim Wechsel von einer warm-trockenen $\mathrm{zu}$ einer kalt-nassen Umgebung lässt sich als Hinweis auf eine bestehende bronchiale Hyperreagibilität deuten, wie sie charakteristischerweise bei einem Asthma bronchiale auftritt.

Beim Vorliegen der akuten Form einer exogen-allergischen Alveolitis treten andere Beschwerden in den Vordergrund. Hier wird von einer rekurrierend auftretenden und beeinträchtigenden Erkrankung mit Fieber, Husten, rezidivierender Dyspnoe und Myalgien berichtet, die 6-8 h nach Antigenexposition (z. B. Stallarbeiten) auftreten. Subakute oder chronische Formen bieten dagegen weniger klare anamnestische Hinweise, da der episodische Charakter nicht so eindeutig zur Darstellung kommt. Es überwiegen unspezifische Beschwerden wie chronischer Husten, Belastungsdyspnoe und Gewichtsabnahme. Eine gewisse Eingrenzung der möglichen ursächlich verantwortlichen Antigene lässt sich durch gezielte Fragen erreichen (s. Übersicht).

Fragen zur Eingrenzung des potenziell verantwortlichen Antigens bei Verdacht auf exogen-allergische Alveolitis

- Beruf: Welchen Beruf haben Sie?

- Arbeitsplatz: Wie sieht die unmittelbare Umgebung an Ihrem Arbeitsplatz aus?

- Wohnung: Wo leben Sie?

- Wohnbedingungen: Bestehen Wohnungsschäden oder haben diese bestanden (Pilzbesiedlung, Überflutung)?

- Freizeitverhalten: Haben Sie bestimmte Hobbys (Schreiner, Vogelzüchter etc.)? 
- Besteht eine Beziehung zwischen Ihrer beruflichen Tätigkeit und den Beschwerden (Wochentage versus Wochenende)?

- Fühlen Sie sich krank wenn Sie verreisen?

- Klagen Kollegen an Ihrem Arbeitsplatz oder Familienangehörige über ähnliche Beschwerden?

- Lassen sich die Symptome in irgendeiner Form vorhersagen?

Besteht ein dringender Verdacht oder hat sich die Diagnose einer Allergie bestätigt, sollten Informationen $\mathrm{zu}$ folgenden anamnestischen Details erhoben werden:

- Häufigkeit und Dauer der Beschwerden mit Bezug zu möglichen auslösenden Faktoren oder zu Maßnahmen einer Vermeidung;

- Schweregrad der Symptome, insbesondere im Hinblick auf lebensbedrohliche Ereignisse;

- Diät, Nahrungsmittelunverträglichkeiten, Intoleranz gegenüber Aspirin, Konservierungsmitteln und Farbzusätzen;

- häusliche, berufliche oder außerhäusliche Umweltfaktoren;

- besonderes Risiko, z. B. Beschäftigte in medizinischen Bereich und der Gummiindustrie oder Kinder mit Spina bifida (hohe Inzidenz von Latexallergien);

- gegenwärtige medikamentöse Behandlung (z. B. $\mathrm{H}_{1}$ Antagonisten, topische oder orale Kortikosteroide).

\section{Körperliche Untersuchung}

Der körperliche Untersuchungsbefund erfasst zunächst die allergieassoziierten Veränderungen des individuellen Organbefalls, z. B. in Form einer Rötung der Konjunktiva (Conjunctivits allergica), Rhinorrhoe (Rhinitis allergica), Giemen bzw. Brummen (Asthma bronchiale) oder Hautekzem (atopische Dermatitis). Bei Atemwegsobstruktion lässt sich ein Pfeifen entweder bei tiefer oder bei forcierter Exspiration mit geöffnetem Mund vernehmen.

Der Auskultationsbefund ist jedoch beim Asthma bronchiale im beschwerdefreien Intervall nicht selten unauffällig. Zudem besitzt die Auskultation in Abhängigkeit vom Alter unterschiedliche Spezifität. Bei jungen Patienten kann Giemen als hochspezifisch angesehen werden. Im Rahmen der akuten Asthmaexazerbation mit schwerer Obstruktion nimmt das Giemen an Intensität ab oder ist überhaupt nicht mehr vorhanden (»silent chest«).

D Die Auskultation ersetzt die Lungenfunktionsmessung nicht, da sie die Atemwegsobstruktion nicht quantifizieren kann.

Die körperliche Untersuchung bietet wertvolle Hinweise zur Differenzierung des Asthma bronchiale gegenüber anderen obstruktiven Lungenerkrankungen. So geben ein Fassthorax, ein leises Atemgeräusch mit trockenen Nebengeräuschen, ein hypersonorer Klopfschall und ein Sahli-Venenkranz (kranzartig angeordnete Venenektasien im Bereich des lateralen unteren Rippenthorax) Hinweise auf das Vorliegen einer chronisch obstruktiven Bronchitis mit Emphysem (COPD).

Bei der frühen Form der akuten exogen-allergischen Alveolitis findet sich ein schwer erkrankter Patient mit Fieber, Tachypnoe und feinblasigen Rasselgeräuschen. Eine Sklerophonie als feines, endinspiratorisch betontes Knisterrasseln (Klettverschluss!) findet sich bei manifesten Lungenfibrosen, wie sie z. B. im fortgeschrittenen Stadium einer exogen-allergischen Alveolitis.

\section{Laboruntersuchungen}

\section{Differenzialblutbild}

Im Vordergrund der Veränderungen des Differenzialblutbildes steht eine grenzwertig normale bis hohe Eosinophilenzahl. Diese ist allerdings nicht spezifisch und normale bis niedrige Werte schließen das Vorliegen einer Allergie nicht aus. Hier bietet der Nachweis von Eosinophilen im Sputum einen verlässlicheren Parameter, der gelegentlich bei der differenzialdiagnostischen Abgrenzung zu anderen chronisch-obstruktiven Atemwegserkrankungen (chronisch-obstruktive Bronchitis, Lungenfibrose) nützlich sein kann.

Für die Beurteilung der Eosinophilenzahl im Blut oder Sputum sollte eine kürzlich zurückliegende (bis zu 5 Tagen) oder eine bestehende Kortikosteroidbehandlung berücksichtigt werden, da Kortikosteroide dosisabhängig zur Elimination der Zellen aus dem Blut und den Atemwegen führen.

\section{Gesamt-IgE-Serumkonzentration}

Die Bestimmung der Gesamt-IgE-Konzentration im Serum bildet einen wesentlichen Bestandteil der allgemeinen Allergiediagnostik (Übersicht 9-4).

Indikationen zur Bestimmung des Gesamt-IgE und des spezifischen IgE im Serum

- Gesamt-IgE:

- differenzialdiagnostische Unterscheidung zwischen allergischen und nichtallergischen Erkrankungen, wie z. B. intrinsischem Asthma bronchiale, chronisch-obstruktiver Bronchitis, Rhinitis und toxischen Nahrungsmittelallergien;

- Diagnose einer latenten oder klinisch manifesten allergischen Diathese;

- Identifikation einer Typ-I-Reaktion bei der ABPA und anderen Alveolitiden; 
- Hinweis für Parasitose;

- Diagnose von Immundefekten (IgE-Mangel, T-Zell-Defekte, Hyper-IgE-Syndrom).

- allergenspezifisches IgE:

- diagnostische Ergänzung in fraglichen Fällen, wenn die übrigen Untersuchungen eine Sensibilisierung nicht belegen;

- sofern Kutantestungen aufgrund bestehender Hauterkrankungen (Ekzem, Urticaria factitia etc.) oder fehlender Mitarbeit (Säuglinge, Kinder) nicht durchgeführt werden können;

- wenn die Möglichkeit zu Hauttesten nicht gegeben ist;

- bei Patienten unter einer Medikation mit Antihistaminika und Kortikosteroiden;

- Gefahr von systemischen Reaktionen nach Hauttestung (Bienengift-, Wespengift- oder Fischallergie);

- Kontrolle bei Hyposensibilisierung und Therapie mit Anti-IgE-Antikörpern.

Der Serum-IgE-Spiegel ist bei den meisten allergischen Erkrankungen vom Typ I erhöht, kann jedoch trotz bestehender Allergie aufgrund der interindividuellen Streuung nicht selten auch im Normbereich liegen. Andererseits ist bei erhöhtem IgE-Serumspiegel differenzialdiagnostisch auch an nichtallergische Erkrankungen zu denken (- Tab. 3.3).
Da die Höhe des IgE-Spiegels mit der Häufigkeit und der Dauer der Allergenexposition im Zusammenhang steht, kommt dem Zeitpunkt der Untersuchung eine gewisse Bedeutung zu. So weisen Patienten mit einer Pollinosis während der Pollenflugzeit höhere GesamtIgE-Konzentrationen auf als während des übrigen Jahres. Im Gegensatz zur Eosinophilenzahl unterliegt der IgESerumspiegel aber nur geringen Schwankungen unter Kortikosteroidbehandlung. Bei erhöhtem Gesamt-IgE ist die weitergehende Diagnostik mit Ermittlung der allergenspezifischen IgE, Hauttestung und ggf. auch der Allergenprovokation indiziert.

\section{Eosinophiles kationisches Protein (ECP)}

Eine Erweiterung der Eosinophilenzählung bildet die Bestimmung des ECP-Spiegels im Serum oder Sputum. Obwohl der Aussagewert dieses löslichen Markers aus eosinophilen Granulozyten nach wie vor umstritten ist, sprechen verschiedene Befunde dafür, dass er neben der Eosinophilenzahl auch den Aktivierungsgrad der Zellen wiedergibt. Innerhalb der allergischen Erkrankungen ist die Konzentration des Serum-ECP im Rahmen der atopischen Dermatitis besonders hoch, gefolgt vom Asthma bronchiale und der Rhinitis allergica, wenngleich auch hier Normwerte vorkommen können. Bei Verdacht auf Vorliegen eines Asthma bronchiale kann die Bestimmung der ECP-Konzentration, aber auch der Eosinophilenzahl im Sputum, insbesondere bei der Abgrenzung zur chronisch-obstruktiven Bronchitis, nützlich sein.

- Tab. 3.3. Differenzialdiagnostik der erhöhten Gesamt-IgE-Konzentration im Blut bei nichtallergischen Erkrankungen

\begin{tabular}{|c|c|}
\hline Erkrankung & Kommentar \\
\hline Parasitose & $\begin{array}{l}\text { Grundsätzlich verursacht von Helminthen wie Nematoden, Trematoden und } \\
\text { Zestoden, nicht aber von Protozoen; über das 10-fache erhöhte IgE-Konzentrati- } \\
\text { onen bei Askariden, Toxocara canis, Schistosomen, Fasciola hepatica, Ankylosto- } \\
\text { matiden u. a.; Abfall der IgE-Spiegel unter adäquater Therapie }\end{array}$ \\
\hline Churg-Strauss-Syndrom & $\begin{array}{l}\text { Per definitionem mit allergischer Diathese vergesellschaftet, meist sehr hohe } \\
\text { IgE-Serumkonzentrationen (>2000 U/L); pANCA in ca. } 50 \% \text { der Fälle nachweisbar }\end{array}$ \\
\hline Andere Vaskulitiden & Selten, meist aber sehr hoher IgE-Spiegel im Blut \\
\hline Hyper-IgE-Syndrom (Job-Syndrom) & $\begin{array}{l}\text { IgE-Blutkonzentration bis über das } 100 \text {-fache des Referenzbereichs bei rezidivie- } \\
\text { renden Infektionen der Haut und des Respirationstrakts }\end{array}$ \\
\hline Monoklonale IgE-Gammopathien & $\begin{array}{l}\text { Sehr seltene Erkrankung ( } 0,1 \% \text { aller monoklonalen Gammopathien) mit z.T. } \\
\text { extremhohen IgE-Serumkonzentrationen }\end{array}$ \\
\hline Maligne Tumoren & $\begin{array}{l}\text { IgE-Konzentration kann wenig bis mittelgradig erhöht sein, vor allem bei } \\
\text { Malignomen des bronchopulmonalen Systems, des Gastrointestinaltrakts, des } \\
\text { Hodens und des Hals-Nasen-Ohrenbereichs }\end{array}$ \\
\hline $\begin{array}{l}\text { T-Zelldysfunktion (Aids, Non-Hodgkin-Syndrom, } \\
\text { Nezelof-Syndrom, Wiskott-Aldrich-Syndrom) }\end{array}$ & Gelegentlich mit mäßiger lgE-Konzentrationserhöhung einhergehend \\
\hline
\end{tabular}


Der Serum-ECP-Spiegel ist jedoch kein allergiespezifischer Parameter. Erhöhte Werte finden sich z. B. auch bei Bronchiektasen, zystischer Fibrose und nichtkleinzelligem Bronchialkarzinom. Bei diesen Erkrankungen fehlt allerdings eine Bluteosinophilie, sodass die Konstellation einer normalen Eosinophilenzahl im Blut und eines erhöhten ECP-Spiegels zur Differenzialdiagnostik herangezogen werden kann. Im Rahmen des Churg-StraussSyndroms und anderer eosinophilenassoziierter Erkrankungen sind dagegen sowohl das Gesamt-IgE als auch die Eosinophilenzahl im Blut erhöht.

\section{Entzündungsparameter}

Allgemeine Laborparameter der Entzündung stehen bei der Diagnostik allergischer Erkrankungen im Hintergrund. Entzündungsparameter (BSG, CRP, Elektrophorese, Fibrinogen etc.) sind zur Erfassung einer systemisch entzündlichen Konstellation, z. B. im Rahmen einer interkurrierenden Pneumonie oder anderer Infekte, sinnvoll. Darüber hinaus sind sie wenige Stunden nach Antigenexposition bei der exogen-allergischen Alveolitis zu finden. Die Serumkonzentration des Angiotensinkonversionsenzyms (ACE) ist neben der Sarkoidose und einigen anderen nichtallergischen Erkrankungen zu 70\% im Rahmen einer Berylliose erhöht.

\section{Radiologische Untersuchungen}

Radiologische Untersuchung des Thorax mittels der klassischen Röntgenaufnahme oder der hochauflösenden Computertomographie spielen vor allem bei der Differenzialdiagnose zum Ausschluss bestimmter Lungenerkrankungen eine Rolle. Hierzu gehören z. B. der Nachweis emphysematöser Veränderungen, die bei der chronischobstruktiven Bronchitis (z. B. zentrilobuläres und panazinäres Emphysem bei chronischem Nikotinabusus), nicht aber bei einem reinen allergischen Asthma bronchiale (allenfalls akute Überblähung, aber ohne Emphysem) nachzuweisen sind. Auch andere Erkrankungen, wie z. B. Bronchialkarzinome, Fremdkörperaspiration, Lungenembolien, Sarkoidose (bihiläre Lymphadenopathie, retikulonoduläre Muster) oder das Churg-Strauss-Syndrom (flaue wechselnde Infiltrate) können asthmatische Symptomatik imitieren.

Im Rahmen der allergischen bronchopulmonalen Aspergillose (ABPA) finden sich radiologisch neben diffusen Infiltraten typischerweise Segment- bzw. Lappenatelektasen als Folge der Bronchialobstruktion durch mukoide Ausgüsse (»mucoid impaction«). Zusätzlich zeigt sich eine entzündliche Verdickung der Bronchialwände, die an Trambahnschienen (»tram-line shadows«) oder Ringschatten ("gloved-ring shadows" oder »ring shadows«) erinnern. In all diesen Fällen können Röntgenuntersuchungen indiziert sein, nicht aber beim unkomplizierten Asthma.

\subsubsection{Spezielle Allergiediagnostik}

Die spezielle Diagnostik allergischer Erkrankungen umfasst standardisierte und nichtstandardisierte Hauttests (einschließlich Epikutantests), die verschiedenen Invitro-Testverfahren, die Lungenfunktionsuntersuchung sowie die unspezifischen und spezifischen Provokationstechniken. Gelegentlich sind zur Diagnostik allergischer Alveolitiden auch invasivere Maßnahmen (Bronchoskopie mit bronchoalveolärer Lavage und Biopsie) angezeigt.

\section{Hauttests}

Hierzu gehören der epikutane Reibetest und Patch-Test sowie die kutanen Prick-, Reibe-, Scratch- und Intrakutantests. Die meisten klinisch relevanten Allergene sind in Form von Naturextrakten kommerziell verfügbar (s. unten). Im Einzelfall ist aber auch die Verwendung des nichtextrahierten, natürlichen Allergens erforderlich.

Bei der Durchführung der Hautteste ist grundsätzlich auf das Anlegen einer Negativ- (Kochsalz) und Positivkontrolle (Histamin) zu achten. Hierdurch werden unspezifische Hautreaktionen ausgeschlossen und die individuelle Reagibilität auf Histamin erfasst. Eine andere Möglichkeit, die Spezifität der kutanen Provokation zu prüfen, ist die Provokation in Form einer Titrationsreihe mit ansteigenden Allergenkonzentrationen. Titrationsreihen bieten sich auch für die Ermittlung des Sensibilisierungsrads, insbesondere bei Testung neuer oder nativer Allergene an. Kontraindikationen zur Durchführung eines Hauttests sind Dermographismus, Urticaria factitia oder ekzematös veränderte Hautareale.

Ein positiver Hauttest liegt dann vor, wenn innerhalb von 15-30 Minuten eine signifikante Rötung der Haut mit Quaddelbildung entsteht. Dabei muss die lokale Reaktion über dem provozierten Bereich deutlich größer sein als die Negativkontrolle. Bei starker Sensibilisierung kann sie andererseits aber die Reaktion der Positivkontrolle übertreffen. Gelegentlich kommt es nach 6-12 h zu einer zweiten Reaktion im Bereich des Provokationsareals. Hierbei handelt es sich dann um eine verzögerte allergische Typ-I-Reaktion, die durch Infiltration aktivierter T-Lymphozyten und Eosinophilen gekennzeichnet ist.

(1)

Die Behandlung mit Antihistaminika oder anti-lgEAntikörpern hemmt die Prick-Reaktion.

Histaminika sollten 1 Woche und anti-IgE-Antikörper 3 Monate vor der Testung abgesetzt werden. Allgemeine Hinweise zur Durchführung und Beurteilung von Hattests gibt die nebenstehende Übersicht. 
Hinweise zur Durchführung und Beurteilung von Hauttests

- Der Hauttest sollte auf der Innenseite des Unterarms z. B. mittels einer sterilen Lanzette (Prick-Test) oder einer feinen Nadel (Intrakutantest) durchgeführt werden, ohne dass dabei lokale Blutungen auftreten.

- Auf ekzematös veränderter Haut sollte keine kutane Provokation durchgeführt werden; eine Alternative ist RAST (»Radio-Allergo-Sorbent-Test «).

- Antihistaminika sollten in den 7 Tagen vor Durchführung des Hauttests nicht eingenommen werden.

- Auch anti-lgE-Antikörper (Omalizumab, Xolair) hemmen die lokale Reaktion des Hauttests und sollten daher 3 Monate vor der Untersuchung abgesetzt werden.

- Niedrig dosierte orale Kortikosteroide (<5 mg Prednisonäquivalent), Leukotrienhemmer und $\beta_{2}$-Mimetika besitzen keinen signifikanten Einfluss auf die Reaktion durch eine kutane Provokation.

- Eine Positiv- (Histamin) und eine Negativkontrolle (Lösungsmittel des Allergens) muss bei jedem Hauttest mitgeführt werden

- Für ein positives Ergebnis muss die allergeninduzierte Schwellung im Durchmesser die Negativkontrolle um $\geq 3 \mathrm{~mm}$ übertreffen.

- Dermographismus kann zu einer falsch-positiven Hautreaktion führen (Überprüfung durch Negativkontrolle).

Ein positiver Ausfall des Hauttests weist auf eine bestehende Sensibilisierung gegenüber dem ausgetesteten Allergen bzw. Antigen oder Hapten mit der Existenz spezifischer IgE-Antikörper (Typ I) hin. Er gibt keine Auskunft über die klinische Relevanz des Allergens oder Antigens. Sensibilisierungen kommen bei 20-40\% der Bevölkerung auch ohne jegliche Erkrankung vor (latente oder subklinische Sensibilisierung). Das Ergebnis des Hauttests muss daher mit der Anamnese, den Symptomen und den übrigen Befunden integriert beurteilt werden.

Die Hauttestung erfolgt derzeit mit Allergenextrakten aus natürlichen Allergenträgern, die in etwa 90\% der Fälle eine ausreichende Sensitivität und Spezifität aufweisen. Im Gegensatz zu der vergleichsweise konstanten Anzahl IgE-bindender Komponenten der Insektengift- und Birkenpollenallergene bestehen andere kommerziell erhältliche Allergenextrakte aus einer großen Zahl an allergenen Determinanten. Dieser Umstand führt zu einer diagnostischen Unsicherheit, die z. B. bei Testungen mit Pilzallergenen, Lebensmittel- und vereinzelten Pollenallergenen am deutlichsten zum Ausdruck kommt.
Zudem enthalten die aus natürlichen Allergenträgern hergestellten Extrakte eine größere Anzahl nichtallergischer Komponenten, die z. T. über eine IgE-unabhängige Mediatorauschüttung zu falsch-positiven Testergebnissen führen. Schließlich ist die Zahl, Menge und die chemische Beschaffenheit der extrahierten Allergene nur unzureichend definiert. Inwieweit molekulargenetisch hergestellte, hochreine Allergene die diagnostische Sicherheit der Hauttestung zukünftig verbessern, muss derzeit noch offen bleiben.

\section{Reibetest (Typ-I-Allergene)}

Die Indikation zum Reibetest besteht, wenn eine hochgradige Sensibilisierung vermutet wurde oder wenn kein standardisiertes Allergen zur Verfügung steht. Hierzu wird das native Allergen (Nahrungsmittel, Medikamente, Stäube etc.) auf der Beugeseite des Unterarms mehrmals (ca. 10-mal) unter leichtem Druck gerieben. Bei bestehender Typ-I-Allergie entwickelt sich nach 10-30 min eine follikuläre urtikarielle Effloreszenz, die zur Quaddel konfluiert. Als Kontrolle dient eine vergleichbare physikalische Provokation am anderen Arm (physikalische Urtikaria!). Der Reibetest gilt heute allerdings als veraltet und wird kaum noch eingesetzt.

\section{Patch-Test (Typ-I- und Typ-VI-Allergene)}

Der Patch-Test wird vor allem zur Ermittlung einer TypIV-Reaktion (Epikutantest), gelegentlich auch bei Typ-IReaktionen (Atopie-Patch-Test) eingesetzt. Hierzu platziert man das zu untersuchende Allergen (z. B. Arzneimittel in weißer Vaseline mit oder ohne DMSO bzw. anderen Lösungsmitteln) offen oder geschützt unter einem dicht abschließenden Testpflaster (»finn chambers«) auf den Rücken oder den Unterarm. Die lokale Reaktion wird nach $30 \mathrm{~min}, 24$ und $48 \mathrm{~h}$ bewertet.

Beim Atopie-Patch-Test wird das lokale Erythem mit Quaddel bewertet (s. oben). Der positive Ausfall des Epikutantests zeigt sich durch die Entwicklung typischer klinischer Veränderungen einer Kontaktdermatitis. Trotzdem bietet gerade beim Epikutantest die Differenzierung $\mathrm{zu}$ unspezifischen irritativen Veränderungen der Haut selbst für einen Erfahrenen nicht selten Probleme. Darüber hinaus sollten Patienten nach Durchführung des Tests für mindestens $3 \mathrm{~h}$ unter ärztlicher Aufsicht bleiben, da sich nach Epikutantestung anaphylaktische Reaktionen entwickeln können (besonders bei Pyrazolonderivaten, Penizillinen und Aminoglykosiden; Cave: innerhalb von 30 min auftretende Hautreaktion).

\section{Prick-Test (Typ-I-Allergene)}

Der Prick-Test ist gegenwärtig das Verfahren der Wahl zum Nachweis einer Typ-I-Allergie. Die heute verwendeten standardisierten Allergenextrakte und Prick-TestNadeln können als ungefährlich gelten und lassen sich 
- Tab. 3.4. Semiquantitative und quantitative Beurteilung der Prick- und Intrakutantestreaktion. Die angegebenen Werte beziehen sich auf den größten Durchmesser ( $\varnothing$ ) der provozierten Hautreaktion

\begin{tabular}{|c|c|c|c|c|}
\hline \multirow[t]{2}{*}{ Semiquantitativ } & \multicolumn{2}{|c|}{ Prick-Test (mm Ø) } & \multicolumn{2}{|c|}{ Intrakutantest ( $\mathrm{mm} \varnothing)$} \\
\hline & Quaddel & Erythem & Quaddel & Erythem \\
\hline 0 & - & $<3$ & $<3$ & $<5$ \\
\hline+ & $>3$ & $3-5$ & $3-5$ & $5-10$ \\
\hline++ & $3-4$ & $6-10$ & $6-10$ & $11-20$ \\
\hline+++ & $4-6$ & $11-20$ & $11-15$ & $21-40$ \\
\hline \multirow[t]{2}{*}{++++} & $>6$ & $>20$ & $>15$ & $>40$ \\
\hline & \multicolumn{2}{|c|}{ Pseudopodien } & \multicolumn{2}{|c|}{ Pseudopodien } \\
\hline
\end{tabular}

ohne Bedenken auch bei Kindern anwenden. Auch der Prick-Test wird gewöhnlich an der Volarseite des Unterarms vorgenommen, wobei an jedem Arm verschiedene Allergene gleichzeitig getestet werden können. Im Gegensatz zum Scratch-Test wird hierzu zunächst die Allergenlösung auf die Haut getropft und mit einer speziellen Prick-Lanzette durch Anstechen und Anheben der Haut inokuliert.

Als positives Ergebnis (semiquantitative Bewertung: »einfach positiv«) gilt eine Quaddel mit einem maximalen Durchmesser von $3 \mathrm{~mm}$ und einem Erythem von über 3-5 mm, sofern die Negativkontrolle keine Reaktion zeigt (-Tab. 3.4). Deutliche Hautreaktionen bestehen bei einem Erythem mit einem Durchmesser $>20 \mathrm{~mm}$ und einer Quaddel mit einem Durchmesser $>6 \mathrm{~mm}$ sowie Pseudopodien (semiquantitative Bewertung: »vierfach positiv«). Die Angabe der tatsächlichen Hautreaktion in Millimetern Erythem/Quaddel (z. B. 6/20) ist der subjektiveren semiquantitativen Bewertung vorzuziehen.

\section{Scratch-Test (Typ-I-Allergene)}

Der Scratch-Test eignet sich insbesondere zur Darstellung einer allergischen Diathese gegenüber nutritiven, medikamentösen und nativen Allergenen. Hierzu wird die Haut an der Beugeseite des Unterarms mit einer Lanzette oberflächlich angeritzt. Im Unterschied zum Prick-Test wird das zu testende Allergen, Kochsalz und Histamin erst danach aufgebracht und die Reaktion nach 20 min beurteilt. Eine positive Reaktion äußert sich, bezogen auf die Negativkontrolle, durch die Entwicklung einer Quaddel mit Pseudopodien.

\section{Intrakutantest (Typ-I- und Typ-III-Allergene)}

Beim Intrakutantest werden 0,03 ml einer Allergenlösung mittels einer Tuberkulinspritze streng i.c. injiziert. Eine positive Reaktion äußert sich nach 20 min in Form einer Quaddel und eines Erythems, z.T. mit Pseudopodien.
Der Intrakutantest ist der sensitivste Hauttest und etwa um 3 Zehnerpotenzen empfindlicher als das Prick-Verfahren. Daher besteht die Indikation zur Durchführung eines Intrakutantests bei Diskrepanz zwischen anamnestischem Verdacht und negativem Prick-Test. Außerdem kann er zur Abschätzung des Sensibilisierungsgrads vor Beginn einer Hyposensibilisierungsbehandlung durchgeführt werden.

Im Vergleich zum Prick-Test kommt es jedoch häufiger auch zu falsch-positiven Reaktionen. Zudem besteht ein höheres Risiko systemischer Nebenwirkungen, sodass die Intrakutantestung nur unter strengen Kautelen (kontinuierliche Überwachung, notfallmedizinische Ausrüstung, Intensivstation verfügbar) durchgeführt werden sollte.

Tuberkulinstempeltest, intrakutaner Tuberkulintest nach Mendel-Mantoux und Multitest Merieux (Typ-IV-Allergene, Recall-Antigene)

Der Tuberkulinstempeltest (10 TE gereinigtes Tuberkulin Behring) und der Multitest Merieux (7 Recall-Antigene) bestehen aus mit Antigenlösung getränkten Teststempeln, die fest in die Haut gedrückt werden.

Der Tuberkulintest nach Mendel-Mantoux wird mittels einer Tuberkulinspritze in der gewünschten Verdünnung (10-100 TE gereinigtes Tuberkulin Behring) streng intrakutan an der Volar- oder Dorsalseite des Unterarms appliziert. Die Allergene lösen eine umschriebene Typ-IVReaktion aus, deren Umfang nach $72 \mathrm{~h}$ beurteilt werden sollte. Eine Induration (nicht jedoch ein Erythem oder Ödem), die beim Stempeltesten über $5 \mathrm{~mm}$ und beim Mendel-Mantoux-Test über $10 \mathrm{~mm}$ (größter Querdurchmesser senkrecht zur Längsachse des Armes) erreicht, gilt als positive Reaktion. Sie gibt nicht nur Auskunft über eine vorausgegangene mykobakterielle Infektion, sondern auch über die individuelle zelluläre Immunkompetenz der Typ-IV-Reaktion. 
Für die Beurteilung der zellulären Immunreagibilität noch besser geeignet ist der Multitest Merieux, der neben Tuberkulin noch 6 weitere Recall-Antigene (Bakterienund Pilzantigene) enthält. Die Bezeichnung Recall bezieht sich darauf, dass der Organismus bereits früher mit diesen Antigenen in Kontakt gekommen sein muss (sekundäre Antigene). Die kutane Reaktion gegenüber den Substanzen führt bei manifester HIV-Infektion oder anderen Immundefekten, fieberhaften Erkrankungen, Sarkoidose, immunsuppressiver Therapie sowie unmittelbar nach Virusinfekten (z. B. Masern, Röteln, Windpocken und schwere grippale Infekte) zu falsch-negativen Ergebnissen. Gleiches gilt auch für die oben genannten Provokationstests mit Tuberkulin.

\section{Berylliumintrakutantest (Typ-V-Allergene)}

Dieser Intrakutantest dient der Ermittlung einer Sensibilisierung gegenüber Beryllium. Hierzu werden ansteigende Konzentrationen $(0,05 \%, 0,01 \%$ und $0,005 \%)$ einer $\mathrm{BeSO}_{4}$-Lösung streng intrakutan injiziert. Bei positivem Ergebnis lässt sich nach 2-4 Tagen eine dosisabhängige erythematöse Induration nachweisen. In der höchsten Dosis treten in einigen Fällen unspezifische Reaktionen auf, sodass eine epitheloidzellige, nicht verkäsende granulomatöse Entzündung 4 Wochen nach Testung bioptisch gesichert werden sollte.

\section{In-vitro-Testverfahren}

Ein weiteres Standbein der speziellen Diagnostik allergischer Erkrankungen bildet der Nachweis einer erhöhten Serumkonzentration spezifischer Immunglobuline vom Typ E, G und A.

\section{Spezifisches IgE}

Das allergenspezifische IgE im Serum wird mithilfe von immunoradiometrischen Verfahren, chemiluminometrischen Assays oder ELISA (»enzyme-linked immuno sorbent assay«) ermittelt. Hierunter sind heute der sog. RAST sowie der CAP die verbreitetsten. Aufgrund seiner vergleichsweise hohen Spezifität von etwa 90\% spricht der Nachweis erhöhter Immunglobulinkonzentrationen in der überwiegenden Zahl der Fälle für eine IgE-vermittelte Sensibilisierung. Zudem ist die Konzentration im Wesentlichen unabhängig von der Medikation mit Antihistaminika und Kortikosteroiden gut reproduzierbar.

Die Durchführung des RAST ist allerdings vergleichsweise kostenintensiv. Ein selektiver Einsatz auf dem Boden von Anamnese und Prick-Test sollte deshalb einem undifferenzierten Screening vorgezogen werden. Bei der bestehenden Kreuzreaktivität von Baumallergenen der Birke, Erle und Hasel ist es beispielsweise auch nicht sinnvoll, die verschiedenen individuellen Baumpollenal- lergene parallel zu testen. Gleiches gilt für die Allergene einzelner Grassorten.

Ein negatives IgE-Ergebnis schließt eine Typ-I-Allergie nicht aus.

Niedrige IgE-Serumkonzentrationen finden sich z. B. bei limitierter Allergenexposition, schwacher Sensibilisierung oder längerer Allergenkarenz. Auch die Anwesenheit von isospezifischen IgG-Antikörpern kann im RAST falschniedrige IgE-Werte vortäuschen, da IgG mit dem IgE um die Allergenbindung konkurriert.

D Die Indikation zur Bestimmung des spezifischen IgE sollte sehr sorgfältig gestellt werden und sich auf die Fälle beschränken, in denen In-vivo-Verfahren nicht eindeutig oder nicht durchführbar sind.

Zunehmend gewinnt der spezifische IgE-Nachweis mittels Immunoblot für spezielle diagnostische Fragestellungen (z. B. Insektengiftallergie) in den Fällen an Bedeutung, bei denen die Antikörperbestimmung mittels CAP bzw. RAST infolge Blockierung relevanter Epitope falsch-negativ ist.

Aufgrund der integrierten Beurteilung der Eosinophilenzahl, der Konzentration des Gesamt-IgE und des ECP sowie des RAST- bzw. CAP-Befundes kann eine diagnostische Beurteilung erfolgen (•Tab. 3.5). Die diagnostische Bedeutung des spezifischen IgE in Bezug auf Hauttestergebnis und Anamnese ist in - Tab. 3.6 dargestellt.

\section{Spezifisches $\lg A$}

Allergenspezifische Gliadinantikörper der Immunglobulinklasse A im Serum lassen sich im Rahmen einer Zöliakie (Sprue) nachweisen. Ein Mangel an sekretorischen IgA-Dimeren in dem die Schleimhäute bedeckenden Flüssigkeitsfilm prädisponiert nicht nur zu häufigen Infekten, sondern auch zur Entwicklung von Autoimmunerkrankungen und Allergien.

\section{Histamine-Release-Assay (HRA)}

Dieser Assay beruht auf der Freisetzung von Histamin aus Blutbasophilen in vitro nach Zugabe spezifischen Allergens. Anhand von Dosis-Wirkungs-Kurven wird die Konzentration des Allergenextrakts ermittelt, die 30\% des Gesamthistamingehalts der Zellen freisetzt. Der HRA ist spezifischer als die Bestimmung des spezifischen IgE, jedoch ungleich aufwendiger und zeitintensiver. Er ist zudem abhängig von der Medikation und bei etwa 5\% der Patienten negativ (Non-Responder). Seine Anwendung ist daher auf wissenschaftliche Fragestellungen begrenzt.

Beryllium-Lymphozytentransformationstest (Be-LTF) Der Test beruht auf der Proliferationsrate bronchoalveolärer oder Blutlymphozyten unter Exposition mit an- 
- Tab. 3.5. Diagnostische Interpretation verschiedener Parameter aus dem Blut

\begin{tabular}{|c|c|c|c|c|}
\hline Eosinophilie & ECP & Gesamt-lgE & RAST & Interpretation \\
\hline+ & + & + & + & $\begin{array}{l}\text { - Allergische Diathese (allergische Sensibilisierung) } \\
\text { - Allergische Erkrankung (z. B. allergisches Asthma bronchiale) } \\
\text { - Churg-Strauss-Syndrom (CSS) }\end{array}$ \\
\hline+ & + & + & - & $\begin{array}{l}\text { - Tropische Eosinophilie } \\
\text { - Löffler-Syndrom }\end{array}$ \\
\hline+ & + & - & - & $\begin{array}{l}\text { - Eosinophilenassoziierte Erkrankung (Eosinophile Pneumonie, } \\
\text { idiopathisches hypereosinophiles Syndrom) }\end{array}$ \\
\hline- & + & - & - & - Bronchialkarzinom \\
\hline- & + & - oder + & - oder + & - Bronchiektasen, zystische Fibrose \\
\hline
\end{tabular}

ECP eosinophiles kationisches Protein; RAST Radio-Allergo-Sorbent-Test

- Tab. 3.6. Diagnostische Interpretation von Anamnese, Hauttest und RAST

\begin{tabular}{|c|c|c|c|c|}
\hline Anamnese & Hauttest & Spezifisches lgE & Interpretation & Maßnahmen \\
\hline Positiv & Positiv & Positiv & $\begin{array}{l}\text { Allergische Diathese mit klinischer } \\
\text { Manifestation }\end{array}$ & $\begin{array}{l}\text { Planung allgemeiner und medika- } \\
\text { mentöser Therapie der jeweiligen } \\
\text { allergischen Erkrankung }\end{array}$ \\
\hline Negativ & Positiv & Positiv & $\begin{array}{l}\text { Allergische Sensibilisierung ohne klinische } \\
\text { Relevanz, subklinische Manifestation?, } \\
\text { klinische Manifestation zukünftig möglich }\end{array}$ & $\begin{array}{l}\text { Möglichkeiten der Allergenkarenz } \\
\text { und Vermeidung von Irritanzien } \\
\text { (Umweltnoxen, Nikotin etc.) }\end{array}$ \\
\hline Negativ & Negativ & Positiv & Allergische Sensibilisierung möglich & $\begin{array}{l}\text { Gezielte Anamnese (»versteckte« } \\
\text { Allergene in Nahrungsmitteln oder } \\
\text { am Arbeitsplatz), Kontrollen, Wieder- } \\
\text { holung des Tests im Intervall }\end{array}$ \\
\hline Negativ & Positiv & Negativ & Allergische Sensibilisierung möglich & $\begin{array}{l}\text { Ausschluss unspezifischer Reaktionen, } \\
\text { Kontrollen, Wiederholung des Tests im } \\
\text { Intervall }\end{array}$ \\
\hline Positiv & Negativ & Negativ & Keine allergische Sensibilisierung & $\begin{array}{l}\text { Überprüfung möglicher Differenzial- } \\
\text { diagnosen, ggf. lokale Provokation mit } \\
\text { potenziellem Allergen }\end{array}$ \\
\hline
\end{tabular}

steigenden Konzentrationen an $\mathrm{BeSO}_{4}\left(10^{-4}-10^{-6}\right.$ Molar $)$ in vitro. Bei einem positiven Testergebnis lässt sich im Vergleich zur Negativkontrolle nach 5 Tagen eine dosisabhängige Proliferation ( ${ }^{3} \mathrm{H}$-Thymidin- oder PDU-Einbau) nachweisen. Der Be-LTF-Test weist sehr spezifisch eine Sensibilisierung gegenüber Beryllium nach, besitzt jedoch nur eine geringe Sensitivität (ca. $40 \%$ falsch-negative Ergebnisse).

\section{Lungenfunktionsprüfungen}

Hierzu gehören als einfachste Möglichkeit die Verlaufskontrolle der Atemwegsobstruktion durch die morgendliche und abendliche Messung des maximalen exspiratorischen Flusses (PEF) mittels eines Peak-flow-Meters bei Asthmaverdacht oder zur Therapiekontrolle. Typischerweise zeigen sich beim Asthma bronchiale niedrigere PEF-Wert am Morgen mit großer Variabilität und deutlicher Besserung unter Therapie mit inhalativen $\beta_{2}$ Sympatikomimetika. Mithilfe von Peak-flow-Protokollen lassen sich auch Hinweise auf mögliche Auslöser (z. B. Arbeitsplatz, Wohnung, Tierkontakt) gewinnen bzw. objektivieren. Eine größere Bedeutung hat das Peak-flowMeter allerdings beim Monitoring des Asthma bronchiale $(\triangleright$ Kap. 3.2.3).

Während die Messung des PEF in der Praxis bzw. zu Hause durchführbar ist, erfordert die zur Sicherung der Diagnose notwendige lungenfunktionelle Diagnostik entsprechend ausgerüstete Spezialpraxen oder Kliniken. Mittels Spirometrie (Tiffeneau-Index $=\mathrm{FEV}_{1} / \mathrm{VK}<70 \%$ ) 
oder Ganzkörperplethysmographie ( $\mathrm{R}_{\mathrm{aw}}$ über Sollwert erhöht) lässt sich eine obstruktive Ventilationsstörung eindeutig ermitteln. Diese bildet sich beim Asthma bronchiale im Bronchospasmolysetest nach Inhalation von $\beta_{2}$-Sympatikomimetika mindestens teilweise zurück (Reversibilität). Die Messung des CO-Transferfaktors erlaubt in der Regel auch eine Abgrenzung zur chronisch-obstruktiven Bronchitis mit Emphysem.

\section{Unspezifische Provokationstests}

Die Lungenfunktion ist bei allergischen Personen mit Asthma im beschwerdefreien Intervall nicht selten normal. Aus diesem Grund bildet der Nachweis einer bronchialen Hyperreagibilität eine wichtige Säule bei der Diagnostik des Asthma bronchiale. Hierzu wird Histamin oder ein Azetylcholinderivat (Carbachol, Metacholin) stufenweise in ansteigender Konzentration standardisiert inhaliert. Zwischen den einzelnen Stufen erfolgt die Messung bestimmter Lungenfunktionsparameter.

Der unspezifische bronchiale Provokationstest umfasst 4 Konzentrationsstufen bis zum Erreichen der Maximaldosis. Nach den Empfehlungen der Deutschen Gesellschaft für Pneumologie (DGP) liegt eine bronchiale Hyperreagibilität dann vor, wenn eine der folgenden Kriterien erfüllt ist:

- Abfall des absoluten exspiratorischen Volumens in einer Sekunde $\left(\mathrm{FEV}_{1}\right)$ um 20\%,

- Anstieg des Atemwegswiderstands $\left(\mathrm{R}_{\mathrm{aw}}\right)$ um 100\% und $0,6 \mathrm{kPa} /(\mathrm{l} / \mathrm{s})$,

- Anstieg des spezifischen Atemwegswiderstands $\left(\mathrm{sR}_{\mathrm{aw}}\right)$ um $100 \%$ und $0,2 \mathrm{kPa} \times \mathrm{s}$,

- Abfall der spezifischen Atemwegsconductance $\left(\mathrm{sG}_{\mathrm{aw}}\right)$ um $40 \%$ und $0,5 /(\mathrm{kPa} \times \mathrm{s})$.

Als Bezugspunkt hierfür gelten die Messwerte vor Provokation, die im Normbereich liegen sollten. Nach der Provokation sollte sich eine Bronchospasmolyse durch Inhalation $\beta_{2}$-Mimetika anschließen.

Die bronchiale Provokation sollte nicht durchgeführt werden bei:

- mittelschwerer bis schwerer Obstruktion $\left(\mathrm{FEV}_{1}<1,2 \mathrm{l}\right.$, Asthmaexazerbation),

- schweren kardiovaskulären Erkrankungen (Herzrhythmusstörungen, Aneurysma, Herzinsuffizienz),

- schwerer Hypertonie,

- Schwangerschaft.

$\mathrm{Zu}$ berücksichtigen ist ferner, dass eine vorbestehende Atemwegsobstruktion, vorausgegangene Belastungen, virale Infekte oder die Behandlung mit $\beta$-Blockern, Parasympathikomimetika und $\alpha$-Sympathikomimetika die bronchiale Hyperreagibilität verstärken können. Andererseits schwächen $\beta_{2}$-Sympathikomimetika, Kortikostero- ide, Parasympatikolytika, Theophyllin, Antihistaminika, Dinatriumcromoglycat (DNCG), Ketotifen und Nedocromil die bronchiale Reagibilität ab und sollten daher vor der Untersuchung abgesetzt werden.

Weitere Details zur Durchführung und Auswertung unspezifischer bronchialer Provokationen sind den Empfehlungen der DGP zu entnehmen. Unsere eigenen Untersuchungen zeigen, dass Spezifität und Sensitivität des Provokationstests durch Messung zweier unabhängiger obstruktiver Parameter $\left(\mathrm{FEV}_{1}\right.$ und $\left.\mathrm{R}_{\mathrm{aw}}\right)$ erheblich zunimmt.

\section{Spezifische Provokationstests}

In Einzelfällen ist die Diagnose mit den oben beschriebenen Verfahren nicht eindeutig zu sichern. In diesen Fällen ist die Durchführung einer Allergenprovokation an den betroffenen Organen indiziert. Eine weitere Indikation bilden rechtliche Fragen im Rahmen von gutachterlichen Stellungnahmen.

Je nach Fragestellung wird hierbei zwischen bronchialer, nasaler, konjunktivaler und gastrointestinaler Provokation unterschieden. Eine Übersicht der spezifischen Provokationsverfahren gibt •Tab.3.7. Das Prinzip der Methode beruht auf der schrittweisen Exposition des zu untersuchenden Organs mit zunehmenden Konzentrationen bzw. Mengen des jeweiligen Allergens. Die Provokationsuntersuchung bedarf einer kontinuierlichen ärztlichen Überwachung einschließlich einer mehrstündigen Nachbeobachtung sowie der Möglichkeit einer intensivmedizinischen Betreuung.

\section{Bronchoskopie, bronchoalveoläre Lavage und transbronchiale Biopsie}

Mittels Bronchoskopie lassen sich Atemwegsgewebe (Bronchialbiopsien) und -zellen (Bürste), Lungengewebe (transbronchiale Biopsie) sowie bronchoalveoläre Zellen (bronchoalveoläre Lavage) gewinnen. Die Bronchoskopie im Rahmen allergischer Erkrankungen ist auf bestimmte Fragestellungen begrenzt. $\mathrm{Zu}$ den Indikationen gehören:

- differenzialdiagnostischer Ausschluss interstitieller, infektiöser und maligner Lungenkrankheiten,

- Diagnostik im Rahmen der exogen-allergischen Alveolitis,

- therapeutische Lavage bei Verlegung der Atemwege durch eingedickten Mukus (Status asthmaticus, allergische bronchopulmonale Aspergillose),

- differenzialdiagnostische Abgrenzung zwischen Asthma bronchiale und anderen obstruktiven und nicht obstruktiven Erkrankungen (nur selten erforderlich),

- gezielte wissenschaftliche Fragestellungen. 
- Tab. 3.7.Zusammenstellung der spezifischen Provokationsverfahren bei allergischen Erkrankungen

\begin{tabular}{|c|c|c|c|}
\hline Organ/Name & Indikation & Prinzip/Substanz & Kriterien/Parameter \\
\hline $\begin{array}{l}\text { Bronchiale } \\
\text { Provokation }\end{array}$ & $\begin{array}{l}\text { Asthma } \\
\text { bronchiale }\end{array}$ & $\begin{array}{l}\text { Inhalation mit steigenden Mengen } \\
\text { an Typ-I-Allergenen }\end{array}$ & $\begin{array}{l}\text { Die zu einem } 20 \% \text {-Abfall der } \mathrm{FEV}_{1} \text { führende Allergen- } \\
\text { menge }\left(\mathrm{PD}_{20}\right)\end{array}$ \\
\hline $\begin{array}{l}\text { Parenchymale } \\
\text { Provokation }\end{array}$ & $\begin{array}{l}\text { Exogen-aller- } \\
\text { gische Alveolitis }\end{array}$ & $\begin{array}{l}\text { Inhalative Exposition mit dem } \\
\text { vermuteten Antigen }\end{array}$ & $\begin{array}{l}\text { Mehrere der folgenden Symptome: } \\
\text { - allgemeine Krankheitssymptome } \\
\text { - Zunahme der Körpertemperatur um } \geq 1{ }^{\circ} \mathrm{C} \\
\text { - Dyspnoe, Blutgase } \\
\text { - BSG-Anstieg }>20 \mathrm{~mm} \\
\text { - Leukozytose }>2,5 \times 10^{9} \\
\text { - Abfall der TLC und IVC } \\
\text { - Abfall des DLCO }>15 \%\end{array}$ \\
\hline $\begin{array}{l}\text { Nasale } \\
\text { Provokation }\end{array}$ & Rhinitis allergica & $\begin{array}{l}\text { Nasale Applikation des Typ-I-Aller- } \\
\text { gens in steigender Mengen }\end{array}$ & $\begin{array}{l}\text { Die zu } 2 \text { der folgenden Symptome führende Allergen- } \\
\text { menge: } \\
\text { - } \geq 3 \text { Punkte im Symptomenscore und/oder } \\
-50 \% \text { Abnahme der maximalen nasalen Flussrate }\end{array}$ \\
\hline $\begin{array}{l}\text { Konjunktivale } \\
\text { Provokation }\end{array}$ & $\begin{array}{l}\text { Conjunctivitis } \\
\text { allergica }\end{array}$ & $\begin{array}{l}\text { Eintropfen steigender Mengen an } \\
\text { Typ-I-Allergenen in die Konjunktiva }\end{array}$ & $\begin{array}{l}\text { Die Allergenmenge, die zu folgenden Symptomen führt: } \\
\text { - Rötung } \\
\text { - Pruritus } \\
\text { - Tränenfluss }\end{array}$ \\
\hline \multirow[t]{2}{*}{$\begin{array}{l}\text { Orale } \\
\text { Provokation }\end{array}$} & $\begin{array}{l}\text { Aspirin- } \\
\text { intoleranz }\end{array}$ & $\begin{array}{l}\text { Einnahme steigender Mengen an } \\
\text { Aspirin }\end{array}$ & $\begin{array}{l}\text { - ein } 20 \%-\text { FEV }_{1} \text {-Abfall } \\
\text { - } 100 \% \mathrm{R}_{\text {aw }} \text {-Anstieg } \\
\text { - nasookuläre Reaktionen }\end{array}$ \\
\hline & $\begin{array}{l}\text { Nahrungsmittel- } \\
\text { allergie }\end{array}$ & $\begin{array}{l}\text { Platzierung von definierten Mengen } \\
\text { an Nahrungsmitteln in den Magen- } \\
\text { darmtrakt }\end{array}$ & $\begin{array}{l}\text { Die Allergendosis, die zu folgenden Symptomen führt: } \\
\text { - Koliken } \\
\text { - Meteorismus } \\
\text { - Emesis } \\
\text { - Urtikaria } \\
\text { - Diarrhoe etc. }\end{array}$ \\
\hline
\end{tabular}

FEV ${ }_{1}$ absolute exspiratorische Sekundenkapazität, TLC Totalkapazitat der Lunge, IVC inspiratorische Vitalkapazität, DLCO Diffusionskapazität der Lunge, gemessen mit der CO-Einatemzugtechnik, $R_{a w}$ Atemwegswiderstand

Die hierfür erforderlichen Vorsichtsmaßnahmen sind detailliert in den Empfehlungen der DGP dargestellt.

\subsubsection{Diagnostisches Vorgehen}

Das diagnostische Vorgehen bei Verdacht auf eine allergische Erkrankung beruht auf der Durchführung allgemeiner und spezieller diagnostischer Methoden. Zur allgemeinen Diagnostik gehören Anamnese, körperlicher Untersuchungsbefund, allgemeine Laboruntersuchungen und das konventionelle Thoraxröntgen. Die weiterführende spezielle Diagnostik umfasst spezielle gezielte Laboruntersuchungen (spezifisches IgE, ECP, Proliferationsteste etc.), Hautprovokationstests, die Lungenfunktionsuntersuchung sowie die unspezifische und spezifische inhalative Provokation. Ein mögliches Vorgehen ist in - Abb. 3.6 dargestellt. Je nach bereits vorliegenden Befunden sollte der Zugang modifiziert werden.

\subsubsection{Differenzialdiagnosen}

Differenzialdiagnostisch müssen Erkrankungen der Atemwege und des Lungenparenchyms berücksichtigt werden.

\section{Erkrankungen der Atemwege}

Vom eigentlichen Asthma abzugrenzen ist ein Spektrum von Erkrankungen, die alle mit einer Beteiligung der Atemwege einhergehen und andere beim Asthma vorkommende, pathophysiologische, laborchemische oder histologische Elemente aufweisen.

\section{Intrinsisches Asthma bronchiale}

Im Gegensatz zum allergischen Asthma bevorzugt das intrinsische Asthma bronchiale ein höheres Alter ( $>40$ Jahre) und entwickelt sich in den meisten Fällen nach einem respiratorischen Infekt. Eine allergische Diathese oder Vermehrung des Gesamt- bzw. spezifischen IgE lässt 


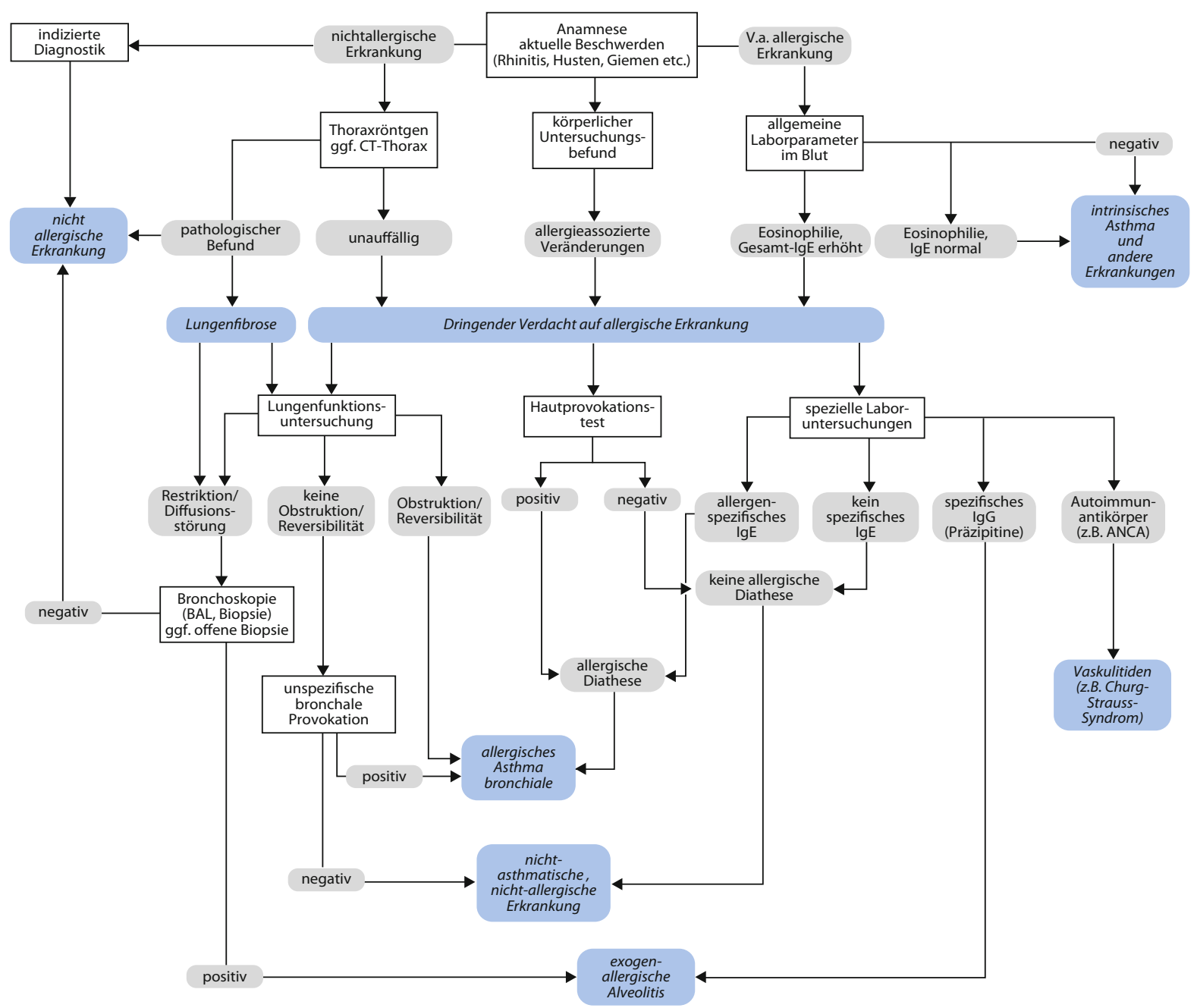

- Abb. 3.6. Algorithmus des praktischen Vorgehens bei Verdacht auf eine allergische Erkrankung. Eckige Kästen beziehen sich auf die diagnostischen Verfahren, runde und schattierte Kästen auf die möglichen Befunde

sich nicht nachweisen. Eine Polyposis nasi ist häufig. Im Vergleich zum allergischen Asthma ist die Eosinophilie im Allgemeinen stärker ausgeprägt und unterliegt ebenso wie die klinische Symptomatik keinen größeren jahreszeitlichen Schwankungen.

Während die immunologische Endstrecke in der Pathogenese beim intrinsischen und extrinsischen Asthma im Sinne einer von Eosinophilen dominierten Entzündung miteinander vergleichbar ist, scheinen sich jedoch die zentralen regulatorischen Immunprozesse beider Formen zu unterscheiden. So findet sich beim intrinsischen Asthma parallel zur fortbestehenden Bluteosinophilie eine auch im symptomarmen Intervall anhaltende Aktivierung der $\mathrm{CD}^{+}$- und $\mathrm{CD}^{+}$-T-Lymphozyten im Blut und in der BAL, die sich durch die Expression der IL-2R-, HLA-DR- und VLA-1-Oberflächenantigene äußert. Die intrinsische Form des Asthma bronchiale zeichnet sich ferner durch eine Umverteilung peripherer Lymphozyten in sog. »Memory«-T-Zellen (CD45R0) aus, die beim extrinsischen allergischen Asthma nicht nachweisbar ist.

Diese Beobachtungen deuten auf einen pathogenetischen Unterschied zwischen extrinsischem und intrinsischem Asthma bronchiale hin. Es wird spekuliert, dass das intrinsische Asthma bronchiale ätiologisch auf eine autoimmunologische Entzündung, z. B. gegen ein bislang nicht definiertes Antigen in der Bronchialschleimhaut, zurückgeht.

\section{Eosinophilenassoziierte pulmonale Krankheiten}

Erkrankungen mit Blut- und Atemwegseosinophilie finden sich bei allen mit Eosinophilen assoziierten pulmonalen Krankheiten wie dem Löffler-Syndrom, der chronischen eosinophilen Pneumonie, der tropischen Eosinophilie, der allergisch bronchopulmonalen Aspergillose 
oder dem Churg-Strauss-Syndrom. Alle aufgeführten Erkrankungen können histopathologisch mit einer eosinophilen Bronchitis und der Ausbildung einer bronchialen Hyperreagibilität sowie der hiermit assoziierten asthmatischen Symptomatik einhergehen. Zudem findet sich beim Churg-Strauss-Syndrom auch eine meist sehr deutliche Vermehrung der Gesamt-IgE-Konzentration im Serum, ein Umstand, der die Abgrenzung zum extrinsischen Asthma zusätzlich erschwert.

Im Gegensatz zum klassischen Asthma kommt es jedoch im Rahmen der oben genannten Erkrankungen auch zu einer parenchymalen Beteiligung mit zumeist wechselnden interstitiellen Infiltraten, die radiologisch als flaue, sich in Ausdehnung und Lokalisation ändernde Verschattungen imponieren.

\section{Chronisch-obstruktive Bronchitis}

Die in der Praxis häufigste und schwierigste Differenzialdiagnose des Asthma bronchiale bildet die chronischobstruktive Bronchitis mit oder ohne Emphysem. Hierbei handelt es sich um eine unspezifische Reaktion des Bronchialsystems auf eine langjährige Inhalation von Umweltnoxen, wobei hierbei eine langjährige Tabakrauchinhalation ätiologisch meist im Vordergrund steht.

Die Erkrankung beginnt als einfache chronische Bronchitis mit Mukushypersekretion und kann sich allmählich zur chronisch-obstruktiven Lungenerkrankung entwickeln. Im fortgeschrittenen Stadium kommt es bei einer Untergruppe dieser Patienten zu irreversiblen emphysematösen Lungenstrukturveränderungen (zentrilobuläres Emphysem) mit pulmonaler Hypertonie und Cor pulmonale (s. auch $\bullet$ Kap. 7.2). Welche endogenen Faktoren für die Emphysementwicklung eine Rolle spielen, ist bisher nicht bekannt.

Im Gegensatz zur chronisch-obstruktiven Bronchitis wird beim Asthma bronchiale kein Emphysem gefunden. Die wichtigsten Unterschiede zwischen dem allergischen Asthma bronchiale und der chronisch-obstruktiven Bronchitis sind in - Tab. 3.8 zusammengestellt.

\section{Sarkoidose}

Obwohl primär eine Erkrankung des Interstitiums, kann die Sarkoidose in fast der Hälfte der Fälle mit einer bronchialen Hyperreagibilität, Husten und Bronchialobstruktion einhergehen und sollte differenzialdiagnostisch in Betracht gezogen werden. Die Pathogenese der bronchialen Hyperreagibilität ist Ausdruck einer granulomatösen Atemwegsbeteiligung im Rahmen der Grunderkrankung (s. - Kap. 8.7).

\section{GERD-Syndrom}

Unter der gastroösophagealen Refluxkrankheit ("gastroesophagel reflux disease«; GERD) versteht man unspezifische pulmonale Beschwerden, die durch einen gast- roösophagealen Reflux (GER) ausgelöst werden. Zu den möglichen Erkrankungen gehören unter anderem Laryngitis, Pharyngitis, intermittierender nächtlicher Husten, Aspirationspneumonie und Asthma. Zwei zur Bronchokonstriktion führende Pathomechanismen des GERDassoziierten Asthmas werden derzeit diskutiert:

- GER-induzierter vagaler ösophagobronchialer Reflex und

- Atemwegsentzündung durch Mikroaspiration von Mageninhalt.

- Tab. 3.8. Charakteristische Unterschiede zwischen allergischem Asthma bronchiale und chronisch-obstruktiver Bronchitis (COPD) mit oder ohne Emphysem

\begin{tabular}{|l|l|l|}
\hline Charakterstika & COPD & $\begin{array}{l}\text { Extrinsisches } \\
\text { Asthma }\end{array}$ \\
\hline Klinik
\end{tabular}

\begin{tabular}{|c|c|c|}
\hline Beginn mit $<40$ Jahren & - & +++ \\
\hline Beginn mit $>40$ Jahren & ++ & - \\
\hline Beginn plötzlich & - & + \\
\hline Raucheranamnese & +++ & - \\
\hline Atopische Diathese & - & +++ \\
\hline Bluteosinophilie & - & ++ \\
\hline Erhöhtes IgE & - & +++ \\
\hline
\end{tabular}

\begin{tabular}{lll}
\hline Rekurrierende Symptomatik & + & +++ \\
\hline Rhinitis/Sinusitis & - & +
\end{tabular}

\begin{tabular}{l|ll}
\hline Polyposis nasi & - & + \\
\hline
\end{tabular}

\begin{tabular}{|c|c|c|}
\hline \multicolumn{3}{|l|}{ Pathophysiologie } \\
\hline Bronchiale Hyperreagibilität & + & +++ \\
\hline Komplette Reversibilität & + & +++ \\
\hline Teilreversibilität & + & ++ \\
\hline
\end{tabular}

Pathologie

\begin{tabular}{l|ll}
\hline Parenchymdestruktion & ++ & - \\
\hline Eosinophile Bronchitis & - & ++ \\
\hline Peribronchiale Fibrose & ++ & ++ \\
\hline Bronchialer Mukusausguss & ++ & ++ \\
\hline Sputum/BAL-Zytologie & & \\
\hline Eosinophilie & $-^{*}$ & ++ \\
\hline Neutrophilie & ++ & $-^{* *}$
\end{tabular}

- nicht vorhanden, + kommt selten vor, ++ wird häufiger beobachtet, +++ fast in allen Fällen nachweisbar, ${ }^{*}$ bei Exazerbationen nachweisbar, ${ }^{* *}$ im Rahmen bakterieller Exazerbationen nachweisbar 
Die Diagnosestellung gestaltet sich häufig schwierig (pHMonitoring, Szintigraphie, Bariumbreischluck). Die Therapie kann konservativ (>3 Monate Omeprazol) oder chirurgisch erfolgen, ohne dass in jedem Fall die Symptome vollständig zurückgehen.

\section{"Reactive airway distress syndrome»}

Unter "reactive airway distress syndrome« (RADS) versteht man eine an Asthma erinnernde Erkrankung, die sehr schnell innerhalb von $24 \mathrm{~h}$ nach einer kurzzeitigen, aber intensiven oder wiederholten Inhalation durch unspezifische inhalative Noxen (Rauch, toxische Gase etc.) entsteht. Sie führt zu einer unspezifischen Entzündung der Atemwege mit Zerstörung des Oberflächenepithels und Entwicklung einer bronchialen Hyperreagibilität. Die Erkrankung bildet sich in einigen Fällen wieder zurück. Sie kann aber auch über Jahre anhaltende Beschwerden verursachen.

\section{Krupp}

Krupp ist ein akutes klinisches Syndrom von Säuglingen und jungen Kindern, das sich durch inspiratorischen Stridor, bellenden Husten, Heiserkeit und Dyspnoe äußert. Die Erkrankung geht in der Regel auf einen viralen Atemwegsinfekt zurück, der zu einer laryngealen und trachealen Entzündung mit Obstruktion führt.

\section{Erkrankungen des Lungenparenchyms}

Der Prototyp der allergischen Parenchymerkrankung ist die exogen-allergische Alveolitis, die mit einer chronischen interstitiellen Entzündung durch Kontakt mit organischen Stäuben entsteht. Hiervon differenzialdiagnostisch abzugrenzen sind andere interstitielle Erkrankungen wie idiopathische pulmonale Fibrose (IPF), Sarkoidose, Kollagenosen mit Lungenbeteiligung (Sklerodermie, Anti-Jo-1-Syndrom etc.), allergische bronchopulmonale Aspergillose sowie die Gruppe der mit Eosinophilen assoziierten pulmonalen Parenchymerkrankungen.

\section{Granulomatöse Erkrankungen}

Granulomatöse Erkrankungen manifestieren sich meist im interstitiellen Lungengewebe und führen im fortgeschrittenen Stadium zu einer restriktiven Ventilationsstörung. Während der Berylliose eine allergische Reaktion vom Typ V zugrunde liegt, ist die Pathogenese der Sarkoidose trotz der klinischen und histopathologischen Ähnlichkeiten beider Erkrankungen nicht bekannt. Gelegentlich tritt im Rahmen der Sarkoidose eine bronchiale Hyperreagibilität, Husten und Obstruktion auf.

\section{Idiopathische pulmonale Fibrose}

Die idiopathische pulmonale Fibrose (IPF) oder kryptogene fibrosierende Alveolitis ist eine chronisch ent- zündliche Lungenparenchymerkrankung unbekannter Ätiologie, die im Verlauf zu einem diffusen fibrotischen Umbau und einer irreversiblen Destruktion der normalen Lungenarchitektur führt. Klinisch, radiologisch und histologisch gleicht die IPF den Kollagenosen mit Lungenbeteiligung. Auch die fortgeschrittene Sarkoidose, Berylliose und chronisch verlaufende EAA ist differenzialdiagnostisch abzugrenzen. Die Möglichkeiten zur Behandlung der IPF sind begrenzt und die Prognose ungünstig (s. auch $>$ Kap. 8.2).

\section{Kollagenosen}

Die heterogene Gruppe der autoimmunologischen Erkrankungen des Bindegewebes gehen vergleichsweise häufig mit einer Lungenbeteiligung einher. Das gilt insbesondere für die Sklerodermie, Polymyositis (Jo-1-Syndrom), rheumatoide Arthritis, das Sjögren-Syndrom und den systemischen Lupus erythematodes (s. auch $>$ Kap. 8.3). Diese Erkrankungen sind differenzialdiagnostisch von einer fortgeschrittenen, chronisch verlaufenden EAA mit Lungenfibrose abzugrenzen.

\section{Erkrankungen der Nase und Orbita}

Die Rhinitis allergica, insbesondere die perenniale Form auf der Grundlage einer allergischen Diathese gegenüber Hausstaubmilben oder Haustieren (Katzen, Hunde), verursacht gelegentlich differenzialdiagnostische Probleme. Dabei sind folgende nichtallergische Rhinitiden $\mathrm{zu}$ erwägen.

\section{Infektiöse Rhinitis}

Infektiöse Rhinitiden können einen akuten oder chronischen Verlauf nehmen. Die chronische Form geht dabei am häufigsten auf eine Pilzbesiedlung oder eine Tuberkulose zurück. Chronische Infektionen der Nase manifestieren sich aber auch im Rahmen einer Immundefizienz (Hypogammaglobulinämie, IgA-Mangel oder Aids).

\section{Idiopathische Rhinitis}

Die idiopathische Form der Rhinitis bezeichnet eine heterogene Gruppe von Patienten mit nasaler Hyperreagibilität gegenüber unspezifischen Triggern, wie z. B. intensiven Gerüchen (Parfüme, Lösungsmittel etc.), Nikotinrauch sowie Wetter- und Temperaturwechsel, ohne erkennbare Ursache.

\section{Nichtallergische Rhinitis mit Eosinophiliesyndrom}

Die nichtallergische Rhinitis mit Eosinophiliesyndrom (NARES) ist durch eine nasale Eosinophilie mit perennialen rhinitischen Symptomen bei normalem IgE-Spiegel und negativem Hauttest charakterisiert. Sie tritt häufig bei jungen Frauen auf und spricht gut auf eine Behandlung mit topischen Kortikosteroiden an. 


\section{Humorale Rhinitis}

Hierbei handelt es sich um eine heterogene Form der Rhinitis, die bei Hypothyreose, Akromegalie oder während der Pubertät und der Schwangerschaft auftritt. Frauen in der Postmenopause entwickeln gelegentlich atrophische Veränderungen, ältere Männer eine wässrige Rhinorrhoe (»Old Man’s Drip«).

\section{Medikamenteninduzierte Rhinitis}

$\beta$-Blocker und ACE-Inhibitoren führen gelegentlich $\mathrm{zu}$ rhinitischen Beschwerden. Seltener beobachtet man einen Zusammenhang mit oralen Kontrazeptiva, Chlorpromazinen, Aspirin und anderen nichtsteroidalen Analgetika.

\section{Polyposis nasi}

Nasale Polypen entstehen durch eine Entzündung als Prolaps der Schleimhautbegrenzung des Sinus (vor allem des anterioren ethmoidalen Sinus) und führen zur nasalen Obstruktion. Allergien spielen hierbei nur selten eine Rolle. Allerdings ist das Vorkommen von nasalen Polypen mit dem intrinsischen Asthma bronchiale und der Aspirinintoleranz assoziiert (Samter-Triade).

\section{Granulomatöse Rhinitis}

Rhinitische Symptome können sich auch im Rahmen eines Morbus Wegener oder einer Sarkoidose entwickeln.

\section{Hereditäres Angioödem}

Das hereditäre Angioödem geht mit einer schmerzlosen Schwellung des Gesichts und der Extremitäten ohne Pruritus oder Erythem einher. Grundlage dieser Beschwerden ist ein angeborener C1-Esterase-Inhibitor-(INA-) Mangel (Typ I) oder eine Proteindysfunktion (Typ II). Als Auslöser gelten emotionale Belastungen oder Traumata. Eine allergologische Ursache im engeren Sinn ist nicht festzustellen.

\subsection{Monitoring allergischer Erkrankungen}

Zum Monitoring allergischer Erkrankungen unter Therapie eignen sich:

- einfach zu messende Lungenfunktionsparameter $\left(\mathrm{FEV}_{1}\right.$, exspiratorischer Spitzenfluss=Peak flow $)$,

- die Bestimmung der unspezifischen bronchialen Hyperreagibilität,

- bestimmte laborchemische Parameter.

Während $\mathrm{FEV}_{1}$ oder PEF-Veränderungen als Nachweis einer bestehenden Obstruktion interpretiert werden können, lassen die bronchiale Hyperreagibilität bzw. Hypersensitivität sowie die Laborparameter Rückschlüsse auf die entzündliche Aktivität der Erkrankung zu.

\section{Lungenfunktionsparameter}

Ohne die objektive Bestimmung der Lungenfunktion lässt sich weder von Seiten des Patienten noch des Arztes der Grad der Atemwegsobstruktion verlässlich abschätzen. So können sich Patienten selbst mit signifikanter Obstruktion durchaus noch wohlfühlen. Ebenso ist der typische Auskultationsbefund einer Atemwegsobstruktion in Form trockener Nebengeräusche nicht immer zu erheben, selbst bei schwerer Obstruktion (»silent lung«).

Die Spirometrie stellt aufgrund ihrer guten Reproduzierbarkeit nach wie vor die verlässlichste Methode zur Objektivierung der Atemwegsobstruktion dar. Für eine tägliche Überprüfung im Sinne eines Monitoring ist die spirometrische Erfassung der Lungenfunktion jedoch ungeeignet. Hierfür bietet sich die Verwendung des Peak-flow-Meters an, mit dem sich der maximale Exspirationsfluss ermitteln lässt. Obwohl im Hinblick auf die Reproduzierbarkeit und Genauigkeit die mit dem Peak-flow-Meter gemessenen Werte nicht mit den spirometrisch ermittelten Parametern vergleichbar sind, bietet das Peak-flow-Meter jedoch aufgrund seiner Größe und der einfachen Handhabung sowie der vergleichsweise niedrigen Anschaffungskosten Vorteile.

In den meisten Fällen korrelieren FEV $_{1}$ und PEF gut miteinander. Es gibt jedoch 2 Ausnahmen, bei denen die tatsächliche Atemwegsobstruktion durch die Durchführung eines Peak-flow-Manövers über- oder unterschätzt wird:

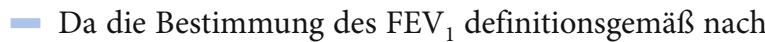
$1 \mathrm{~s}$ erfolgt, der maximale exspiratorische Fluss aber bereits innerhalb der ersten $150 \mathrm{~ms}$ erreicht wird, erfasst der PEF-Wert bevorzugt die Obstruktion größerer Atemwege.

- Einzelne Peak-flow-Meter überschreiten die empfohlene Messvariation von $10 \%$, sodass es auch hier je nach Produkt und Hersteller zu einer Über- bzw. Unterschätzung kommen kann. Da diese Unterschiede vom jeweiligen Produkt abhängen, sollte beim Monitoring immer das gleiche Gerät Verwendung finden. Zudem sollten die PEF-Bestimmungen im Rahmen von ambulanten Kontrolluntersuchungen regelmäßig mit den spirometrisch ermittelten Werten verglichen werden.

Unter den oben genannten Einschränkungen bildet das Peak-flow-Meter in der Mehrzahl der Fälle jedoch eine nützliche Hilfe bei der Verlaufsbeobachtung der asthmatischen Atemwegsobstruktion. Allmählich von den maximal erreichbaren Ausgangswerten nach unten abweichende PEF-Werte müssen als Ausdruck einer zunehmenden Obstruktion im Rahmen einer bevorstehenden Exazerbation gewertet werden.

Ein anderer Hinweis auf eine bevorstehende Exazerbation eines Asthma bronchiale bildet die Variation 
der PEF-Werte (PEF-Variabilität) innerhalb eines Tages (zirkadiane Rhythmik). Sie lässt sich als Quotient aus $\mathrm{PEF}_{\max }-\mathrm{PEF}_{\min }$ und $\mathrm{PEF}_{\max }-100$ errechnen und beträgt bei einem gut eingestellten Asthma bronchiale weniger als $10 \%$. Eine Zunahme der täglichen PEF-Variabilität sollte ebenso wie eine Abnahme der absoluten PEF-Werte zu einer weiteren Abklärung und ggf. zu entsprechenden therapeutischen Maßnahmen führen.

\section{Bronchiale Hyperreagibilität}

Die entzündliche Aktivität der Erkrankung lässt sich entweder indirekt durch Erfassung der bronchialen Hyperreagibilität oder direkt durch bestimmte zelluläre oder humorale Laborparameter ermitteln. Die bronchiale Entzündung wird nicht nur mit der Entwicklung der bronchialen Hyperreagibilität in Verbindung gebracht, sondern es besteht auch eine Beziehung zwischen der Entzündungsaktivität des Asthmas und dem Ausmaß der bronchialen Hyperreagibilität ( Kap. 3.2.2). Als Parameter für die individuelle Ausprägung der bronchialen Hyperreagibilität lässt sich die Konzentration der zur Provokation verwendeten Substanz (Histamin, Carbachol, Metacholin) heranziehen, die zu einem 20\%-Abfall der FEV führt $_{1}$ $\left(\mathrm{PD}_{20}\right)$.

Die unspezifische bronchiale Hyperreagibilität sollte unter einer konsequenten antientzündlichen Behandlung allmählich abnehmen. Sowohl inhalative bzw. orale Kortikosteroide als auch Nedocromil und DNCG vermindern die unspezifische bronchiale Hyperreagibilität im Rahmen eines Asthma bronchiale.

\section{Entzündungsparameter}

Während eine signifikante Abnahme der bronchialen Hyperreagibilität erst nach Wochen bis Monaten nachweisbar ist, lassen bestimmte Laborparameter eine unmittelbare Beurteilung der antientzündlichen Therapie zu. Von den verschiedenen bisher untersuchten Parametern (Eosinophilenzahl, Produkte des Eosinophilen und der Mastzelle, Zytokine, lösliche Adhäsionsmoleküle, Stickstoffmonoxid im Exhalat) kommt nach praktischen und ökonomischen Gesichtspunkten der Ermittlung der Eosinophilenzahl im Blut oder im Sputum die größte Bedeutung zu.

Die Sputum- und Bluteosinophilenzahl ist bei Asthmatikern im Vergleich zu Gesunden und Patienten mit chronischer Bronchitis erhöht. Eine Vermehrung der Zellzahlen beobachtet man ferner im Rahmen von Exazerbationen des Asthma bronchiale. Darüber hinaus besteht eine Korrelation zwischen der Eosinophilenzahl, dem Grad der bronchialen Hyperreagibilität und der $\mathrm{FEV}_{1}$-Variation. Die Zahl an Eosinophilen im Sputum sollte unter einer adäquaten Behandlung abfal- len und die Zellen idealerweise nicht mehr nachweisbar sein.

\section{Eosinophiles kationisches Protein}

Auch die Konzentrationsbestimmung basischer Proteine aus den spezifischen Granula eosinophiler Granulozyten im Blut und Sputum, wie z. B. des ECP, stellt heute einen vergleichbar einfach messbaren und hilfreichen Parameter dar. Inter- bzw. intraindividuelle Schwankungen sind jedoch groß und erhöhte Serum-ECP-Konzentrationen finden sich neben dem Asthma auch bei Patienten mit Mukoviszidose, Bronchiektasen und Bronchialkarzinom sowie bei atopischer Dermatitis. Sofern diese Erkrankungen differenzialdiagnostisch ausgeschlossen sind, ist die Bestimmung des ECP ein durchaus nützlicher Parameter, der über die Eosinophilenzahl hinaus vermutlich auch den Grad der Zellreaktivität erfasst.

Grundsätzlich gilt auch für das ECP, dass der Parameter nach Beginn einer wirkungsvollen antientzündlichen Therapie abfallen sollte. Je höher der Ausgangswert, um so deutlicher stellt sich dabei die nachweisbare Konzentrationsabnahme dar.

\section{Stickstoffmonoxid}

In den vergangen Jahren haben verschiedene Studien zeigen können, dass sich die Konzentration des Stickstoffmonoxids (NO) in der Ausatemluft als nichtinvasiver Biomarker der asthmatischen Entzündung eignet. NO wird von allen Zellen der Atemwege freigesetzt, wenngleich das Atemwegsepithel den größten Anteil bildet. Die Messung selbst ist vergleichsweise einfach und unter standardisierten Bedingungen gut reproduzierbar, sofern Beimengungen nasalen Ursprungs vermieden werden. Allerdings sind die Kosten für das Analysegerät nicht unerheblich.

NO findet sich im Gegensatz zu anderen obstruktiven Atemwegserkrankungen (chronisch-obstruktive Bronchitis, Mukoviszidose) beim Asthma in erhöhten Konzentrationen im Exhalat. Nach Allergenprovokation steigt die NO-Konzentration während der asthmatischen Spätreaktion an. Unter antientzündlicher Therapie mit Kortikosteroiden nimmt die Konzentration wieder ab. Erhöhte NO-Konzentrationen finden sich jedoch auch bei Rauchern und im Rahmen respiratorischer Infekte.

\section{Weitere Entzündungsparameter}

Eine Reihe anderer Parameter zur Erfassung der entzündlichen Aktivität und zum Monitoring allergischer Atemwegserkrankungen wird im Hinblick auf Sensitivität und Spezitivität gegenwärtig untersucht. Hierzu gehören beispielsweise S-Nitrosothiol im induzierten Sputum, Pentan im Exhalat oder Leukotrien $\mathrm{E}_{4}$ im Exhalat bzw. Urin. Es bleibt abzuwarten, ob sich ein weiterer Entzündungsparameter für den Routinegebrauch durchsetzt. 


\subsection{Therapie}

\subsubsection{Allgemeine therapeutische Maßnahmen}

Eine Anzahl allgemeiner Maßnahmen kann die individuellen Beschwerden und den chronischen Verlauf einer allergischen Erkrankung günstig beeinflussen und erlaubt ggf. eine Reduktion der antientzündlichen Therapie. Hierzu gehören vor allem präventive Maßnahmen wie die Vermeidung des ursächlich verantwortlichen Allergens und die Patientenschulung. Die Wirksamkeit jeder antiallergischen Therapie ist begrenzt, solange die Exposition mit den potenziell auslösenden Faktoren fortbesteht.

\section{Prävention}

Präventive Maßnahmen zur Verhinderung oder Reduktion allergischer Erkrankungen lassen sich in primäre und sekundäre Maßnahmen unterteilen. Unter der sekundären Prävention versteht man Maßnahmen zur Vermeidung von Exazerbationen bzw. der klinischen Verschlechterung der Erkrankung bei Patienten mit bereits bestehender Allergie. Hierauf wird in $>$ Kap. 3.4.3 näher eingegangen. Demgegenüber sucht die primäre Prävention, die Entwicklung der Erkrankung a priori zu verhindern.

\section{Primäre Prävention}

Zur primären Prävention gehören Maßnahmen zur Allergenvermeidung innerhalb und außerhalb des Hauses sowie am Arbeitsplatz, zur Reduktion von Infektionen, zum Expositionsschutz gegenüber inhalativen Noxen, zur
Vermeidung eines niedrigen Geburtsgewichts und zur Sicherstellung einer natürlichen Ernährung einschließlich des Stillens (•Tab. 3.9).

Die Bedeutung einzelner Aspekte für die allgemeine Bevölkerung oder für Kinder mit erhöhtem Risiko ist nach wie vor nicht ausreichend bekannt. Hierzu gehört auch die aktuelle Diskussion über die Bedeutung der Omega-6-(n-6)-Fettsäuren (in Margarine) für die Entwicklung allergischer Erkrankungen. Die Reduktion der häuslichen Milbenkonzentration ebenso wie die mütterliche Laktation scheinen dagegen einen gesicherten präventiven Einfluss zu besitzen und sollten heute bei Kindern allergischer Eltern berücksichtigt werden.

\section{Sekundäre Prävention (Allergenkarenz)}

Die Vermeidung einer Allergenexposition spielt bei Patienten mit bestehender allergischer Erkrankung eine wesentliche Rolle im Rahmen des gesamten Therapiekonzepts. Soweit möglich sollten hierbei die eingeleiteten Maßnahmen alle relevanten Allergene einbeziehen.

Vergleichsweise einfach sind solche Maßnahmen bei berufsbedingtem Asthma durch einen Arbeitsplatz- oder Berufswechsel (Bäcker, Müller, landwirtschaftliche Berufe, chemisch-pharmazeutische Industrie, Medizin) umzusetzen. Aber auch sonst gibt es Möglichkeiten, z. B. bei Hausstaubmilbenallergie (trockene Schlafzimmerluft die keine Milbenvermehrung erlaubt, spezielle Überzüge für Betten, Matratzen und Kopfkissen, Vermeidung von Polstermöbeln, Teppichen und anderen staubtragenden Stoffen; s. Übersicht). Bei einer Haustierallergie ist das konsequente Entfernen des jeweils verantwortlichen Tieres aus der Wohnung indiziert.

- Tab. 3.9. Maßnahmen zur primären Prävention allergischer Erkrankungen

\begin{tabular}{|c|c|c|}
\hline Faktor & Risikobedingung & Maßnahmen \\
\hline $\begin{array}{l}\text { Häusliche Allergen- } \\
\text { belastung }\end{array}$ & Grad der Allergenbelastung & $\begin{array}{l}\text { Lüften, Feuchtigkeit reduzieren (Lufttrockner), Entfernen von } \\
\text { Teppichen oder gepolstertem Mobiliar, Encasing von Matratze, } \\
\text { Kopfkissen und Oberbett, keine Pflanzen, keine Haustiere }\end{array}$ \\
\hline $\begin{array}{l}\text { Berufliche Allergen- } \\
\text { belastung }\end{array}$ & $\begin{array}{l}\text { Expositionsdauer und Intensität mit } \\
\text { Sensitizern }\end{array}$ & Gezielte Berufswahl, adäquater Arbeitsschutz \\
\hline Umweltnoxen & $\begin{array}{l}\text { Staub- und Schadstoffe, wie } \mathrm{NO}, \mathrm{SO}_{2} \\
\text { etc. }\end{array}$ & $\begin{array}{l}\text { Verlegung der Wohnung in Gebiete ohne Industrie und dichte } \\
\text { Verkehrsanbindung }\end{array}$ \\
\hline Tabakrauchexposition & Aktiv- u. Passivrauchen & Reduzieren bzw. Eliminieren vor allem vor und nach Geburt \\
\hline Schwangerschaft & Geburtsgewicht $<2.500 \mathrm{~g}$ & $\begin{array}{l}\text { Vermeidung von Frühgeburten, Nikotin- und Alkoholabstinenz, } \\
\text { ausgewogene Ernährung }\end{array}$ \\
\hline Infektionen & $\begin{array}{l}\text { Respiratorische Virusinfekte, Bron- } \\
\text { chiolitis durch »respiratory syncytial } \\
\text { virus« (RSV) }\end{array}$ & $\begin{array}{l}\text { Ausgeglichene Ernährung, Stillen, Vakzination gegen RSV } \\
\text { (zukünftig) }\end{array}$ \\
\hline Ernährung & $\begin{array}{l}\text { Einseitige Ernährung, Verzicht auf } \\
\text { Muttermilchernährung }\end{array}$ & $\begin{array}{l}\text { Stillen, ausgewogene Ernährung, Vermeidung von n-6-Fettsäuren } \\
\text { (z. B. in Magarine)? }\end{array}$ \\
\hline
\end{tabular}


Eine Sonderstellung nimmt das Analgetikaasthma ein, bei dem Analgetika/Antiphlogistika (Cyclooxygenasehemmer!) weggelassen werden müssen. Selbstverständlich sollten soweit möglich auch alle anderen unspezifischen Auslöser gemieden werden, die auf der Basis der bronchialen Hyperreaktivität zu Asthmaanfällen führen, wie Staub, Rauch, Reizgase, aktives oder passives Rauchen.

Maßnahmen zur Minimierung der Hausstaubmilbenbelastung

- Obligate Maßnahmen:

- Einschlag von Matratzen (»encasing «) und Sprungfedern mit spezieller, milbendichter Bettwäsche (z. B. Polyurethanbeschichtung),

- Encasing von Kopfkissen und Oberbett mit spezieller, milbendichter Bettwäsche oder wöchentliches Waschen bei $60^{\circ} \mathrm{C}$,

- wöchentliches Waschen der Bettbezüge und Deckbezüge bei $60^{\circ} \mathrm{C}$,

- regelmäßige wöchentliche Lüftung unter der Matratze und dem Bett,

- Entfernung allen stoffbezogenen Mobiliars,

- Entfernung von Teppichen und Bettvorlegern jeglicher Art aus Schlafzimmer und Wohnung;

- wünschenswerte Maßnahmen:

- Reduktion der Feuchtigkeit in der Wohnung auf weniger als 50\% (regelmäßiges Lüften, keine Pflanzen, keine Luftbefeuchter etc.), Lufttrocknereinsatz im Schlafzimmer,

- Entfernung von Stofftieren aus dem Schlafzimmer,

- Reinigung von nicht entfernbaren Teppichen und des stoffbezogenen Mobiliar mit Mitiziden (Wirkung nicht bewiesen!),

- keine aktive Durchführung einer Staubsaugerreinigung oder Tragen einer Staubmaske und Benutzen eines besonders saugfähigen Geräts oder eines Geräts mit entsprechendem Filter,

- Aufenthalt in Räumen zum Zeitpunkt der Staubsaugerreinigung meiden.

\section{Patientenschulung}

Der Schulung des Patienten, ggf. mit Einbeziehung der Familie, kommt eine wesentliche Bedeutung bei der längerfristigen Kontrolle des Asthma oder anderer allergischer Erkrankungen zu. Ziel ist es, den Allergiker über die Krankheit und deren Ursachen aufzuklären und ihn auf diese Weise für eine qualifizierte Mitarbeit zu gewinnen. Wesentliche Ziele einer solchen Schulung sind:

- Vermittlung grundlegender Kenntnisse über die Ursachen, die Pathogenese, den Verlauf und die Gefahren der Erkrankung,
- Erreichen einer verbesserten Akzeptanz der Erkrankung mit größtmöglicher Eigenverantwortlichkeit,

- Verständnis der Therapiekonzepte für die Notfallund Langzeitbehandlung, einschließlich der Wirkmechanismen antiallergischer oder antientzündlicher Medikamente,

- Erlernen der richtigen Inhalationstechnik,

- Bewältigung der täglichen Anforderungen trotz der Erkrankung,

- Vermeidungmöglicher Anfallsursachen, einschließlich der sinnvollen Gestaltung von Freizeit und Urlaub,

- korrekte Einschätzung des Krankheitsverlaufs unter Nutzung des Peak-flow-Meters,

- rechtzeitiges Erkennen von drohenden Exazerbationen sowie die Möglichkeiten einer Anpassung der Arzneimitteldosierung, einschließlich der rechtzeitigen Kontaktaufnahme mit dem Arzt.

Die Schulung findet am günstigsten in der Gruppe statt, weil die Solidarisierung der Betroffenen und der Erfahrungsaustausch zwischen den Gruppenmitgliedern positiv wirken. Patientenschulungen werden in der Zwischenzeit in vielen Zentren von Ärzten, Krankenschwestern bzw. Pflegern, Arzthelferinnen, Pädagogen und Psychologen angeboten. Dabei bemüht sich die Sektion Prävention und Rehabilitation der DGP um eine qualitative Optimierung der Schulung durch »Train-theTrainer-Seminare

\subsubsection{Spezifische Immuntherapie (Hyposensibilisierung)}

Die spezifische Immuntherapie (Desensibilisierung, Hyposensibilisierung) als kausale Behandlung allergischer Erkrankungen geht auf Noon und Freeman zurück, die bereits 1911 am St. Mary's Hospital in London die ersten Hyposensibilisierungen durchführten. Seither haben verschiedene kontrollierte Studien, meistens mit einem einzigen Allergen, gezeigt, dass die Hyposensibilisierung der allergischen Rhinokonjunktivitis die Beschwerden lindert. Die Studien zeigen auch, dass bei adäquater Dosierung und konsequenter Durchführung eine signifikante Reduktion der Beschwerden gelingt.

Im Gegensatz zur allergischen Rhinokonjunktivitis ist der Einsatz der spezifischen Immuntherapie beim Asthma bronchiale Gegenstand kontroverser Diskussion. Entsprechend den aktuellen Leitlinien der DGAI, des ÄDA und der GPA von 2006 ist beim intermittierenden und geringgradig-persistierenden, IgE-vermittelten allergischen Asthma die spezifische Immuntherapie (SLIT) gut untersucht und als Therapieoption neben Allergenkarenz und der Pharmakotherapie zu empfehlen. Eine frühzeitige spezifische Immuntherapie ist zu- 
dem unter präventiven Aspekten durchzuführen, um das Risikos, ein Asthma zu entwickeln (Etagenwechsel), und ein Zunehmen des Sensibilisierungsspektrums zu vermeiden.

Wegen der Möglichkeit von ernsten Nebenwirkungen (anaphylaktischer Schock, Asthmaattacke) sollte eine Hyposensibilisierungsbehandlung ausschließlich von erfahrenen Allergologen durchgeführt werden, die über ein entsprechend ausgebildetes Personal und eine intensivmedizinische Überwachungseinheit verfügen, um lebensbedrohlichen Reaktionen adäquat zu begegnen.

\section{Indikationen}

Grundsätzlich sollte eine Hyposensibilisierung in Erwägung gezogen werden, wenn

- eine Allergenkarenz nicht oder schwer möglich ist (z. B. gegenüber Pollen oder Hausstaubmilben),

- eine klare Beziehung zwischen Symptomen und der Exposition mit einem relevanten Allergen besteht (Provokationstestungen),

- eine IgE-vermittelte Sensibilisierung (Hauttest und In-vitro-Diagnostik) nachgewiesen ist,

- sich die Beschwerden nicht durch eine adäquate Therapie ausreichend kontrollieren lassen,

- standardisierte bzw. qualitativ hochwertige Allergenextrakte verfügbar sind und

- die Wirksamkeit einer geplanten Immuntherapie für die jeweilige Indikation nachgewiesen ist (mod. nach Kleine-Tebbe et al. 2000).

\section{Vorgehen}

Die klassische und verbreitetste Technik der Desensibilisierungsbehandlung basiert auf der regelmäßigen (meist wöchentlichen), streng subkutanen Applikation allmählich ansteigender Dosen des relevanten spezifischen Allergens bis zum Erreichen einer maximalen, vom Patienten individuell noch tolerierten Dosis. Diese maximale Allergenmenge wird dann in regelmäßigen Abständen (1-4 Wochen) verabreicht, um eine möglichst hohe kumulative Allergendosis zu erreichen. Die ganzjährige Behandlung, z. B. auch während der Pollensaison, ist daher einer präsaisonalen Behandlung überlegen.

Eine Modifikation der Hyposensibilisierungstechnik stellt die Rush- bzw. UltraRush-Desensibilisierung dar, bei denen mit Insektengiftextrakten in wässriger Lösung unter schneller Dosissteigerung mehrere Injektionen (meist 4) innerhalb weniger Stunden über einen Zeitraum von 8-10 Tagen vorgenommen werden.

Die aktuelle Leitlinie zur spezifischen Immuntherapie empfiehlt die sublinguale Allergenapplikation bei allergischer Rhinokonjunktivitis gegenüber Pollen bei
Erwachsenen dann, wenn eine subkutane Applikation nicht infrage kommt. Bei Hausstaubmilbenallergie bzw. allergischem Asthma durch Inhalationsallergene stellt die Sublinguale Immuntherapie (SLIT) keinen Ersatz für die Subkutane Immuntherapie (SCIT) dar. Eine regelmäßige Anwendung wird derzeit bei Kindern und Jugendlichen nicht empfohlen.

\section{Ziele und Wirkungsweise}

Das Ziel der Densibilisierungsbehandlung besteht darin, den Ablauf zugrunde liegender entzündlicher Prozesse und damit der allergischen Beschwerden zu reduzieren. Während noch in den 70er-Jahren ihre Wirkung auf die Bildung sog. blockierender allergenspezifischer IgGund $\mathrm{IgG}_{4}$-Antikörper zurückgeführt wurde, scheinen verschiedene andere Vorgänge ebenfalls von Bedeutung zu sein. Bei Patienten mit allergischer Rhinitis vermindert eine Hyposensibilisierung die Konzentration von Entzündungsmediatoren im Nasensekret, reduziert die Zahl sowie die Reaktivität eosinophiler Granulozyten und bessert die nasale Hyperreagibilität. Auch histologisch zeigt sich eine verminderte $\mathrm{Zahl}$ an aktivierten $\mathrm{EG}^{+}{ }^{+}$-Eosinophilen. Gleichzeitig nimmt die Reagibilität allergenspezifischer T-Zellklone (klonale Anergie) ab.

Andere Untersuchungen konnten zeigen, dass unter der Immuntherapie die Sekretion von IL-4 aus Lymphozyten abnimmt, sodass auch eine Verschiebung der TH-Differenzierung in Richtung des TH-1-Phänotyps als zugrunde liegender Mechanismus diskutiert wird (Immundeviation).

\subsubsection{Pharmakologische Behandlung}

Die medikamentöse Behandlung allergischer Erkrankungen beruht auf einer Palette von Medikamenten, die je nach vorliegender Organmanifestation und Schwere intravenös, systemisch oder topisch appliziert und in unterschiedlicher Form kombiniert werden (•Tab. 3.10). Nach der dominierenden pharmakologischen Wirkung lassen sich die Antiallergika willkürlich in 4 Gruppen unterteilen (-Tab. 3.11). Allerdings kommen Überschneidungen im Wirkmechanismus zwischen den Gruppen vor. Hierzu zählen Medikamente mit

- systemischer antiinflammatorischer Wirkung,

- topischer antiinflammatorischer Wirkung,

- überwiegend bronchodilatorischer Wirkung sowie einem schwachen antiinflammatorischen Effekt,

- bronchodilatorischer Wirkung ohne antiinflammatorischen Effekt.

Die verschiedenen Gruppen werden nachfolgend im Einzelnen erläutert. 
- Tab. 3.10. Zusammenfassung der Behandlungsmöglichkeiten allergischer Typ-I-Erkrankungen

\begin{tabular}{|c|c|c|c|c|c|}
\hline $\begin{array}{l}\text { Rhinitis } \\
\text { allergica }\end{array}$ & $\begin{array}{l}\text { Conjuctivitis } \\
\text { allergica }\end{array}$ & $\begin{array}{l}\text { Allergisches Asthma } \\
\text { bronchiale }\end{array}$ & Atopische Dermatitis & $\begin{array}{l}\text { Allergische } \\
\text { Gastroenteritis }\end{array}$ & Anaphylaxie \\
\hline $\begin{array}{l}\text { Allergen- } \\
\text { karenz }\end{array}$ & Allergenkarenz & Allergenkarenz & $\begin{array}{l}\text { Allergenkarenz, } \\
\text { Meidung von Hautir- } \\
\text { ritanzien (Wolle, sythe- } \\
\text { tische Fasern, Seife) }\end{array}$ & Allergenkarenz & $\begin{array}{l}\text { Allergenkarenz } \\
\text { (kann lebens- } \\
\text { rettend sein) }\end{array}$ \\
\hline $\begin{array}{l}\text { Antihistami- } \\
\text { nika oral oder } \\
\text { nasal (Spray) }\end{array}$ & $\begin{array}{l}\text { Antihistaminika } \\
\text { oral }\end{array}$ & $\begin{array}{l}\text { Bronchodilatoren bei } \\
\text { Bedarf }\end{array}$ & $\begin{array}{l}\text { Seifenersatz und } \\
\text { Emollienzien }\end{array}$ & Individuelle Diät & Individuelle Diät \\
\hline $\begin{array}{l}\text { Kortikosteroi- } \\
\text { de nasal, Cro- } \\
\text { moglycinsäure } \\
\text { (bei Kindern } 1 . \\
\text { Wahl) }\end{array}$ & $\begin{array}{l}\text { Cromoglycinsäure- } \\
\text { oder Nedocromil- } \\
\text { Augentropfen }\end{array}$ & $\begin{array}{l}\text { Inhalative Kortikosteroide, } \\
\text { Cromoglycinsäure und } \\
\text { Nedocromil bei mildesten } \\
\text { Formen und Kindern }\end{array}$ & $\begin{array}{l}\text { Kortikosteroidhaltige } \\
\text { Hautcremes und Salben }\end{array}$ & & $\begin{array}{l}\text { Adrenalin-Ferti- } \\
\text { ginjektion und } \\
\text { trinkbare Kortiko- } \\
\text { steroide (für den } \\
\text { Notfall mitführen) }\end{array}$ \\
\hline $\begin{array}{l}\text { Kurztherapie } \\
\text { mit oralen } \\
\text { Kortikoste- } \\
\text { roiden (z. B. } \\
20 \mathrm{mg} / \mathrm{Tag} \\
\text { über } 5 \text { Tage) }\end{array}$ & $\begin{array}{l}\text { Topische Kortiko- } \\
\text { steroide (niemals } \\
\text { ohne ophthal- } \\
\text { mologische } \\
\text { Überwachung) }\end{array}$ & $\begin{array}{l}\text { Kurz- und langwirksame } \\
\beta_{2}-\text { Mimetika, ggf. plus } \\
\text { Leukotrienhemmer oder } \\
\text { retardiertes Theophyllin }\end{array}$ & $\begin{array}{l}\text { Antibiotika für } \\
\text { Exazerbationen }\end{array}$ & & \\
\hline $\begin{array}{l}\text { Hyposensibili- } \\
\text { sierung }\end{array}$ & & $\begin{array}{l}\text { Kurz- oder Langzeitthe- } \\
\text { rapie mit oralen Kortiko- } \\
\text { steroiden mit niedrigster } \\
\text { möglicher Dosis verteilt } \\
\text { auf } 2 \text { Dosen/Tag }\end{array}$ & $\begin{array}{l}\text { Photochemotherapie, } \\
\text { Diät, Verhaltensthera- } \\
\text { pie, Immunsuppressiva } \\
\text { (nur bei schwersten } \\
\text { Formen) }\end{array}$ & & $\begin{array}{l}\text { Erwägung einer } \\
\text { Hyposensibilisie- } \\
\text { rung (Bienen- und } \\
\text { Wespengift- } \\
\text { allergie) }\end{array}$ \\
\hline
\end{tabular}

- Tab. 3.11. Aufstellung der derzeit verfügbaren Medikamente für die Therapie allergischer Erkrankungen

\begin{tabular}{|c|c|c|c|c|}
\hline Name & Anwendungsart & Nebenwirkungen & Arzneistoff & Präparat \\
\hline \multicolumn{5}{|c|}{ I. Stark wirkende antientzündliche Medikamente } \\
\hline \multirow[t]{10}{*}{ Kortikosteroide } & \multirow{6}{*}{$\begin{array}{l}\text { Inhalativ } \\
\text { (2. Generation) }\end{array}$} & \multirow{6}{*}{$\begin{array}{l}\text { Heiserkeit, orale Candidiasis (selten); } \\
\text { hohe Dosen (>1 mg/Tag) können zu } \\
\text { Hautatrophie, Katarakt, Hämatomnei- } \\
\text { gung und Nebennierensuppression } \\
\text { führen }\end{array}$} & Fluticason & Viani ${ }^{\oplus b}$ \\
\hline & & & Mometason & Atemur $^{\oplus}$, Flutide ${ }^{\oplus}$ \\
\hline & & & Budesonid & Pulmicort $^{\oplus}$, Symbicort ${ }^{\oplus c}$ \\
\hline & & & Flunisolid & Asthmanex ${ }^{\circledast}$ \\
\hline & & & Beclometason & Inhacort ${ }^{\oplus}$, Sanasthmy| ${ }^{\oplus}$ \\
\hline & & & Triamcinolon & Volonimat $^{\oplus}$ \\
\hline & $\begin{array}{l}\text { Inhalativ } \\
\text { (3. Generation) }\end{array}$ & $\begin{array}{l}\text { keine lokalen oder systemischen Neben- } \\
\text { wirkungen bis zur 8-fachen Überdosie- } \\
\text { rung. Hautatrophien, Katarakte, Hämatom- } \\
\text { neigung sowie Nebennierensuppression } \\
\text { treten nach bisherigen Kenntnissen nicht } \\
\text { auf. Auch eine Verlangsamung des Kno- } \\
\text { chenwachstums bei Kindern bleibt aus. }\end{array}$ & Ciclesonid & Alvesco ${ }^{\oplus}$ \\
\hline & \multirow[t]{3}{*}{ Nasal } & \multirow{3}{*}{$\begin{array}{l}\text { Gelegentlich trockene und gereizte } \\
\text { Nasen- und Rachenschleimhaut, } \\
\text { Geruchs- und Geschmacksstörung }\end{array}$} & Fluticason & Flutide $^{\circledR}$ Nasal \\
\hline & & & Mometason & Nasonex ${ }^{\circledast}$ \\
\hline & & & Budesonid & Pulmicort $^{\oplus}$, Topinasal ${ }^{\oplus}$ \\
\hline & \multirow[t]{3}{*}{ Systemisch } & \multirow{3}{*}{$\begin{array}{l}\text { Nach längerer Einnahme mit Osteoporo- } \\
\text { sis, arterieller Hypertonie, Diabetes, Ka- } \\
\text { tarakten, Hemmung der Hypothalamus- } \\
\text { Hypophysen-Nebennieren-Achse, Obe- } \\
\text { sitas, Hautatrophie und Muskelschwäche } \\
\text { assoziiert }\end{array}$} & Methylprednisolon & Urbason $^{\circledR}$ \\
\hline & & & Prednisolon & Decortin $^{\oplus} \mathrm{H}$ \\
\hline & & & Prednison & Decortin $^{\oplus}$ \\
\hline
\end{tabular}


- Tab. 3.11. Fortsetzung

\begin{tabular}{|c|c|c|c|c|}
\hline Name & Anwendungsart & Nebenwirkungen & Arzneistoff & Präparat \\
\hline $\begin{array}{l}\text { Anti-lgE-Thera- } \\
\text { peutika }\end{array}$ & Subkutan & $\begin{array}{l}\text { Lokal im Bereich der Injektionsstelle; } \\
\text { selten: Nausea, Kopfschmerz }\end{array}$ & Omalizumab & Xolair $^{\oplus}$ \\
\hline \multicolumn{5}{|c|}{ II. Topisch nur schwach wirkende antiinflammatorische Medikamente } \\
\hline \multirow[t]{2}{*}{$\begin{array}{l}\text { Dinatrium- } \\
\text { cromoglycat } \\
\text { (DNCG) }\end{array}$} & Inhalativ & $\begin{array}{l}\text { Minimal, gelegentlich Husten nach } \\
\text { Inhalation, Heiserkeit }\end{array}$ & DNCG & $\begin{array}{l}\text { Aarane }^{\oplus}, \text { Allergospasmin }^{\oplus} \\
\text { (in Kombination mit } \beta_{2^{-}} \\
\text {Mimetika) }\end{array}$ \\
\hline & Nasal & s. oben & DNCG & Lomupren $^{\oplus}$ \\
\hline \multirow[t]{3}{*}{ Nedocromil } & Inhalativ & Keine bekannt & Nedocromil & Tilade $^{\odot}$ \\
\hline & Nasal & Lokales Stechen und Brennen & Nedocromil & $\operatorname{Irtan}^{\ominus}$ Nasenspray \\
\hline & Konjunktival & Lokales Stechen und Brennen & Nedocromil & Irtan ${ }^{\oplus}$ Augentropfen \\
\hline \multicolumn{5}{|c|}{ III. Nur auf die oberen Atemwege antiinflammatorisch wirkende Medikamente } \\
\hline \multirow{6}{*}{$\begin{array}{l}\text { Antihistaminika } \\
\left(\mathrm{H}_{1} \text {-Antago- }\right. \\
\text { nisten der } 2 \text {. } \\
\text { und 3. Genera- } \\
\text { tion) }\end{array}$} & \multirow[t]{5}{*}{ Oral } & \multirow{5}{*}{$\begin{array}{l}\text { Leichte Sedation, Mundtrockenheit, } \\
\text { Sehstörungen, Glaukomauslösung, selten } \\
\text { Überempfindlichkeitsreaktion, Kopf- } \\
\text { schmerzen }\end{array}$} & Cetrizin & Zyrtec $^{\oplus}$ \\
\hline & & & Fexofenadin & Telfast $^{\oplus}$ \\
\hline & & & Azelastin & Allergodil $^{\oplus}$ \\
\hline & & & Loratadin & Lisino $^{\circ}$ \\
\hline & & & Terfenadin & Teldane $^{\circledast}$ \\
\hline & Nasal & Selten Brennen, Pruritus & Azelastin & Rhinolast $^{\oplus}$ Nasenspray \\
\hline \multicolumn{5}{|c|}{ IV. Bronchodilatorische Medikamente mit schwacher antiinflammatorischer Wirkung } \\
\hline \multirow{2}{*}{$\begin{array}{l}\text { Leukotrien- } \\
\text { hemmer }\end{array}$} & & \multirow{2}{*}{$\begin{array}{l}\text { Selten Kopfschmerzen; einzelne Fälle } \\
\text { einer Vaskulitis (Churg-Strauss-Syndrom) } \\
\text { wurden beobachtet, ohne dass ein di- } \\
\text { rekter kausaler Zusammenhang mit den } \\
\text { Medikamenten nachgewiesen wurde }\end{array}$} & Zafirlukast $^{\mathrm{a}}$ & Vanticon ${ }^{\oplus}$ \\
\hline & & & Montelukast & Singulär $r^{\oplus}$, Singulär ${ }^{\circledast}$ Junior \\
\hline $\begin{array}{l}\text { Retardiertes } \\
\text { Theophyllin }\end{array}$ & & $\begin{array}{l}\text { Übelkeit und Erbrechen; bei Überdosie- } \\
\text { rung: epileptische Anfälle, Tachykardie, } \\
\text { Arrhythmie (strenge Spiegelkontrollen } \\
\text { sind erforderlich) }\end{array}$ & Theophyllin & $\begin{array}{l}\text { Euphylong }{ }^{\oplus} \text {, Bronchore- } \\
\operatorname{tard}^{\oplus}, \text { Afonilum }^{\oplus}\end{array}$ \\
\hline \multicolumn{5}{|c|}{ V. Bronchodilatorische Medikamente ohne antiinflammatorische Wirkung } \\
\hline \multirow{5}{*}{$\begin{array}{l}\text { Schnell, aber } \\
\text { nur kurz } \\
\text { wirksame } \beta_{2^{-}} \\
\text {Mimetika }\end{array}$} & \multirow[t]{4}{*}{ Inhalativ } & \multirow{4}{*}{$\begin{array}{l}\text { Inhalative } \beta_{2}-\text { Mimetika haben weniger } \\
\text { und geringere Nebenwirkungen als } \\
\text { Tabletten oder Sirup }\end{array}$} & Albuterol & Sultanol ${ }^{\circledR}$ \\
\hline & & & Fenoterol & Berotec $^{\oplus}$ \\
\hline & & & Salbutamol & Rotadisk $^{\oplus}$ \\
\hline & & & Terbutalin & Bricanyl ${ }^{\oplus}$ \\
\hline & Systemisch & $\begin{array}{l}\text { Kardiovaskuläre Stimulation, Muskel- } \\
\text { tremor, Kopfschmerzen, Verwirrtheit }\end{array}$ & Salmeterol & Volmac $^{\oplus}$, Salbulair ${ }^{\oplus}$ \\
\hline \multirow[t]{2}{*}{$\begin{array}{l}\text { Nur lang } \\
\text { wirksame } \beta_{2}- \\
\text { Mimetika }\end{array}$} & Inhalativ & $\begin{array}{l}\text { Inhalative } \beta_{2}-\text { Mimetika haben weniger } \\
\text { und geringere Nebenwirkungen als } \\
\text { Tabletten }\end{array}$ & Salmeterol & Serevent ${ }^{\oplus}$, Viani ${ }^{\oplus d}$ \\
\hline & Systemisch & $\begin{array}{l}\text { Kontinuierliche Freisetzung kann mit } \\
\text { kardiovaskulärer Stimulation, Ängstlich- } \\
\text { keit, Muskeltremor, Kopfschmerzen oder } \\
\text { Hypokaliämie einhergehen }\end{array}$ & Terbutalin & Bricany ${ }^{\oplus}$-Duriles \\
\hline $\begin{array}{l}\text { Schnell und } \\
\text { lang wirksame } \\
\beta_{2} \text {-Mimetika }\end{array}$ & Inhalativ & $\begin{array}{l}\text { Inhalative } \beta_{2} \text {-Mimetika haben weniger } \\
\text { und geringere Nebenwirkungen als } \\
\text { Tabletten }\end{array}$ & Formoterol & Oxis $^{\oplus}$, Foradil ${ }^{\oplus}$ P, Symbicort ${ }^{\oplus e}$ \\
\hline \multirow{2}{*}{$\begin{array}{l}\text { Anticholiner- } \\
\text { gika }\end{array}$} & \multirow[t]{2}{*}{ Inhalativ } & \multirow{2}{*}{$\begin{array}{l}\text { Mundtrockenheit und unangenehmer } \\
\text { Geschmack }\end{array}$} & Ipratropium & Atrovent $^{\oplus}$ \\
\hline & & & Oxitropium & Ventilar $^{\circledast}$ \\
\hline
\end{tabular}

a Nicht in Deutschland verfügbar, ${ }^{b}$ In Kombination mit Salmeterol, ${ }^{\mathrm{c}}$ In Kombination mit Formoterol, ${ }^{\mathrm{d}}$ In Kombination mit Fluticason, ${ }^{\mathrm{e}}$ In Kombination mit Budesonid 


\section{Systemisch wirkende antiinflammatorische Medikamente}

Die vorwiegend systemisch antiinflammatorisch wirkenden Substanzen beeinflussen zelluläre Prozesse, die der allergischen Entzündung zugrunde liegenden, einschließlich der Antigen- bzw. Allergenerkennung, der Proliferation und Funktion regulierender Lymphozyten und peripherer Effektorzellen, und somit das Ausmaß der chronisch-allergischen Entzündung. Da für ihre Wirkung unter anderem genomische Mechanismen aktiviert werden müssen, ist nach Einnahme der Medikamente kein unmittelbarer Effekt zu erwarten. Vielmehr müssen diese Substanzen regelmäßig über einen längeren Zeitraum eingenommen werden. Sie werden daher eher als langfristig wirkende präventive Medikamente angesehen.

Zur Gruppe antientzündlicher Medikamente gehören die Kortikosteroide. Die beiden vorwiegend bronchodilatorisch wirkenden Klassen der Methylxanthine (z. B. Theophyllin) und Leukotrienrezeptorantagonisten (z. B. Zafirlukast oder Montelukast) besitzen ebenfalls einen, wenn auch sehr schwachen, antientzündlichen Effekt auf regulatorische Lymphozyten des zentralen Immunsystems.

\section{Glukokortikoide}

Glukokortikoide gelten als die wirksamsten gegenwärtig verfügbaren antientzündlich wirkenden Medikamente. Die Effekte von Kortikosteroiden werden über einen intrazellulär lokalisierten Rezeptor vermittelt. Dieser Rezeptor liegt in allen Zellen als Teil eines Heterokomplexes vor, der aus dem Rezeptormolekül und mehreren Hitzeschockproteinen (HSP) besteht. Nach Bindung eines Kortikosteroidmoleküls löst sich der aktivierte Rezeptor aus dem Komplex und transloziert vom Zytoplasma in den Nukleus. Dort kann er auf 2 Wegen sein Signal umsetzen:

- nach Bindung an spezifische DNA-Sequenzen (»glucocorticoid response elements«; GRE) in der regulatorischen Region glukokortikoidabhängiger Gene durch die nachfolgende Produktion inhibitorischer Proteine (Typ-1-Mechanismus),

- nach Bindung an Transkriptionsfaktoren, wie z. B. Fos und Jun oder NF-kB, durch eine Synthesehemmung proinflammatorisch wirkender Proteine (Typ-2-Mechanismus).

Das Resultat dieser molekularen Wirkmechanismen der Glukokortikoide mit Änderung der Proteinsynthese ist eine Hemmung des Funktionszustands der Zelle (Aktivierungsgrad, Zelladhäsion und -migration, Freisetzung von Mediatoren, etc.). Neben ihrer Wirkung auf verschiedene Entzündungszellen, einschließlich Makrophagen, T-Lymphozyten, Mastzellen sowie eosinophile und basophile
Granulozyten, beeinflussen Glukokortikoide aber auch Strukturzellen der Atemwege, wie etwa Epithelzellen und Fibroblasten.

Kortikosteroide werden bei nahezu allen allergischen Erkrankungen eingesetzt (•Tab.3.10). Sie liegen neben der intravenösen und oralen Form auch in topisch anwendbaren Formulierungen vor. Die lokale Anwendung erlaubt es in vielen Fällen, eine orale Behandlung zu umgehen oder zumindest die orale Dosis zu reduzieren. Akute Verschlechterungen allergischer Erkrankungen lassen sich durch "Kortikoidstöße« abfangen, die mit einer Dosierung von $50 \mathrm{mg}$ oral über einige Tage die übrige $\mathrm{Me}$ dikation begleiten. Beim Status asthmaticus ist dagegen bei der Erstgabe ein Bolus von 1.000 mg i.v. Prednisolon zu empfehlen, die dann zunächst mit 50-150 mg i.v. alle 6 $\mathrm{h}$ fortgeführt werden sollte.

Nur in seltenen Fällen gelingt der Versuch, den zirkadianen Kortisolmetabolismus durch die Gabe der Tagesdosis am Morgen möglichst wenig zu beeinträchtigen. Hierdurch treten Versuche, die Hemmung des zirkadianen Kortisolmetabolismus durch oral zugeführte Kortikosteroide (frühmorgendliche Einmalgabe oder alternierende Medikamenteneinnahme an jedem 2. Tag) zu vermeiden, in den Hintergrund. Zum anderen gilt es, die in der Zelle zur Verfügung stehenden Kortikosteroidrezeptoren möglichst permanent zu besetzen, um eine maximale antientzündliche Wirkung zu erreichen. Daher ist nach aktueller Auffassung eine Zwei- oder Mehrfachgabe der täglichen Kortisondosis zu empfehlen.

Dagegen kann die Anwendung lang wirkende Depotkortikoidpräparate nicht empfohlen werden, da die Präparate sich schlecht steuern lassen und kortikosteroidassoziierte Nebenwirkungen verstärkt auftreten. Auch die Gabe des Makrolidantibiotikums Troleandomycin, das durch eine Verzögerung des Katabolismus die Halbwertszeit von Methylprednisolon verdoppelt, ist obsolet. Auch dieses Medikament besitzt keinen therapeutischen Vorteil und führt zu einer Verstärkung der steroidinduzierten Nebenwirkungen. Hierzu zählen unter anderem Hypertonie, Gewichtszunahme, Cushing-Syndrom, Diabetes mellitus, Osteoporose, Wachstumsstörungen, Infektanfälligkeit, Akne, Glaukom, Myopathien und aseptische Knochennekrosen, seltener auch Myopathien und Psychosen. Magengeschwüre werden bezüglich Exazerbation verstärkt.

\section{Topisch wirkende antiinflammatorische Medikamente}

Der Effekt lokal wirkender antientzündlicher Medikamente erstreckt sich vorwiegend auf Entzündungszellen wie z. B. Mastzellen. Zu den Medikamenten dieser Gruppe gehören das Dinatriumcromoglycat (DNCG), Nedocromilnatrium und $\mathrm{H}_{1}$-Antagonisten. 


\section{Dinatriumcromoglycat und Nedocromilnatrium}

Der Wirkmechanismus von DNCG und Nedocromilnatrium ist noch nicht vollkommen aufgeklärt, schließt aber vermutlich eine Blockade von Chloridkanälen in der Zellmembran ein. Bezogen auf Wirkstärke und -spektrum sind beide Substanzen miteinander vergleichbar; sie hemmen die Mediatorfreisetzung aus Mastzellen und die Rekrutierung eosinophiler Granulozyten aus dem Blut.

Ihre Wirkung erstreckt sich sowohl auf die allergische Früh- und Spätreaktion nach Allergenprovokation als auch auf die durch körperliche Belastung oder Kaltluft ausgelöste Atemwegsobstruktion. Beide Medikamente werden topisch zur Behandlung milder Formen des Asthma bronchiale, der Rhinitis allergica und der Conjunctivitis allergica eingesetzt (•Tab.3.10 und 3.11). Sie spielen auch eine Rolle bei der Behandlung allergischer Erkrankungen im Kindesalter.

\section{H1-Antagonisten (Antihistaminika)}

Zur Gruppe der auf die Sofortreaktion wirkenden antientzündlichen Medikamente gehören auch die $\mathrm{H}_{1}$-Ant- agonisten oder Antihistaminika (• Tab. 3.12). Sie wirken als spezifische Rezeptorantagonisten und unterdrücken die proinflammatorische Wirkung des aus Mastzellen und basophilen Granulozyten freigesetzten Histamins. Antihistaminika reduzieren auf diese Weise Pruritus, Gefäßdilatation mit Erythem und Ödem und sind sowohl nach systemischer als auch topischer Gabe wirksam.

$\mathrm{H}_{1}$-Rezeptorantagonisten der 2. Generation sind aufgrund ihrer geringen Liquorgängigkeit besser verträglich als die Substanzen der 1. Generation. Neben ihrer symptomatischen Wirkung als Histamin-1-Rezeptorblocker besitzen sie offenbar eine nicht $\mathrm{H}_{1}$-Rezeptor-vermittelte, antientzündliche Wirkkomponente, auch wenn die hier zugrunde liegenden molekularen Mechanismen noch nicht im Detail bekannt sind. Cetirizin beispielsweise hemmt die Gewebeinfiltration durch eosinophile Granulozyten sowie verschiedene Effektorfunktionen der Zelle.

Die Indikation zur Behandlung mit $\mathrm{H}_{1}$-Rezeptorantagonisten der 2. Generation umfasst die der Rhinitis allergica und Conjunctivitis allergica. Im Rahmen der atopischen Dermatitis ist ihre Wirkung nicht eindeutig belegt,

- Tab. 3.12. Medikamente für die Notfalltherapie allergischer Erkrankungen

\begin{tabular}{|c|c|c|}
\hline Arzneistoff & Präparat & Dosierung \\
\hline \multicolumn{3}{|c|}{ Inhalierbare kurz wirkende $\beta 2$-Mimetika (Kombination mit Anticholinergika empfehlenswert) } \\
\hline Terbutalin & $\begin{array}{l}\text { z. B. Bricanyl DA } \\
\text { oder als } 1 \% \text {-Lösung }\end{array}$ & $\begin{array}{l}2 \mathrm{Hub}(0,5 \mathrm{mg}) \text { insgesamt 3-mal alle } 20 \mathrm{~min} \text { bzw. } 10 \text { Trpf. in } 2 \mathrm{ml} \mathrm{NaCl} \text { über } \\
\text { Feuchtvernebler alle } 20 \mathrm{~min} \text {, dann alle } 1-4 \mathrm{~h}\end{array}$ \\
\hline Fenoterol & $\begin{array}{l}\text { z. B. Berotec DA } \\
\text { oder als } 1 \% \text {-Lösung }\end{array}$ & $\begin{array}{l}2 \mathrm{Hub}(400 \mu \mathrm{g}) \text { insgesamt 3-mal alle } 20 \mathrm{~min} \text { bzw. } 10 \text { Trpf. in } 2 \mathrm{ml} \mathrm{NaCl} \text { über } \\
\text { Feuchtvernebler alle } 20 \mathrm{~min} \text {, dann alle } 1-4 \mathrm{~h}\end{array}$ \\
\hline \multirow[t]{2}{*}{ Adrenalin } & Adrenalin-Medihaler ${ }^{a}$ & $1-2 \mathrm{Hub}(350-700 \mu \mathrm{g})$ alle $20 \mathrm{~min}$ \\
\hline & Adrenalin $(1: 10.000)$ & $1-2 \mathrm{ml}(0,1-0,2 \mathrm{mg})$ über Feuchtvernebler alle $20 \mathrm{~min}$ \\
\hline \multicolumn{3}{|c|}{ Systemische (injizierte) kurz wirkende $\beta 2$-Mimetika } \\
\hline Terbutalin & Bricanyl Injektionslösung & $0,25 \mathrm{mg}$ s.c. alle $20 \mathrm{~min} 3-\mathrm{mal}$ \\
\hline Adrenalin & Fastjekt & $0,2-0,3$ mg i.m. \\
\hline Adrenalin & Adrenalin 1:1000 (1 mg/ml) & 0,3-0,5 mg s.c. über 3 Dosen alle $20 \mathrm{~min}$ \\
\hline \multicolumn{3}{|c|}{ Anticholinergika (Kombination mit $\beta 2$-Mimetika empfehlenswert) } \\
\hline \multirow[t]{2}{*}{ Ipratropiumbromid } & Atrovent LS 0,025\% Lsg. & $0,5 \mathrm{mg}$ alle $20 \mathrm{~min}$, dann alle $1-4 \mathrm{~h}$ über Feuchtvernebler \\
\hline & Atrovent DA & 4-8 Hub $(80-160 \mu \mathrm{g})$ alle $20 \mathrm{~min}$, dann alle $1-4 \mathrm{~h}$ \\
\hline \multicolumn{3}{|c|}{ Nichtretardiertes Theophyllin } \\
\hline Theophyllin & Aminophyllin, Solosin & i.v. $5-6 \mathrm{mg} / \mathrm{kg}$ \\
\hline \multicolumn{3}{|l|}{ Kortikosteroide } \\
\hline Methylprednisolon & Urbason & $1-2 \mathrm{mg} / \mathrm{kg} \mathrm{KG}$ oral oder i.v. alle $6 \mathrm{~h}$ \\
\hline Prednisolon & Decortin $\mathrm{H}$ & $1-2 \mathrm{mg} / \mathrm{kg} \mathrm{KG}$ oral oder i.v. alle $6 \mathrm{~h}$ \\
\hline Prednison & Decortin & $1-2 \mathrm{mg} / \mathrm{kg} \mathrm{KG}$ oral oder i. v. alle $6 \mathrm{~h}$ \\
\hline \multicolumn{3}{|l|}{ Antihistaminika } \\
\hline Dimetinden & Fenistil & 1 Amp. $(4 \mathrm{mg})$ i.v. \\
\hline
\end{tabular}


wenngleich einzelne Patienten mit einer betont allergischen Komponente von der Behandlung mit Antihistaminika profitieren können. Ihre Rolle beim Asthma bronchiale ist ebenfalls nicht überzeugend dargestellt worden. $\mathrm{H}_{1}$-Antagonisten gehören daher nicht zur etablierten antiasthmatischen Behandlung. In diesem Zusammenhang sei allerdings darauf verwiesen, dass Antihistaminika die antiobstruktive Wirkung von Leukotrienrezeptorantagonisten verstärken können.

\section{Bronchodilatorische Medikamente mit schwacher antiinflammatorischer Wirkung}

Von den rein antientzündlich wirkenden Substanzen ohne bronchodilatorische Wirkung lassen sich Bronchodilatoren unterscheiden, die ebenfalls eine gewisse antientzündliche Wirkung entfalten. Hierzu gehören das Methylxanthin Theophyllin und die Klasse der Leukotrienhemmer. Diese Medikamente kommen zurzeit ausschließlich beim Asthma bronchiale zur Anwendung, wenngleich Leukotrienhemmer auch einen gewissen günstigen Einfluss auf die Rhinitis allergica und möglicherweise die atopische Dermatitis besitzen.

\section{Theophyllin}

Theophyllin ist ein unspezifischer Phosphodiesteraseinhibitor, der seine pharmakologische Wirkung über die Erhöhung der intrazellulären cAMP-Konzentration in Muskel-, Epithel- und Nervenzellen vermittelt. Die pharmakologische Wirkung des Theophyllins bei einer Serumkonzentration zwischen $10-20 \mathrm{mg} / \mathrm{l}$ umfasst daher

- eine Bronchodilatation,

- eine Steigerung der mukoziliären Clearance sowie

- eine schwache zentrale Atemstimulation.

Bei geringerer Serumkonzentration von $5-10 \mathrm{mg} / \mathrm{l}$ hat Theophyllin einen schwachen antientzündlichen Effekt, der möglicherweise über purinerge Rezeptoren vermittelt wird.

Nicht retardiertes Theophyllin steht zur intravenösen Akuttherapie im Rahmen eines Asthmaanfalls zur Verfügung. Demgegenüber kommt retardiertes, lang wirksames Theophyllin gegenwärtig als adjuvante Behandlung beim Asthma bronchiale zum Einsatz und ist besonders wirkungsvoll zur Kontrolle nächtlicher Beschwerden.

Aufgrund der individuell unterschiedlichen Metabolisierung des Theophyllins und der komplexen Interaktionen mit anderen Arzneimitteln, aber auch zur Vermeidung akzidenteller Überdosierungen sind Kontrollen des Blutspiegels bei der Einstellung und während der Therapie unerlässlich. Bei einer Konzentration von über $20 \mathrm{mg} / \mathrm{l}$, gelegentlich bereits schon bei $15 \mathrm{mg} / \mathrm{l}$, kann es zu Unruhe, Schlaflosigkeit, Kopfschmerzen, Übelkeit und Erbrechen, in noch höheren Konzentrationen sogar zu Krampfanfällen, kommen.

\section{Leukotrienrezeptorantagonisten}

Mit der Einführung der Leukotrienrezeptorantagonisten Montelukast und Zafirlukast steht nach über 20 Jahren eine neue Medikamentenklasse zur Behandlung des Asthma bronchiale zur Verfügung. Die günstige therapeutische Wirkung der Medikamente umfasst eine moderate Bronchodilatation während der asthmatischen Frühund Spätreaktion sowie eine Minderung der bronchialen Hyperreagibilität. Neuere Untersuchungen zeigen zudem, dass die Substanzen einen schwachen antientzündlichen Einfluss haben, der durch eine Verminderung der Entzündungszellen im Blut und in den Atemwegen zum Ausdruck kommt. Der bronchiale Effekt der Leukotrien-(LT-) Hemmer beruht auf der Blockade des Cys-LT1-Rezeptors auf glatten Muskelzellen, der die leukotrienvermittelte bronchiale Muskelkontraktion unterbindet.

Die klinische Bedeutung der Leukotrienhemmer liegt vor allem darin, dass sie ihre bronchodilatorische Wirkung additiv zu der von $\beta_{2}$-Mimetika entfalten können und sich durch die Kombination beider Medikamente eine weitere Bronchodilatation erreichen lässt. Ein unbedeutender synergistischer bronchodilatorischer Effekt entsteht bei Kombination von Leukotrienhemmern mit $\mathrm{H}_{1}$-Antagonisten. Schließlich lassen sich mit Leukotrienhemmern orale Kortikosteroide einsparen. Allerdings profitieren nicht alle Patienten in gleichem Umfang von den Medikamenten.

Die Verträglichkeit der Leukotrienrezeptorantagonisten ist im Allgemeinen gut. Nur selten klagen die Patienten über Kopfschmerzen. Bei den unter Behandlung mit Zafirlukast aufgetretenen 8 Fällen einer infiltrativen, Eosinophilie-assoziierten Lungenerkrankung handelt es sich vermutlich um die Exazerbation eines primär als Asthma bronchiale fehldiagnostizierten Churg-StraussSyndroms, zu der es nach Reduktion der oralen Kortikosteroiddosis kam.

\section{Bronchodilatorische Medikamente ohne antiinflammatorische Wirkung}

Diese Gruppe von Medikamenten entfaltet ihre Wirkung entweder direkt auf die glatte Muskulatur ( $\beta_{2}$-Sympathikomimetika) oder auf die neurale Regulation des Bronchotonus (Anticholinergika).

\section{$\beta_{2}$-Sympathikomimetika ( $\beta$-Agonisten)}

Bei den $\beta$-Sympathikomimetika handelt es sich um rezeptorspezifische Medikamente, die den $\beta_{2}$-adrenergen Rezeptorsubtyp auf den glatten Muskelzellen der Atemwege besetzen. $\beta_{2}$-Mimetika sind die stärksten gegenwärtig verfügbaren Bronchospasmolytika. Dieser pharmakologische Effekt wird ergänzt durch:

- Verringerung der Permeabilität im Bereich der Kapillaren und

- Verbesserung der mukoziliären Clearance. 
Der hierbei zugrunde liegende pharmakologische Wirkmechanismus wird von einem Anstieg der intrazellulären cAMP-Konzentration mit einer Verringerung des $\mathrm{Ca}^{++}$ im Zytosol und einer Eröffnung von $\mathrm{Ca}^{++}$-aktivierten $\mathrm{K}^{+}$Kanälen getragen. $\beta_{2}$-Mimetika können bei ausreichender Dosierung die allergische Sofortreaktion der Bronchien weitgehend hemmen, während die verzögerte Reaktion unbeeinflusst bleibt.

Nach Wirkungseintritt und Wirkdauer lassen sich die Medikamente dieser Gruppe einteilen in:

- $\beta_{2}$-Sympathikomimetika mit schneller und kurzer Wirkdauer (z. B. Fenoterol),

- $\beta_{2}$-Sympathikomimetika mit schneller und längerer Wirkdauer (z. B. Formoterol),

- $\beta_{2}$-Sympathikomimetika mit langsamer und längerer Wirkdauer (z. B. Salmeterol).

Kurz- und schnell- wirksame $\beta_{2}$-Sympathikomimetika bilden heute die Bedarfsmedikation für die Asthmabehandlung, die stets mitgeführt wird, um im Falle von plötzlich auftretender Atemnot inhalieren zu können. Umgekehrt ist die Häufigkeit der Anwendung des Bedarfsmedikaments auch ein Maß für die Kontrolle der Erkrankung. Nach inhalativer Applikation tritt die Wirkung innerhalb weniger Minuten ein und kann über einen Zeitraum von 3 bis maximal $12 \mathrm{~h}$ (Formoterol) anhalten. Als Nebenwirkungen werden relativ häufig Tremor, kardiovaskuläre Stimulation, z. B. in Form einer Tachykardie, Kopfschmerzen, Unruhe und Hypokaliämie beobachtet. Der günstigste Weg zur selektiven und nebenwirkungsarmen Nutzung der $\beta_{2}$-Effekte ist die inhalative Applikation.

Die verlängerte Wirkdauer lang wirksamer $\beta_{2}$-Mimetika wird mit den lipophilen physikochemischen Eigenschaften dieser Substanzen in Verbindung gebracht, ohne dass der Mechanismus gegenwärtig in allen Einzelheiten verstanden wird. Die Wirkungsdauer dieser inhalativen Medikamente von etwa $12 \mathrm{~h}$ gewährleistet eine ganztägig anhaltende Bronchodilation bei zweimaliger Anwendung. Der besonderer Vorteil der lang wirksamen $\beta_{2}$-Mimetika bezieht sich deshalb auf eine Vermeidung asthmatischer Beschwerden im Sinne einer Protektion, beispielsweise gegenüber nächtlichen, anstrengungsinduzierten oder durch andere Irritanzien ausgelösten Beschwerden.

Die Indikationen zur Gabe lang wirksamer $\beta_{2}$-Mimetika umfassen daher leichte, mittelschwere bis schwere Asthmaformen insbesondere mit nächtlich betonter Symptomatik. Der Wirkeintritt von Formoterol beträgt wenige Minuten, der von Salmeterol etwa $1 \mathrm{~h}$. Formoterol könnte daher auch zur Notfallbehandlung eingesetzt werden. Studien hierzu liegen allerdings noch nicht vor.

\section{Anticholinergika}

Der therapeutische Effekt der Anticholinergika beruht auf der Blockade cholinerger (muskarinerger) Rezeptoren
(M-Rezeptoren), wodurch die Substanzen mit der vagalen bzw. azetylcholinvermittelten Bronchokonstriktion interferieren. Von den 5 bisher bekannten muskarinergen Bindungsstellen ist die Funktion des M1-Rezeptorsubtyps auf submukösen Drüsenzellen und des M3-Rezeptorsubtyps auf glatten Muskelzellen für die Pathogenese des Asthma bronchiale relevant. Die beiden derzeit zur Verfügung stehenden Substanzen Ipratropiumbromid und Oxitropiumbromid wirken unspezifisch auf alle Rezeptorsubtypen.

Die Wirkung der oben genannten Anticholinergika tritt etwas verzögerter ein als die der kurz wirksamen $\beta_{2}$-Mimetika, hält dafür aber auch länger an (bis zu $6 \mathrm{~h})$. Ihr bronchodilatorischer Effekt ist schwächer ausgeprägt als der von $\beta_{2}$-Sympathikomimetika und eine universale Wirksamkeit für die Langzeitbehandlung des Asthma konnte nicht belegt werden. Während Exazerbationen kann allerdings die Kombination von Anticholinergika mit $\beta_{2}$-Mimetika sinnvoll sein (z. B. Berodual). Auch die Inhalation von Ipratropiumbromid und eines $\beta_{2}$-Mimetikums mittels Düsenvernebler (z. B. Pari-Boy; jeweils 8 Tropfen auf $2 \mathrm{ml} \mathrm{NaCl}$ ) alle $3 \mathrm{~h}$ im Wechsel hat sich bei mittelschweren bis schweren Asthmaattacken als günstig erwiesen.

Relevante Nebenwirkungen werden nach Gabe von Anticholinergika kaum beobachtet. Gelegentlich kann es zu Mundtrockenheit oder unangenehmem Geschmack kommen.

\section{Notfallmedikamente}

Schwere Asthmaattacken und anaphylaktische Reaktionen unterschiedlichster Ätiologie können zu lebensbedrohlichen Situationen führen. Dabei geht es vor allem darum, bereits bei geringsten klinischen Anzeichen möglichst frühzeitig eine effektive Behandlung einzuleiten. Daher sollten beispielsweise Patienten mit bekannter schwerer Insektengiftallergie Kortison in Form von Tabletten oder Suppositorien sowie ein Adrenalininjektionsbesteck stets mitführen, um in der Lage zu sein, selbst Maßnahmen einzuleiten. Dieses und andere Notfallmedikamente zur Akutbehandlung lebensbedrohlicher allergischer Erkrankungen sind in • Tab. 3.12 aufgeführt.

\subsubsection{Zukünftige antiallergische Medikamente}

Gegenwärtig befinden sich eine ganze Palette verschiedener antiallergisch wirkender Medikamente mit antiasthmatischer und antiallergischer Wirkung in der klinischen Prüfung. Ihr Wirkmechanismus beruht auf den Fortschritten im Verständnis der Pathogenese allergischer Erkrankungen. Deshalb handelt es sich bei den Substanzen um Medikamente, die selektiv die Funktion eines Rezeptors oder eines Mediators blockieren bzw. neutralisie- 
ren, sodass sie vermutlich eine differenzierte Behandlung allergischer Erkrankungen erlauben werden. $\mathrm{Zu}$ diesen Medikamenten gehören:

- spezifische Typ-III- und Typ-IV-Phosphodiesteraseinhibitoren,

- subtypspezifische Muskarinrezeptorantagonisten,

- Interleukin-5-Rezeptorantagonisten,

- Interleukin-4-Rezeptorantagonisten,

- neutralisierende anti-IgE-Antikörper (E25),

- Tryptaseinhibitoren und

- Chemokinrezeptorantagonisten.

Selbst wenn einzelne der oben aufgeführten Substanzen aufgrund von Nebenwirkungen, unzureichender Wirksamkeit oder aus anderen Gründen nicht zum klinischen Einsatz gelangen, darf damit gerechnet werden, dass bestimmte Medikamente ihren Weg in die Pharmakotherapie allergischer Erkrankungen finden. So könnte in Zukunft ein Spektrum neuer antiallergisch wirkender Therapeutika verfügbar werden, die es nicht nur erlauben allergische Erkrankungen wirksamer zu behandeln, sondern auch eine Behandlung an individuelle Bedürfnisse anzupassen.

\section{Literatur}

Bergmann KC, Bergmann RL, Bauer CP et al. (1993) Atopie in Deutschland. Untersuchung zur Vorhersagemöglichkeit einer Atopie bei Geburt. Erste Ergebnisse der multizentrischen Allergie-Studie. Dtsch Ärztebl 90:1341-1347

Blair H (1977) Natural history of childhood asthma. 20 year follow-up. Arch Dis Child 52:613-622

Bousquet J, Chanez P, Lacoste JY et al. (1990) Eosinophilic Inflammation in Asthma. N Engl J Med 323:1033-1039

Buhl R, Brdel D, Criée CP et al (2006) Leitlinie zur Diagnostik und Therapie von Patienten mit Asthma bronchiale 2005. Pneumologie 60:139-179

Douglass JA, Thien FCK, O'Hehir RE. Immunotherapy in asthma. Thorax 52(Suppl 3):S22-S29

Frischer T, Kühr J, Meinert R et al. (1991) Prävalenz allergischer Manifestationen im Schulkindalter in Südbaden. Münch Med Wochenschr 133:52-55

Gerritsen J, Koeter GH, Postma DS, Schouten LP, Knol K (1989) Prognosis of asthma from childhood to adulthood. Am Rev Respir Dis 140:1325-1330

Global Initiative for Asthma. GINA workshop report, global strategy for asthma management and prevention. www.ginastma.org, 22.12.2006

ISAAC Steering Committee (1998) Worldwide variation in prevalence of symptoms of asthma, allergic rhinoconjunctivitis, and atopic eczema: ISAAC. Lancet 351:1225-1232

Jäger L, Kroegel C (1998) Gegenwärtige Behandlung des Asthma bronchiale. In: Kroegel C (Hrsg) Asthma bronchiale. Pathogenetische Grundlagen, Diagnostik und Therapie. Thieme, Stuttgart, S. 71-106

Kleine-Tebbe J, Fuchs T, Klimek L et al. (2000) Die spezifische Immunotherapie (Hyposensibilisierung) mit Allergenen. Allergo J 9:317-324
Koller DY, Götz M, Eichler I, Urbanek R (1994) Eosinophil activation in cystic fibrosis. Thorax 49:496-499

Kroegel C, Kortsik C, Luttmann W, Matthys H, Werner P, Virchow JC Jr (1993) Pathomechanismen der asthmatischen Entzündungsreaktion. Entzündungszellen und Mediatoren. Dtsch Ärztebl 90 (Suppl 46):4-15

Kroegel C, Förster M, Braun R (1998) Pathogenetische Grundlagen des Asthma bronchiale. In: Kroegel C (Hrsg) Asthma bronchiale. Pathogenetische Grundlagen, Diagnostik und Therapie. Thieme, Stuttgart, S. 13-51

Kroegel C, Schüler M, Förster M, Braun R, Grahmann PR (1998) Evidence for eosinophil activation in bronchiectasis unrelated to cystic fibrosis and bronchopulmonary aspergillosis: discrepency between blood eosinophil counts and serum eosinophil cationic protein levels. Thorax 53:498-500

Kroegel C, Bergmann N, Foerster M et al (2006) Interferon-acon-1 treatment of three patients with severe glucocorticoid-dependent asthma - Effect on disease control and systemic glucocorticosteroid dose. Respiration 73:566-570

Kroegel C, Reißig A, Walter R et al (2006) Inhalierbare Glucocorticoide der dritten Generation Ciclesonid. Arzneimittelth 24:73-83

Kroegel C, Förster M (2007) Omalizumab. In: Dübel S (Hrsg.) Handbook of Therapeutic Antibodies, 1. Aufl. Wiley-VCH, Weinheim, Vol. III, S. 534-583

Kumar RK, Webb DC, Herbert C, Foster PS (2006) Interferon-gamma as a possible target in chronic asthma. Inflamm Allergy Drug Targets 5:253-256

Kunz B, Ring J, Überla K (1989) Frequency of atopic diseases and allergic sensitization in preschool children in different parts of Bavaria. Allergology 12:144

Manian P (1998) Genetics of asthma. Chest 112:1397-1408

Mansueto P, Montalto G, Pacor ML et al (2006) Food allergy in gastroenterologic diseases: Review of literature. World J Gastroenterol 12:7744-7752

Martin AJ, Landau LI, Phelan PD (1992) Asthma from childhood at age 21: the patient and his (or her) disease. Br Med J 284:380-382

Menz G, Ismail C, Crameri R (2000) Die allergische bronchopulmonale Aspergillose. Pneumologie 54:375-384

Merget R, Schulze-Werningshaus G (1998) Diagnostik des Asthma bronchiale. In: Kroegel C (Hrsg) Asthma bronchiale. Pathogenetische Grundlagen, Diagnostik und Therapie. Thieme, Stuttgart, S. $53-70$

Moritani C, Ishioka S, Haruta Y, Kambe M, Yamakido M (1998) Activation of platelets in bronchial asthma. Chest 113:452-458

Mortensen E (1963) Follow-up on children with asthmatic bronchitis. A view to prognosis. Acta Paediatr 140 (Suppl):122-130

Mutius E von, Weiland SK, Fritzsch C, Duhme H, Keil U (1998) Increasing prevalence of hay fever and atopy among children in Leipzig, East Germany. Lancet 351:862-866

National Institutes of Health (1998) Guidelines for the diagnosis and management of asthma. Expert panel report 2. (NIH Publication No. 98-4051)

Panhuysen CIM, Vonk JM, Koeter GH et al. (1997) Adult patients may outgrow their asthma. A 25-year follow-up study. Am J Respir Crit Care Med 155:1267-1272

Patterson R, Grammer LC, Harris KE, Shaughnessy MA (1996) The role of allergens in airway disease. In: Busse WW, Holgate ST (eds) Asthma and Rhinitis. Blackwell, Oxford, pp. 895-897

Peat JK (1996) Prevention of asthma. Eur Respir J 9:1545-1555

Petro W, Wettengel R, Worth $\mathrm{H}$ (1995) Empfehlungen zum strukturierten Patiententraining bei obstruktiven Atemwegserkrankungen. Pneumologie 49:455-460

Rackemann FM, Edwards MC (1952) Asthma in children: follow-up study of 688 patients after intervl of 20 years. N Engl J Med 246:858-591 
Roberts CR (1995) Is asthma a fibrotic disease. Chest 107:111s-117s

Saarinen UM, Kajosaari M (1995) Breastfeeding as prophylactis against atopic disease: prospective follow-up study until 17 years old. Lancet 346:1065-1069

Schulenburg JM von der, Greiner W, Molitor S, Kielhorn A (1996) Kosten der Asthmatherapie nach Schweregrad. Eine empirische Untersuchung. Med Klin 91:670-676

Sears MR (1997) Epidemiology of childhood asthma. Lancet 350:10151020

Sennekamp HJ, Müller-Wening D (2003) 12. Tagung der Arbeitsgemeinschaft Eogen-allergische Alveolitis, 12.-14. September 2003, Freyburg an der Unstrut. Allergologie 26:307-308

Turner KJ, Stewart GA, Woolcock AJ, Green W, Alpers MP (1998) Relationship between mite densities and the prevalence of asthma: comparative studies in two populations in the Eastern Highlands of Papua New Guinea. Clin Allergy 18:331-340

Warner JA, Julius P, Luttmann W, Kroegel C (1997) Matrix metalloproteinases in bronchoalveolar lavage fluid following antigen challenge. Int Arch Allergy Immunol 113:318-320

Wettengel R, Volmer T (1994) Asthma. Medizinische und ökonomische Bedeutung einer Volkskrankheit. Rupp, Stuttgart

Wüthrich B (1995) Pollenallergie. Aktuelles zur Epidemiologie, Pathogenese, Diagnostik und Therapie. Dtsch Ärztebl 92:1091-1095 